\title{
A comprehensive review on metallic implant biomaterials and their subtractive manufacturing
}

\author{
Rahul Davis ${ }^{1,4} \cdot$ Abhishek Singh ${ }^{1} \cdot$ Mark James Jackson ${ }^{2} \cdot$ Reginaldo Teixeira Coelho ${ }^{3}$. Divya Prakash ${ }^{4} \cdot$ \\ Charalambos Panayiotou Charalambous ${ }^{5,6}$. Waqar Ahmed ${ }^{7}$. Leonardo Rosa Ribeiro da Silva ${ }^{8}$ (1) \\ Abner Ankit Lawrence ${ }^{4}$
}

Received: 25 July 2021 / Accepted: 17 January 2022 / Published online: 23 February 2022

(c) The Author(s), under exclusive licence to Springer-Verlag London Ltd., part of Springer Nature 2022

\begin{abstract}
There is a tremendous increase in the demand for converting biomaterials into high-quality industrially manufactured human body parts, also known as medical implants. Drug delivery systems, bone plates, screws, cranial, and dental devices are the popular examples of these implants - the potential alternatives for human life survival. However, the processing techniques of an engineered implant largely determine its preciseness, surface characteristics, and interactive ability with the adjacent tissue(s) in a particular biological environment. Moreover, the high cost-effective manufacturing of an implant under tight tolerances remains a challenge. In this regard, several subtractive or additive manufacturing techniques are employed to manufacture patient-specific implants, depending primarily on the required biocompatibility, bioactivity, surface integrity, and fatigue strength. The present paper reviews numerous non-degradable and degradable metallic implant biomaterials such as stainless steel (SS), titanium (Ti)-based, cobalt (Co)-based, nickel-titanium (NiTi), and magnesium (Mg)-based alloys, followed by their processing via traditional turning, drilling, and milling including the high-speed multi-axis CNC machining, and non-traditional abrasive water jet machining (AWJM), laser beam machining (LBM), ultrasonic machining (USM), and electric discharge machining (EDM) types of subtractive manufacturing techniques. However, the review further funnels down its primary focus on $\mathrm{Mg}$, NiTi, and Ti-based alloys on the basis of the increasing trend of their implant applications in the last decade due to some of their outstanding properties. In the recent years, the incorporation of cryogenic coolantassisted traditional subtraction of biomaterials has gained researchers' attention due to its sustainability, environment-friendly nature, performance, and superior biocompatible and functional outcomes fitting for medical applications. However, some of the latest studies reported that the medical implant manufacturing requirements could be more remarkably met using the non-traditional subtractive manufacturing approaches. Altogether, cryogenic machining among the traditional routes and EDM among the non-traditional means along with their variants, were identified as some of the most effective subtractive manufacturing techniques for achieving the dimensionally accurate and biocompatible metallic medical implants with significantly modified surfaces.
\end{abstract}

Keywords Metallic implant biomaterials - Subtractive manufacturing · Traditional and non-traditional machining · Biocompatibility $\cdot$ Cryogenic Machining $\cdot$ Electric discharge machining

Leonardo Rosa Ribeiro da Silva

leonardo.rrs@gmail.com

1 Department of Mechanical Engineering, National Institute of Technology Patna, Patna 800005, India

2 School of Integrated Studies, College of Technology and Aviation, Kansas State University, Salina, KS 67401, USA

3 School of Engineering at São Carlos, The University of São Paulo, São Carlos 13566-590, Brazil

4 Department of Mechanical Engineering, Vaugh Institute of Agricultural Engineering and Technology, Sam
Higginbottom University of Agriculture, Technology and Sciences, Prayagraj 211007, India

5 School of Medicine, University of Central Lancashire, Preston, UK

6 Department of Orthopaedics, Blackpool Victoria Hospital, Blackpool, UK

7 School of Mathematics and Physics, College of Science, University of Lincoln, Brayford Pool, Lincoln, LN6 7TS, UK

8 School of Mechanical Engineering, Federal University of Uberlandia, Av. João Naves de Ávila, Uberlândia, MG 38400-902, Brazil 


\section{Introduction}

With the constant growth of the world's population and globalization, a constant rise in people's living standards is being noticed, increasing the chances of lifestyle-related physical sicknesses, for example, cardiovascular and orthopedic diseases. Each day, many human bone or tissue fracture cases, possibly caused by sports injuries, falls, and vehicle accidents, are dealt with by medical practitioners across the globe. However, every type of injury or damaged tissue may not require surgical interventions due to the human body's self-renewing and regenerative abilities to conduct the healing process. For instance, minor damages to epithelial skin or a bone can receive easy healing without any surgery, unlike the spinal cord, articular-cartilage, neural-retina, cardiac muscle, lung, kidney glomerulus, etc., requiring either transplantation or reconstructive/ regenerative surgery for complete restoration. In addition, the human body's self-healing potential tends to decrease or disappear over time due to many reasons such as aging, decreasing progenitor population within the body, poor repairing ability of tissues, and inflammation caused by the injured tissue. Therefore, in this regard, medical science, in association with material science and engineering, has been consistently attempting to introduce smart and novel materials that are biocompatible or biologically compatible with the human body, also known as biomaterials, to deal with such challenges, physical damages or fracture fixation/arthrodesis.

A recent report, having included the impact of COVID19 , demonstrated the present and forecasted growth of the global biomaterials market between 2018 and 2026. The study pointed to North America and the Asia Pacific as the most significant and fastest-growing biomaterials markets, respectively, with a compound annual growth rate (CAGR) of $13.69 \%$. However, India is expected to display the most rapid growth in Asia to rising dental, cardiovascular, and orthopedic surgeries [1]. An extensive range of these biomaterials, including metals and their alloys, polymers, composites, and ceramics, is used to manufacture implantable medical devices. These medical devices, popularly known as biomedical implants or structures, have a great potential to prolong the survivability and comfort of the life of patients essentially suffering from diseased or missing body tissues.

Moreover, using these implants, the organs can be substantially supported, body functions can be monitored, and medication can be delivered at specific locations in the body [2]. In this regard, patients with damaged/lost tissues, and resultant challenges, are dealt with the assistance of biomedical implants such as ventricular assist devices, bone plate, cardiovascular devices, screws, and maxillofacial devices. The functional abilities of these implants can cause them to replace a part or even the entire biological organ, however, with a finite lifespan and uses due to inferior biocompatible, immune repression, physiologic harm of associated tissues, and other similar characteristics [3]. Thus, the implants are designed and fabricated on the basis of an accurate selection of the potential biomaterials. In this relation, due to superior mechanical, fatigue, wear, and corrosion properties, Ti-6Al-4 V alloy, 316L stainless-steel (SS), Co-Cr-Mo, and nickel-titaniumshape memory alloy (NiTi-SMA) metallic implant biomaterials are often given preference over other biomaterials such as polymers and ceramics [4].

\section{Biomaterials and biocompatibility}

The constantly growing demand for biomedical implants depicts the expectations of a more comfortable life. These implants comprise a specific engineering material category, known as "biomaterials" or "biocompatible materials." This category was duly recognized as an outcome of the Ist meeting on materials used in medicine at Clemson University in 1969, maintaining its incomparable contribution. Biomedical implants are mainly the emulation (biomimetic) of natural body parts, adopted to treat the afflicted or lost biological structure, regain its original structure, and work efficiently. In this regard, the term biocompatibility can be defined as the potentiality of a material to execute its anticipated activities associated with a particular remediation (without causing any unwanted local/systemic influences in the beneficiary's body), leading to a superior cellular response and optimized therapy amid a specific use [5]. Biomaterials were elucidated by the American National Institute of Health, as, "Any substance or combination of substances, other than drugs, synthetic or natural in origin, which can be used for any period, which augments or replaces partially or any tissue, organ or function of the body, to maintain or improve the quality of life of the individual." Also, as outlined by [6], "Biomaterials or biocompatible materials do not produce any toxic/immune or malignant effect when exposed to the body (depending on the short-term or long-term use) and find their wide applications in biomedical implants and prosthetics to enhance a smooth functioning between the implant and the human body." Moreover, the ISO (International Organization for Standardization) 10,993-1:2018 standard for the Biological Evaluation of Medical Devices-Part 1 defines biocompatibility as the "ability of a medical device or material to perform with an appropriate host response in a specific application." In addition, the latest definition of biomaterials, receiving a signed agreement in 2018, stated, 
"a biomaterial is designed to take a form that can direct, through interactions with living systems, the course of any therapeutic/diagnostic procedure" [7].

Hence, the biocompatibility testing of a biomaterial discovers its technical fitness for human use by critically checking the potentially harmful physiological effects. The biocompatibility can be examined through a series of analyses starting with cytotoxicity in vitro testing (ISO 10993-5), which is conducted to examine the toxicity and chemicals generally by bringing the sample biomaterial directly in contact with the cultured mammalian cells. Further, according to ISO 10993-18, the leachable materials are extracted from the sample biomaterial at an elevated temperature, followed by the assessment of the extracts. Subsequently, ISO 10993-4:2017 and ASTM F756 are used to assess the hemocompatibility, which ascertains the possibility of a sample to induce injurious effects on red blood cells, thrombosis, coagulation, platelets, and the complement system. Subsequently, depending upon the type of application, suitable in vivo testing(s) such as skin-irritation testing, sensitization testing, and implantation testing can be performed [8].

In short, biocompatibility can be referred to as the potential of a biomaterial to function, exhibiting an adequate host reaction without displaying an inflammatory or allergic reaction during a particular application. The term "host" refers to a living organism or system (microenvironment), and "host-response" can be briefly defined as the behavior of a host towards a foreign biomaterial. For instance, the resistance to bacterial colonization. Hence, the interactive physical attributes of a biomaterial with the adjacent host principally determine biocompatibility. The use of a non-biocompatible material can adversely affect the body's immune system, making it prone to attacks by viruses, fungi, and bacteria. Additionally, according to Fig. 1, for satisfactory clinical performance, the biocompatibility of a biomedical implant needs to be pivotally supported by the implant's own physical, mechanical, and degradation properties, sterilization (freeing implant's surface from all types of microorganisms), toxicological aspects (examination and treatment of any toxin or intoxicating substance), surgical procedure, site of implantation, and load-bearing capacity [9]. For instance, (i) a hip-prothesis needs to be rigid and is not expected to fail before 20 years irrespective of the type of loading, and (ii) a tissue's heart-valve leaflet needs to be tough and should be able to flex sixty-times/minute without any tearing in the remaining life of the patient.

\section{Interaction of biomaterials with the living-organism}

Further, as shown in Fig. 2, some of the major activities occurring at the surface can be categorized as water-surface interaction, protein-adsorption, cell-adherence and spreading, and proliferation. In the initial phase, during the first few nanoseconds (ns), the water molecules react with the biomaterial surface, and on the basis of the wetting features of the surface, the surface can be endorsed as a "hydrophilic" (contact angle $<90^{\circ}$ ) or "hydrophobic" (contact angle $>90^{\circ}$ ) surface. A hydrophilic surface has a strong affinity towards water molecules and thus promotes their spreading and maximizes their contact with the surface. In contrast, a hydrophobic surface repels the water molecules and minimizes their contact with the surface, causing the formation of droplets. The angle at which the water molecules' interface meets the biomaterial surface is termed as "contact

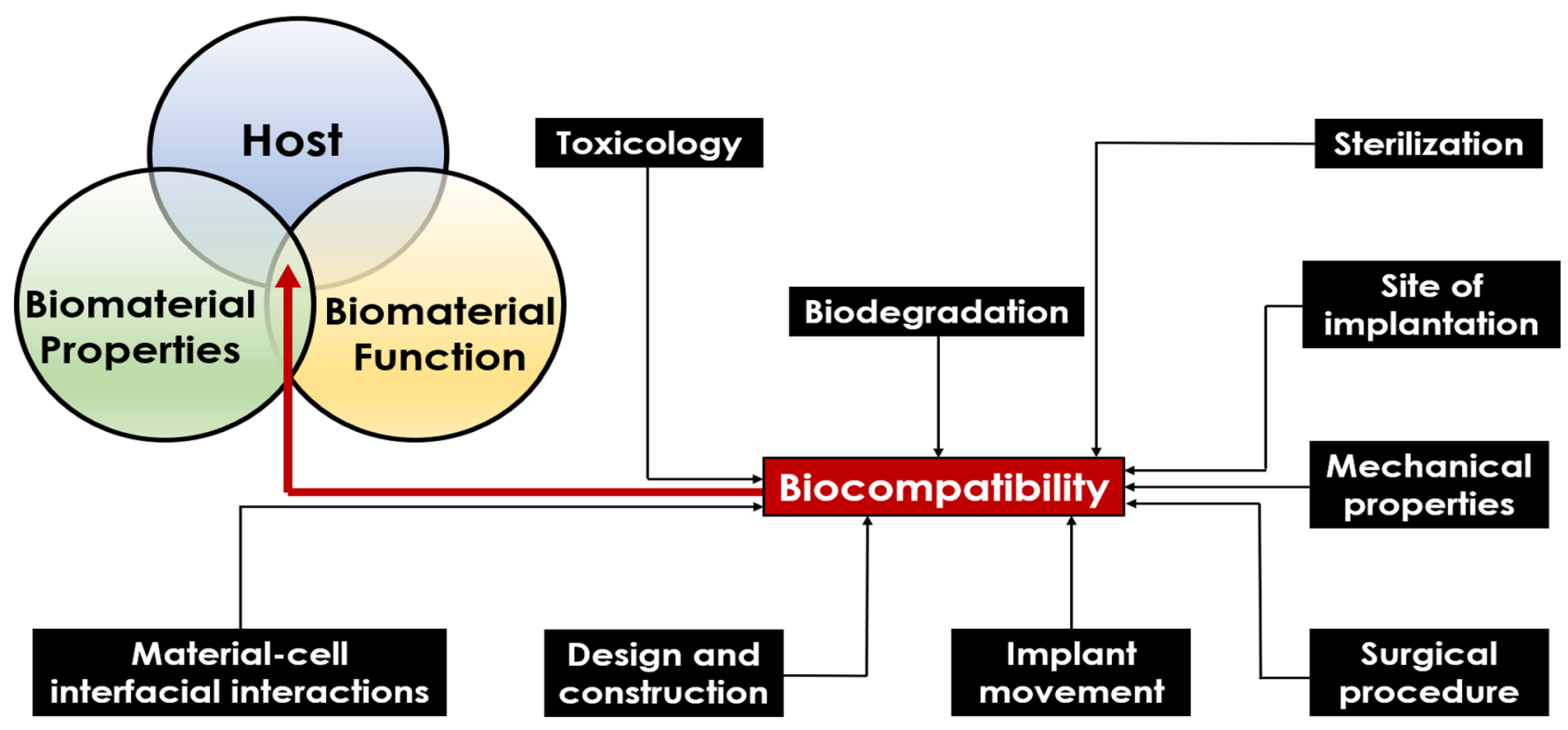

Fig. 1 Primary factors affecting the functional biocompatibility of a biomedical implant 


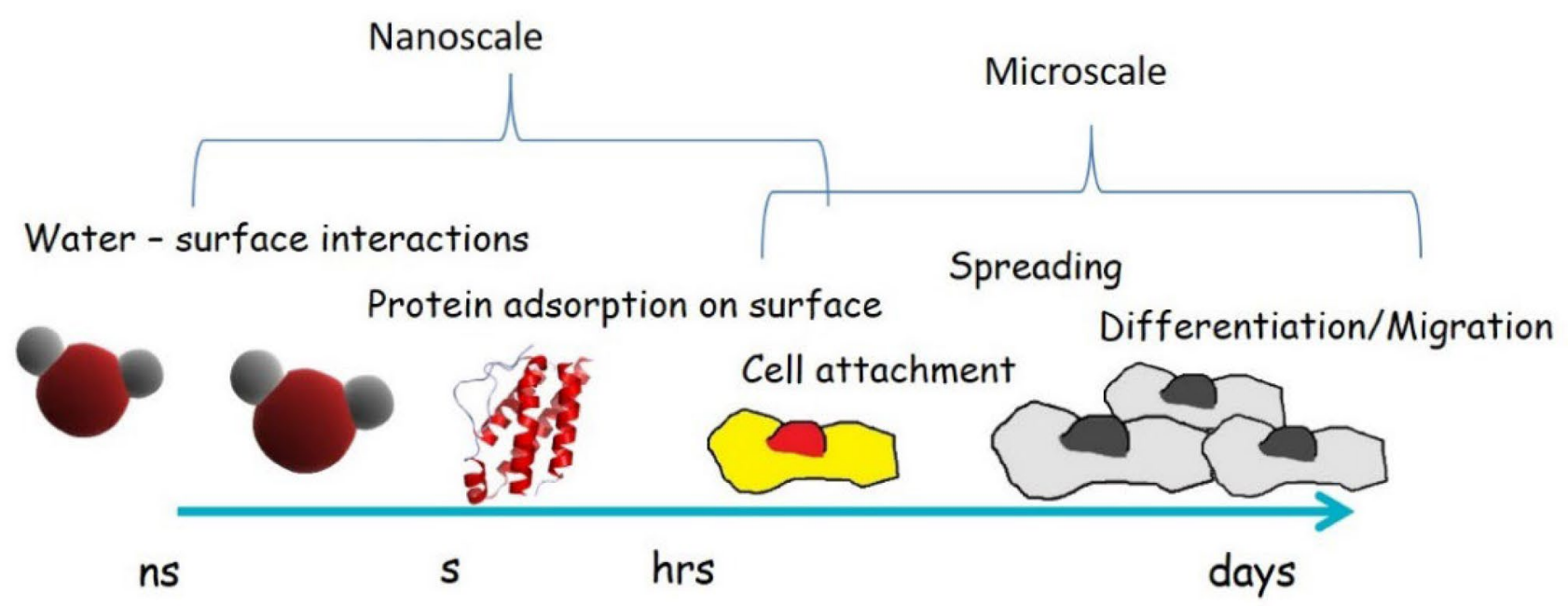

Fig. 2 Biomaterial's interaction with the living-organism [11]

angle." Further, the second phase comprises the adsorption of several proteins in a few seconds (s) on the surface with the rapid migration of small proteins, followed by the big ones, forming a considerably thick protein layer [10]. Subsequently, the third phase consumes a few hours (hrs) of cells' interaction along with the soaked-up protein layer and later with the surface's topography. In this stage, the biomaterial's surface gets exposed to numerous molecular interactions. It can be substantially affected by the biological molecules (cell membrane, cytoskeleton, and extracellular matrix proteins) and biophysical surroundings. The following evolved physicochemical characteristics such as stiffness, wettability or wetting properties, functional groups (such as trimethylammonium (hydrophilic) and n-butyl groups (hydrophobic)), topography (surface protrusions and depressions), and ion enrichment of the surface. Proliferation occurs in the last (fourth) phase and is continuing development of the previous stages and thus, may require a few days (for example, biodegradable screw) or even several years (for example, total hip replacement). However, the occurrence of both the third and the fourth phases largely depends upon the surface's topographic and wetting properties [11].

Further, in this regard, Fig. 3 attempts to demonstrate how the physicochemical characteristics of the biomaterials

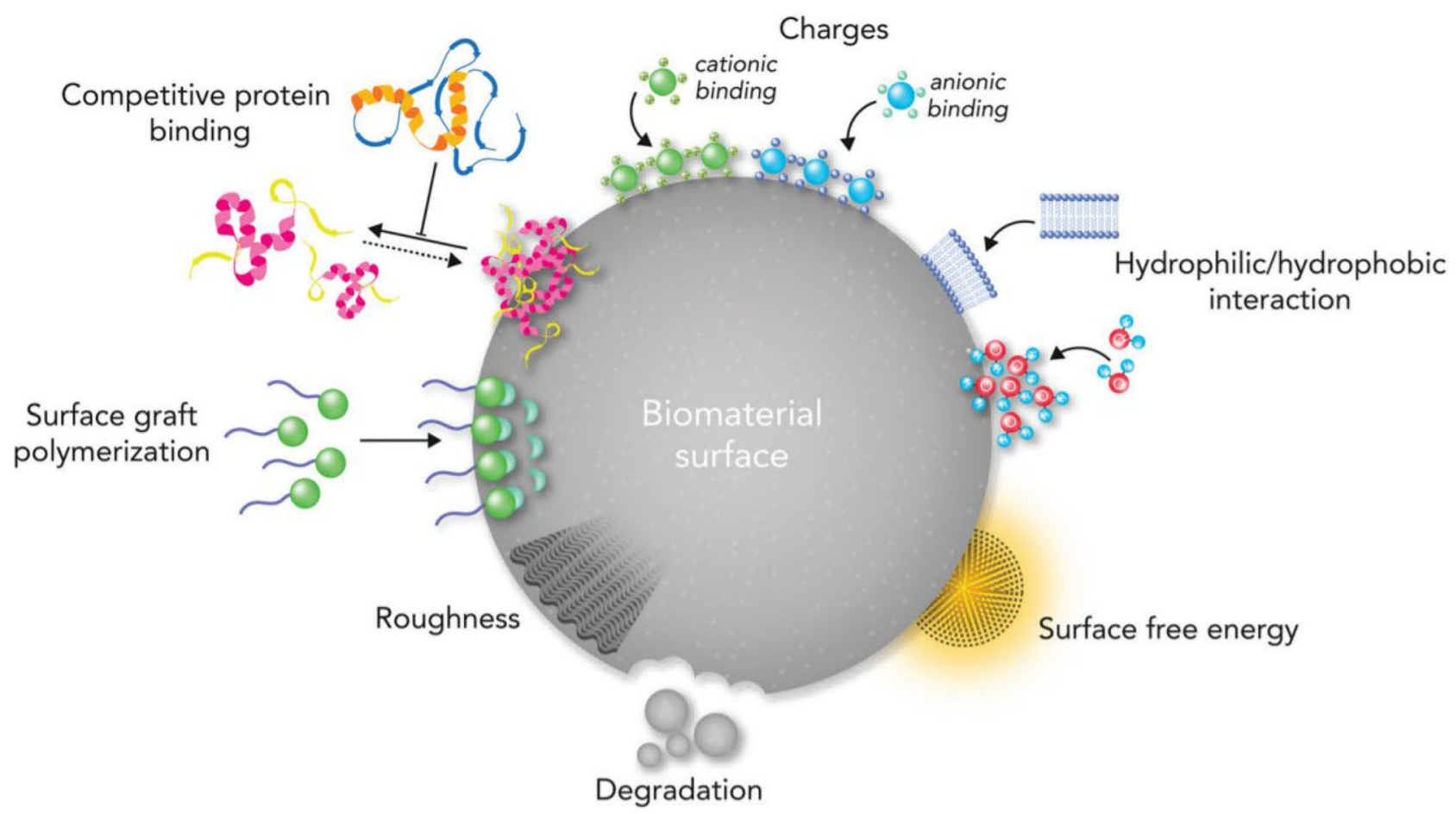

Fig. 3 Diagrammatic illustration of key-surface physicochemical characteristics in biological responses towards a biomaterial [12] 
are intensely employed to govern the various molecular and cellular indicating pathways [12]. The mechanical-electrochemical aspect of these interactions may also lead to quick corrosion, disseminating ions, by-products, and particulate fragments in periprosthetic tissue. The biomaterial's surface is thus expected to contribute interim mechanical support and exhibit a profound affinity towards the targeted cells in terms of emitting physical and chemical signals to trigger the neotissue development.

\section{Classification of biomaterials}

Biomaterials can be categorized primarily based on the following.

\subsection{Generation}

Three generations have witnessed the advancements in the development of biomaterials for medical applications over the years. In the early 1930's SS and cobalt-chromium alloys and 1940's polymers were introduced as the acceptable biomaterials. The first total-hip prosthesis was released in 1938, and the first blood vessel (made up of Vinyon and Copolymer) in 1952. Similarly, the following years 1953, 1958, 1960, and 1976 reported the inventions of vascular grafts, total-hip replacement, heart valves, and artificial heart, respectively. In this regard, Fig. 4 displays the different generations and their respective goals in the last few decades (1940-2021).

Progressive growth in cell and molecular biology, materials science, chemistry, and engineering has been identified as some of the primary reasons for the consistent evolution of biomaterials. The first generation biomaterials were developed to combine the functional features to acceptably meet the tissue's requirements without any detrimental behavior of the surrounding biological environment. Due to the inertness, materials such as silicone rubber and SS were counted as biocompatible. In comparison, the second generation biomaterials came into existence due to advances in the first generation and were targeted to develop an uninterrupted reaction with the adjacent tissue. Based on the bioactivity of these materials, implants such as drug-eluting endovascular stents were developed. In addition, degradable materials such as polymeric biomaterials were also evolved in that period. Further, the expanding state-of-the-art gave rise to the fabrication of the third generation biomaterials, intending to stimulate the regeneration of functional or living tissues.

\subsection{Elemental composition}

- Metals and alloys such as SS, titanium (Ti) and Ti alloys, cobalt (Co) alloys, shape memory alloys, and magnesium $(\mathrm{Mg})$ alloys.

- Ceramics such as aluminum oxide (Alumina), zirconium oxide (Zirconia), Ti oxide (Titania), bio-glass, carbon (pyrolytic), carbon (graphite), carbon (vitreous), and vitro-ceramic.

- Polymers such as polyethylene (PE), polyamide (PA), polyetheretherketone (PEEK), polyethylene terephthalate (PET), polymethylmethacrylate (PMMA), polystyrene (PS), polytetrafluorethylene (PTFE), polyurethane (PU), and synthetic rubber.

- Composites such as carbon-PTFE and alumina-PTFE.

\subsection{Host-tissue's response}

- Bioinert materials have the slightest or little interaction with their neighboring tissues. For example, Ti, Ti alloys, and $\mathrm{Zr}$.

- Bioactive materials can develop direct chemical bonding with the surrounding bone or even soft tissues in particular cases. For example, Glass-ceramics.

- Bio-tolerant materials possess fibrous tissue encapsulation at the implant interface. For example, SS and tantalum.

Further, in the last few decades, biomedical implants have been finding an extensive application at different human body locations for the desired purposes. Some notable examples can be easily witnessed in orthopedics, neural prosthetics, pacemakers, and drug delivery systems [13, 14].

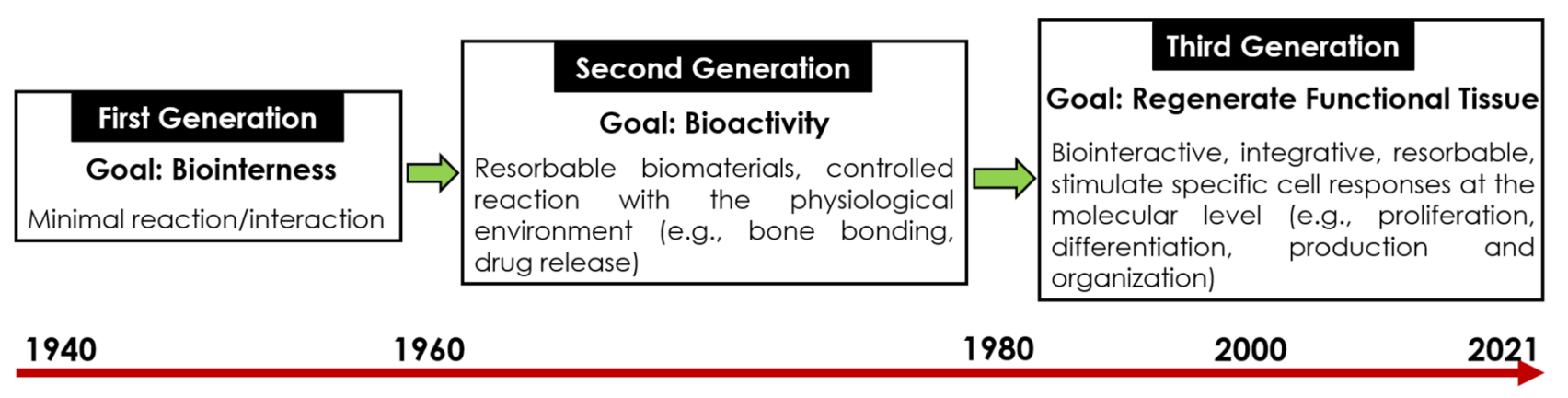

Fig. 4 The evolution of biomaterials science and technology 


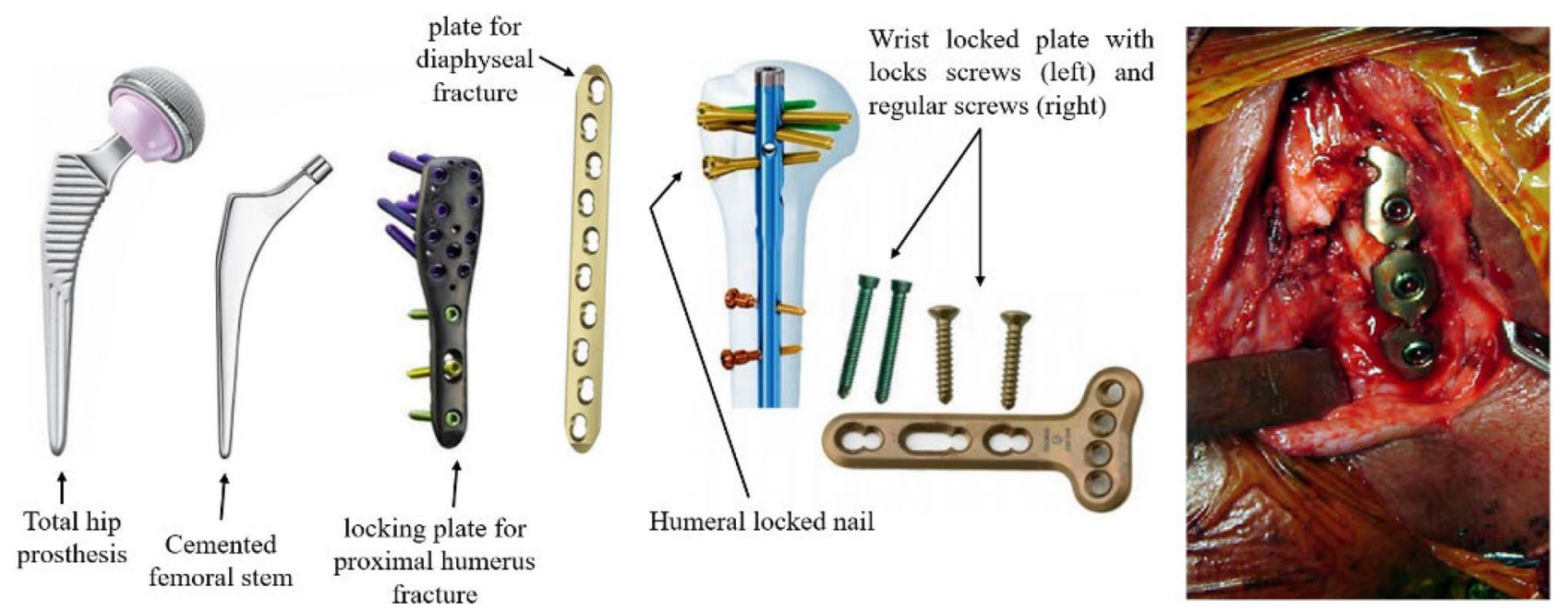

Fig. 5 Various orthopedic implants primarily made up of SS and Ti-6Al-4 V alloy [19,20]

Therefore, based on the applications, these implant materials are expected to possess excellent corrosion resistance, surface integrity, mechanical strength, and compatibility with bones and surrounding tissues. Figures 5 and 6 represent different biomedical implants or devices, whereas Fig. 7 displays the X-ray images of various body parts with implanted devices. The durability of an implant largely depends on selecting the input biomaterial [15]. The manufacturing of implants from these biomaterials through potential techniques can directly impact the metallurgical, mechanical, and biocompatibility characteristics $[16,17]$. Therefore, selecting a suitable manufacturing technique for a particular biomaterial needs to be predetermined. Moreover, finishing processes such as grinding, or polishing should achieve the desired surface finish (as the surface quality directly influences these implants' mechanical performance) [18].

For instance, orthopedics is demanding biomedical implants, such as highly engineered hip joint prostheses, on a larger scale from the manufacturers. The hip joint prosthesis facilitates smoother mobility and causes less pain inside the body of arthritic patients. The femoral head of such prosthesis should have physical properties such as high surface finish, sufficient resistance towards friction, corrosion, wear, high mechanical strength, and enough compatibility to make the chances of inflammation and rejection null and void.

\section{Metallic implant biomaterials and their common behavior}

Generally, for load-bearing dental and orthopedic applications (such as bone repair), the biomedical implants, in addition to the satisfactory biocompatibility, need to exhibit high yield, fatigue, tensile, compressive, and shear strength along with sufficient ductility, hardness, and fracture toughness. Therefore, metallic implant biomaterials are superior and more suitable for such applications than the traditional ceramic and polymeric biomaterials. However, the release of ions (from the metallic surface), chemical reaction of a metallic surface with the body enzymes and acids, and high elastic modulus can cause toxicity, oxidative corrosion or galvanic corrosion, and stress shielding (bone resorption), respectively, leading to the implant failure. Consequently, adjacent tissue's vascularity can deteriorate [28]. Some
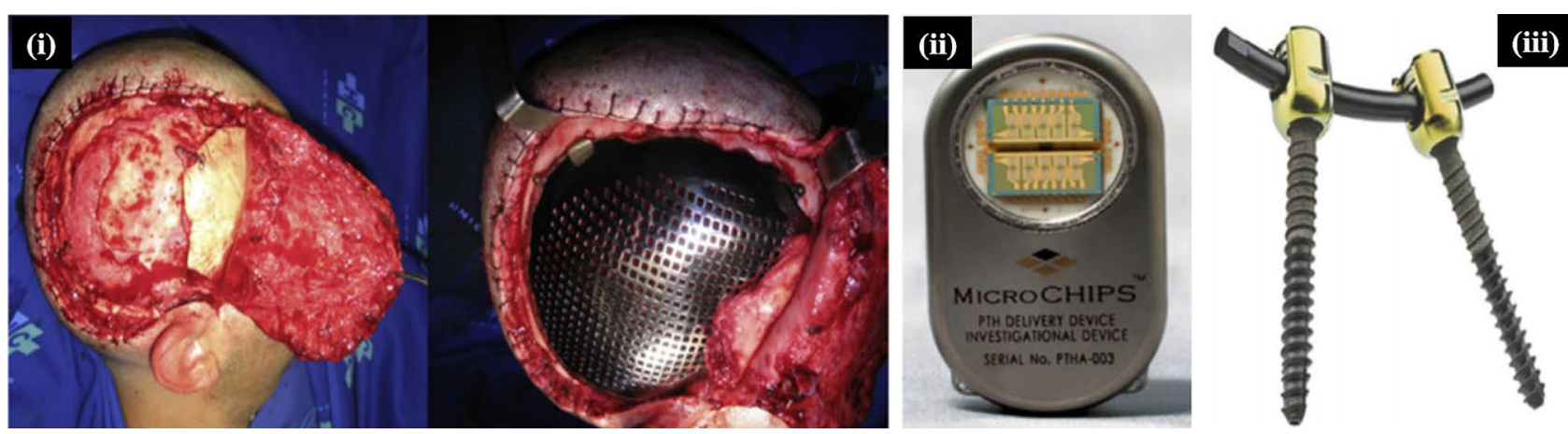

Fig. 6 (i) Titanium alloy cranial implant, (ii) Wirelessly controlled drug-delivery implantable chip, and (iii) Carbon fiber pedicle screws with a titanium polyaxial head and carbon-fiber-reinforced rods [21-23] 

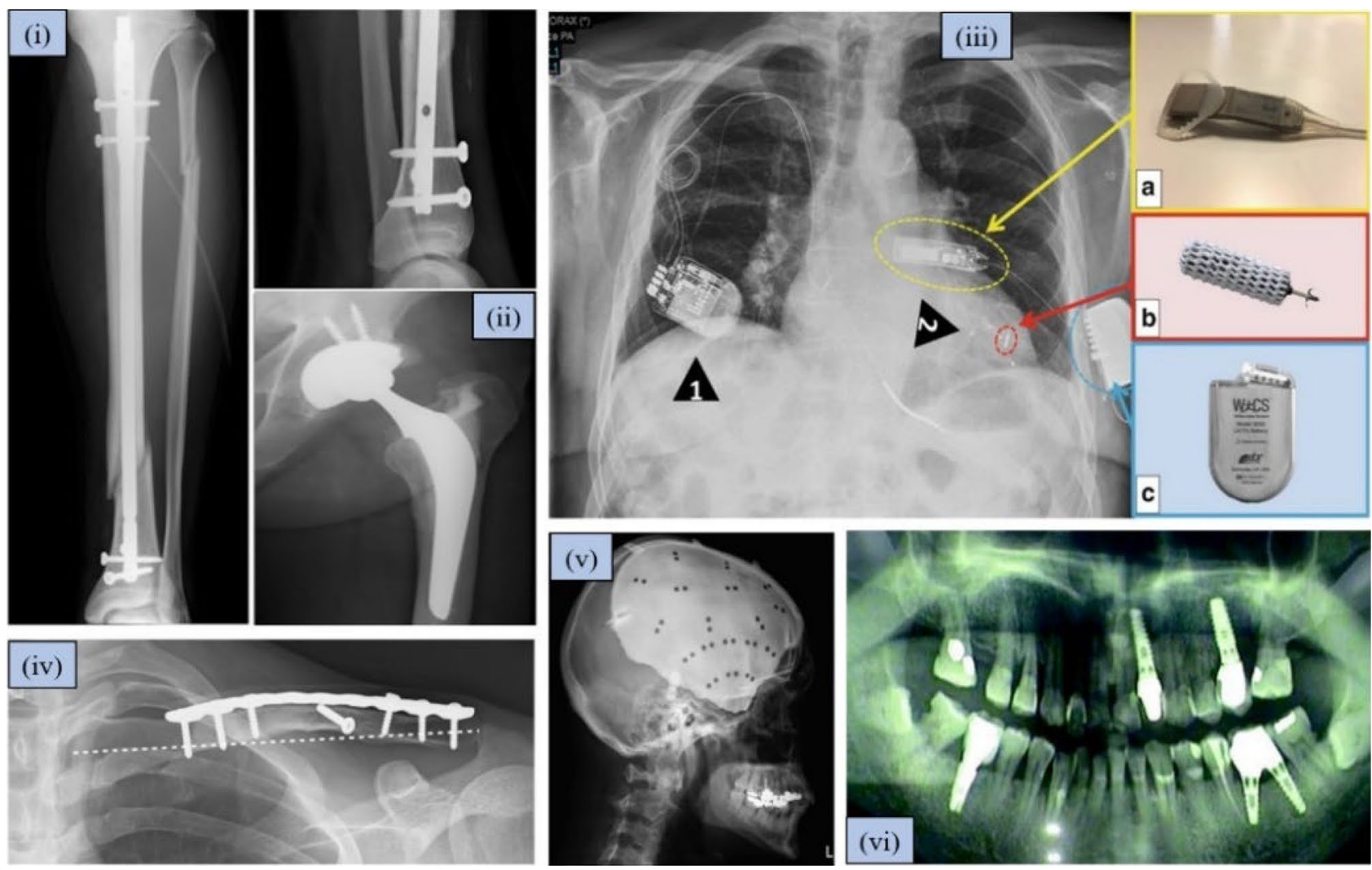

Fig. 7 X-ray image of (i) tibial fracture with a locked nail and distal locking, (ii) cemented femoral stem, (iii) wireless drug delivery system, (iv) projection of clavicle, (v) cranial, and (vi) dental implant [19, 24-27]

widely used metallic implant biomaterials and their mechanical properties are displayed in Table 1.

\subsection{SS}

Stainless-steel (SS) implants are considered to be one of the cheapest and easiest to manufacture medical devices. However, about ten times higher stiffness of SS than human bone often induces bone resorption due to stress shielding. Moreover, the conductive oxides of SS can cause inflammation. Nonetheless, nickel-SSs exhibit superb mechanical properties and ease of work hardening. In the annealed condition, they exhibit higher strength than other conventional SSs in implant manufacturing. This may cause the formation and advancement of more robust and tougher implants, as per the particular patient's need [40].

\subsection{Ti-based alloys}

Despite the high cost, the biomedical grade titanium (Ti), and its alloys, such as commercially pure titanium (CpTi) and Ti-6Al-4 V alloy, have always been some of the most reliable choices of the users due to their appealing properties such as outstanding biocompatibility, mechanical properties, wear, and corrosion resistance, high strength-to-weight ratio, lower stiffness, and elastic modulus [41]. Titanium is widely used as a competent biomaterial in biomedical implants such as joint replacement, bone plate, screw, pacemaker, and dental implant. Ti and its alloys generally offer a satisfactory osteointegration and configure an adequately rich oxide layer, displaying a remarkable resistance to corrosion [42]. In this series, Ti-6Al-4 V was identified as one of the most useful alloys of titanium [41]. However, there are several issues with $\mathrm{Ti}$ and $\mathrm{Ti}$ alloys that do not allow their basic form. For instance, the contrast between the composition of Ti alloys and human bone opposes the fiber capsule formation around the implant, leading to the weak chemical bonebonding amid osseointegration [41].

Additionally, the spontaneous formation of a highly stable, thin, and biocompatible nanoporous layer of titanium oxide enhances titanium alloys' corrosion resistance and hinders the ions from getting released from the metallic surface into the body [43]. However, in the case of a weak passivation oxide layer, wear, and corrosion properties, the particles, and ions may get released from the Ti-implant and accumulate on the adjacent/host tissue. Subsequently, the problems of inflammation, hypersensitivity, and toxicity can be induced. Also, the almost negligible resorption of 
Table 1 Mechanical properties of primarily used metallic implant biomaterials [28-33]

\begin{tabular}{|c|c|c|c|c|}
\hline Metallic implant biomaterial & Yield strength (MPa) & $\begin{array}{l}\text { Ultimate tensile } \\
\text { strength }(\mathrm{MPa})\end{array}$ & Elongation (\%) & Hardness (HV) \\
\hline \multicolumn{5}{|l|}{ Stainless-steel (SS) } \\
\hline AISI316L & $220-260$ & $500-540$ & $55-65$ & $130-160$ \\
\hline PANACEA P558 [34] & 600 & 923 & 54 & 367 \\
\hline Biodur®108 [35] & 586 & 931 & 52 & --- \\
\hline X13CrMnMoN18-14-3 [36] & 590 & 1030 & 70 & 259 \\
\hline $24 \mathrm{Cr}-1 \mathrm{~N}$ [37] & --- & 1032 & 26 & --- \\
\hline 24Cr-2Mo-1 N [38] & --- & 1167 & 45 & --- \\
\hline BIOSSN4 [39] & 559 & 938 & 54 & 248 \\
\hline \multicolumn{5}{|l|}{ Titanium-based alloys } \\
\hline Ti-6Al-4 V (Equiaxed (Std)) & 951 & 1020 & 15 & --- \\
\hline Grade 2 Cp Ti (Coarse-grained) & 380 & 460 & 26 & 1800 \\
\hline Ti-6Al-4 V ELI (Annealed) & 900 & 970 & 20 & --- \\
\hline Ti-35Nb-7Zr-5Ta (ST $(0.06 \%$ O)) & 530 & 590 & 21 & --- \\
\hline \multicolumn{5}{|l|}{ Cobalt-based alloys } \\
\hline Co-Cr-Mo (castable) & $450-520$ & $780-1080$ & 10 & 298 \\
\hline Co-Cr-Mo (wrought) & $452-660$ & 860 & 30 & 240 \\
\hline Co-Ni-Cr-Mo (wrought) & $242-655$ & $795-1000$ & 50 & - \\
\hline \multicolumn{5}{|l|}{ Shape memory alloys (SMAs) } \\
\hline \multirow[t]{2}{*}{ NiTi SMA (Nitinol) } & 195-690 (austenitic phase) & 895 & 8 & 242 \\
\hline & 70-140 (martensitic phase) & --- & --- & 346 \\
\hline \multicolumn{5}{|l|}{ Magnesium-based alloys } \\
\hline AZ31 (extruded) & 200 & 385 & 15 & 62 \\
\hline AZ91D (die cast) & 160 & 248 & $3-7$ & 65 \\
\hline Mg-Zn-Mn (extruded) & 156 & 259 & 12 & 59 \\
\hline $\mathrm{Mg}-\mathrm{Ca}$ & 148 & 240 & 9 & 55 \\
\hline
\end{tabular}

titanium implants over time obstructs the diagnostic imaging process, and thus, the visualization of surrounding tissues becomes very difficult [44].

\subsection{Co-based alloys}

Therefore, to overcome such challenges, the researchers attempted to develop another alternative and its variants, chemically inert and known as cobalt-chrome $(\mathrm{Co}-\mathrm{Cr})$ alloys. The implants made up of $\mathrm{Co}-\mathrm{Cr}$ alloys can also be used in dentistry and orthopedics, just like Ti-alloys. A review stated that the $\mathrm{Co}-\mathrm{Cr}$ alloy implant rod possessed superior fatigue strength and corrosion resistance to $\mathrm{Ti}$ alloy after posterior spinal arthrodesis. However, $\mathrm{Co}-\mathrm{Cr}$ alloy implants with high nickel content may cause allergy and exhibit low biocompatibility with the host tissue [43, 45]. F75 (Co-Cr-Mo), F90 (Co-20Cr-15 W-10Ni), F562 (Co-35Ni-20Cr-10Mo), and F1537 (Co-28Cr-6Mo) are some of the widely used variants of Co-based alloys for implant applications.

\subsection{NiTi SMAs}

In recent years, another alloy comprising an association of approximately equiatomic proportions of nickel and titanium alloys, termed as nickel-titanium (NiTi) shape memory alloy (SMA), has attracted numerous researchers' attention as a result of its shape memory and superelastic characteristics. The NiTi SMA was also termed as "Nitinol" after the U.S. Ni-Ti-Naval Ordnance Laboratory. Nitinol is lightweight and exhibits high strength and corrosion resistance, shapechanging capabilities, no cytotoxicity, and even relatively lower cost than gold-cadmium SMAs [46]. The diffusionless thermal conversions between the austenitic and martensitic phases are primarily responsible for the well-known shapememory effect of a NiTi SMA (Nitinol). According to Fig. 8 [47], with cooling, the progression from $\mathrm{O}$ to $\mathrm{A}$ presents the transformation of the predominant austenitic phase, giving rise to martensite start temperature $\left(\mathrm{M}_{\mathrm{s}}\right)$, into complete martensitic phase (martensite finish temperature $\left(\mathrm{M}_{\mathrm{f}}\right)$ ). Whereas the progression from $\mathrm{A}$ to $\mathrm{B}$ shows the reorientation and 


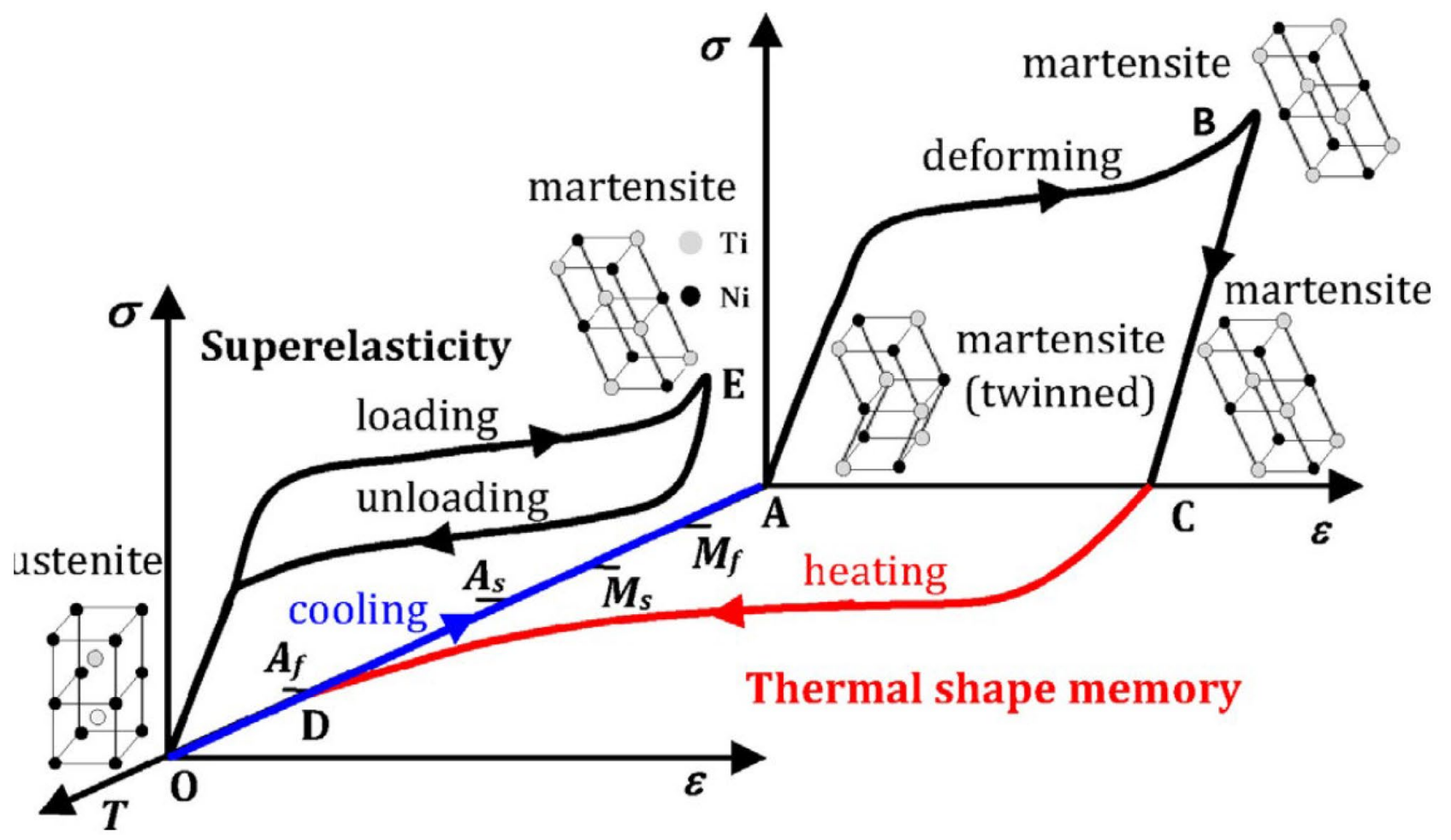

Fig. 8 Schematic display of stress-strain-temperature behavior shown by Nitinol [47]

detwinning of the martensitic phase towards the deformation of the material. Further, the progression from B to C displays the elastic-unloading (as soon as the load is lifted) in the reoriented and detwinned martensite, confirming the deformation of Nitinol. However, heating of pure martensitic phase leads to austenite start temperature $\left(\mathrm{A}_{\mathrm{s}}\right)$, leading the

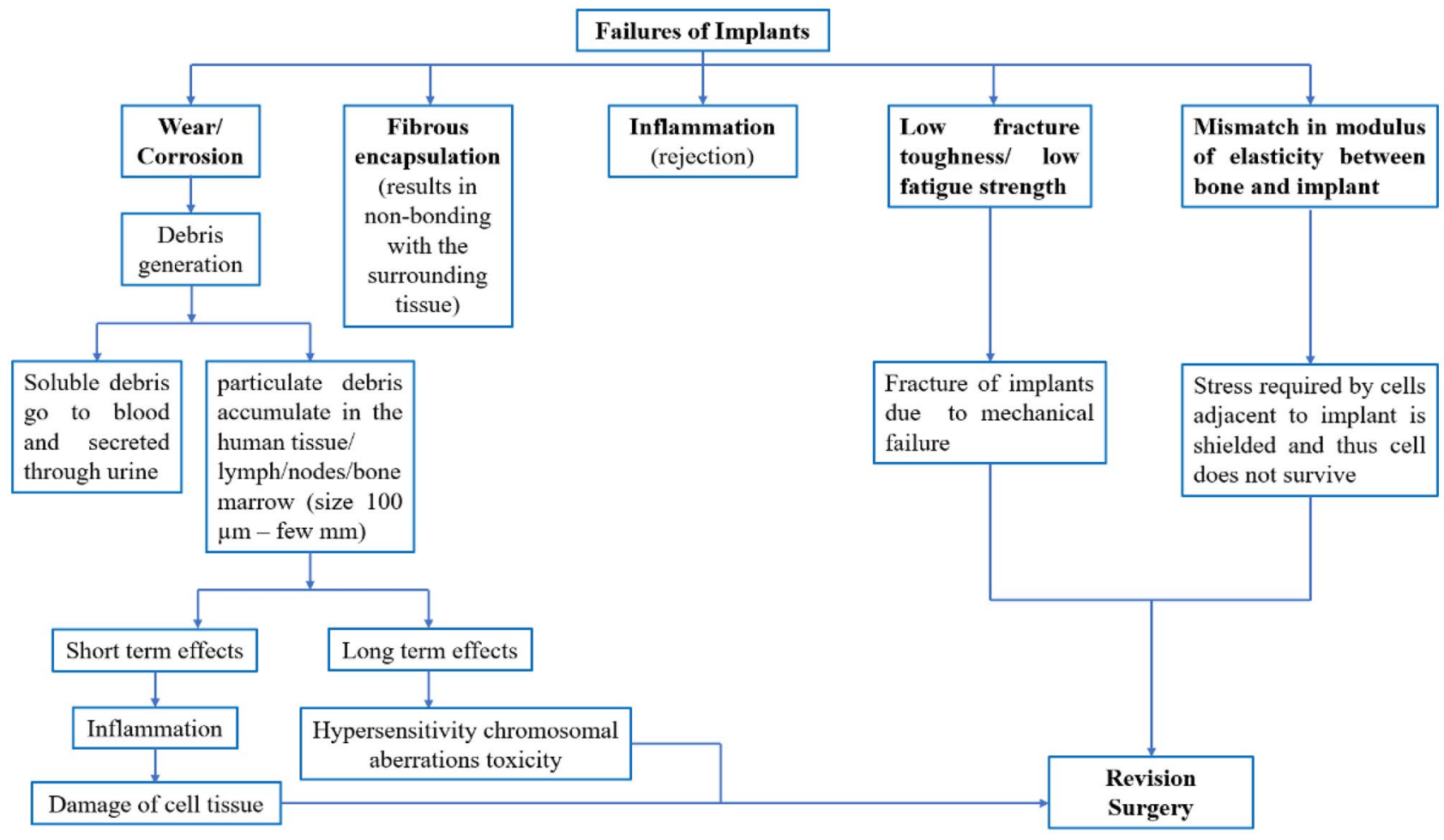

Fig. 9 Causes of deterioration of implants compelling for revision surgery [59] 
conversion into complete austenite phase at austenite finish temperature $\left(\mathrm{A}_{\mathrm{f}}\right)$. The reversible and insatiable behavior of this transformation along with martensite's deforming ability with no breaking of inter-atomic bonds, leads Nitinol to come back to its initial state imputed amid its austenitic phase [48]. In the similar manner, the progression from $\mathrm{O}$ to $\mathrm{E}$ and $\mathrm{E}$ to $\mathrm{O}$ present the conversion from austenite into martensite through an induced stress and vice versa, respectively. Nitinol displays a substantially lower elastic modulus and stiffness (closer to human bone) before transitioning to the martensitic phase than other Ti-alloys. Moreover, the superelastic properties of Nitinol wire facilitate greater comfort to the patient and lesser bone resorption than SS and $\mathrm{Co}-\mathrm{Cr}$ wires during the application of continuous force on teeth by the dentist [49]. Also, NiTi stents find application in the reinforcement of blood vessels. The fundamental reasons behind the versatile performance of Nitinol can be principally found in terms of its featherweight, inertness, and shape memory features that are promising for its biomedical applications such as orthodontics and stents [50].

In some previous investigations, Nitinol implants assisted with a faster recovery of bone than $\mathrm{SS}, \mathrm{Ti}$, and $\mathrm{Co}-\mathrm{Cr}$ implants due to its feature of reducing stiffness in the exact proportion of a bone, causing a superior load-bearing in the healing mechanism $[46,51,52]$. However, despite all such excellent features, the high amount of nickel may cause carcinogenic and allergic reactions [53].

\subsection{Mg-based alloys}

Further, the installation of an implant may be on a longterm or short-term basis. The implants can either replace the missing body part or support the injured ones on a permanent (non-degradable) or temporary (degradable) basis. Heart pacemakers, cardioverter defibrillators, dental devices, spine screws, rods, and disks are examples of non-degradable and degradable implants [2]. A relatively higher value of Young's modulus of the nondegradable metallic implants, for instance $200 \mathrm{GPa}$, being highly stiff, can deteriorate fractured bone's (10-45 GPa) density noticeably [54]. This is the reason why, the nondegradable implants, for example chemotherapy ports, are often detached after a specified timespan. However, the implant's removal might further involve the endanger of failure and side effects [2]. In this regard, according to Fig. 9, several causes play their roles in implant failure, which increases the chances of revision surgeries. These surgeries are not very successful and cause much discomfort to the patient. An engineered biomedical implant insertion inside the human body causes the implant surface to interact with the blood, fluids, tissues, proteins, and cells, even up to the micro-level. Such interactions may lead to the generation of fiber-like covering around the inserted implant and ascertain the recovery time of the body's damaged tissue or organ. Thus, such unpredictable attributes led the researchers to discover some capable substitutes, that were later recognized as degradable implantable devices, that could avoid the anticipated hazards of post-surgical procedures. Also, the patient gets freed from the tense thought of secondary surgery if it can be avoided by removing the implant. In this series, in terms of superior degradability, Young's modulus (40-45 $\mathrm{GPa})$, biocompatibility, and density $\left(1.75-18.5 \mathrm{~g} / \mathrm{cm}^{2}\right)$, magnesium and its alloys were found to be the better alternatives to the degradable polylactide and polydioxanone and other similar synthetic polymers [55, 56]. Additionally, the alloying of $\mathrm{Mg}$ with $\mathrm{Ag}, \mathrm{Ca}, \mathrm{Cu}$, and $\mathrm{Sr}$ results into a relatively faster bone-formation and cell simulation [57]. However, $\mathrm{Mg}$ and its alloys are often challenged by their early degradation that can partially heal or recover the damaged bone.

\subsection{Bulk metallic glass (BMG)}

Besides the abovementioned metallic alloys and crystalline metals, bulk metallic glass (BMG) has also been considered a suitable biomedical implant material due to its favorable toughness, tensile strength, elasticity, low internal friction, and sufficient resistance towards corrosion and wear. However, the absence of crystallinity causes problems in the production of BMG [58].

\subsection{Merits, demerits, and applications of metallic implant biomaterials}

Further, Table 2 presents some standard merits, demerits, and applications of the primarily or conventionally used metallic implant materials.

\section{Basic design considerations for biomedical implants}

The basic design procedure of biomedical implants includes considering the biomaterials' bulk and surface attributes/ properties. The bulk attributes comprise the physical and mechanical properties such as crystallinity, thermal transition points, elasticity, strength, ductility, fatigue, and hardness of the biomaterial that are generally dictated by its physicochemical characteristics. The bulk attributes of an implant are displayed throughout its lifetime. The biomaterial can mimic the physicochemical properties of the tissue to be augmented or replaced by altering its bulk attributes.

On the other hand, the surface features of the implant can noticeably affect the host tissue. These surface interactions can accelerate healing and lead to toxicity, inflammation, 
infection, and tumorigenesis in the host tissue. Moreover, the unfavorable body environment can adversely affect the implant and its performance through many physical-mechanical effects (such as wear, corrosion, fatigue, and stress-induced cracking) and biological effects (such as enzymatic degradation, adsorption of tissue constituents, and calcification), leading to implant failure. Hence, the surface attributes, such as chemical composition, wettability, topography, biocompatibility, corrosion resistance, and cytotoxicity, determine the cell response towards the surface [10]. Therefore, the various ISO (International Organization for Standardization), ASTM (America Society for Testing and Materials), BSI (British Standards Institution), AISI (American Iron and Steel Institute), and BIS (Bureau of Indian Standards) standards are adopted for the regulation purpose while designing and manufacturing the biomedical implants. For instance, ISO 25539-2:2020 is to be considered to examine the overall performance of cardiovascular implants- endovascular devices and the surface preparations including texture/coating, need to chiefly consider ASTM F86-21, ASTM F2791-15, and F-2743-11 standards [69].

Besides, as shown in Fig. 10, the basic procedure of achieving a biomedical implant in its intended application involves several facilitators. It encompasses the study of a biomaterial's properties, implementing various engineering tools on the biomaterial to process and fabricate a biomedical implant/device, getting the necessary approval from the concerned healthcare agencies, and obtaining permission from the concerned industries for product development and its commercialization.

The facilitators involved in the first step are generally researchers, whereas the second step requires physicians, engineers, and metallurgists/ceramicists/polymer chemists, and machinists. Subsequently, there comes a role of bioengineers and surgeons/physicians in the third step, followed by the approval of regulatory specialties/agencies and legislators. The last step incorporates the role of physicians/ dentists/optometrists/pathologists [70].

\section{Surface modification of metallic implant biomaterials}

As discussed in the previous sections and subsections, the surface of a biomaterial exhibits an inviolable affinity towards a large number and varieties of proteins and thus is prone to attract a plasma protein, mainly albumin, fibrinogen, and fibronectin. However, such a tendency of a biomaterial's surface can often lead to developing some undesirable alterations, such as an excess adherence of fibrinogen, in the surface attributes of the biomaterial, resulting in denaturation. Therefore, in such cases, the unwanted rise in the degree of neoepitopes exposure following cell and tissue reactions 


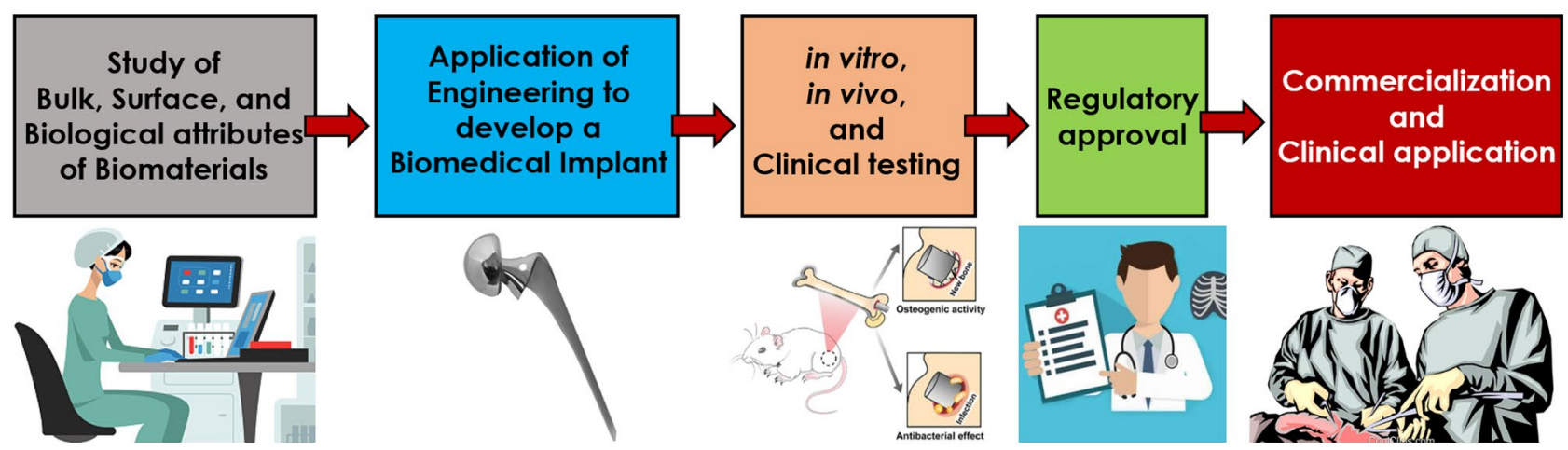

Fig. 10 The path from the fundamental study of biomaterials to the development of a biomedical implant, followed by its clinical application

needs to be treated to guard the biomaterial's surface during its anticipated service life for satisfactory performance. Moreover, some processing defects can also adversely affect the surface attributes of the biomaterials, leading to failure. For instance, titanium (Ti) is widely used as a competent biomaterial in medical implants such as joint replacement, bone plate, screw, pacemaker, and dental implant. However, there are several issues with $\mathrm{Ti}$ and $\mathrm{Ti}$ alloys that do not allow their basic form. The contrast between the composition of Ti alloys and human bone opposes the fiber capsule formation around the implant, leading to the weak chemical bone-bonding amid osseointegration [41].

Moreover, the sub-surface of $\mathrm{Ti}$ alloys remains prone to plastic shear and work hardening, which are unfavorable for the desired bone growth. In addition, even if a protective oxide (passive) layer gets formed on the Ti alloy implant surface due to specific chemical reactions, the low adhesive strength of Ti alloys might result in an easy peeling off the protective layer when exposed to substantial loading and human body fluid. Therefore, the unprotected implant surface may liberate the toxic elements from its surface into the body fluid and induce thrombus and inflammation [41, 71]. Also, some processing defects, such as poor machining, may adversely affect these desirable properties of $\mathrm{Ti}$ and its alloys and induce poor surface integrity, leading to implant loosening and final failure [72]. Besides, the relative motion between the bone and implant, in addition to the body fluid environment, triggers excess adhesive and abrasive wear, causing an impairment of the protective layer integrated into the implant surface [73].

Therefore, in this regard, "surface modification" of biomaterials is a potential solution to secure the biomaterial's surface against harmful reactions and elements and improve its existing attributes/properties remarkably. Surface modification can noticeably improve the biomaterial's/implant's performance by altering its physical, chemical, mechani$\mathrm{cal}$, and biological properties. Moreover, the damaged tissue is more responsive when interacting with a modified implant surface [74]. Additionally, the surface modification of titanium implants results in their considerably improved osteointegration and antibacterial properties [73]. One of the latest articles thematically reviewed the most recent developments in the surface modification of titanium and its alloys via physical and chemical approaches, specifically for biomedical applications. In this relation, Fig. 11 presents various methods used to modify the biomaterials' surfaces with their respective advantages, disadvantages, and applications. The significant advantages of the various surface modification techniques, such as plasma immersion ion-implantation and deposition, physical-vapor-deposition (PVD), chemical-vapor-deposition (CVD), and micro-arc oxidation (MAO), were discussed in detail. However, the review also revealed some of the main limitations of the techniques mentioned above: poor bonding strength of the coated layer, the unstudied impact of the thermal effect on the modified surface, and considerable toxicity, leading to poor biological performance [73].

In this relation, another review systematically presented the recent progress and prospect of biomedical Ti alloys and found equal-channel-angular-extrusion (ECAP), accumulative-roll-bonding (ARB), and friction-stir-processing (FSP) as some of the most significant severe plastic deformation (SPD) tools for the improved bioactivity of Ti alloys in vivo [41].

\subsection{Surface modification of metallic implant biomaterials via traditional subtractive manufacturing techniques}

Based on some of the outlined negative aspects of the previously mentioned surface modification techniques, the researchers and scientists have realized the pressing need to develop some adequate substitutes or alternatives over the years to improve the surface properties of the biomaterials. In this relation, "subtractive manufacturing" has been proposed as one of the most influential processing methods to 


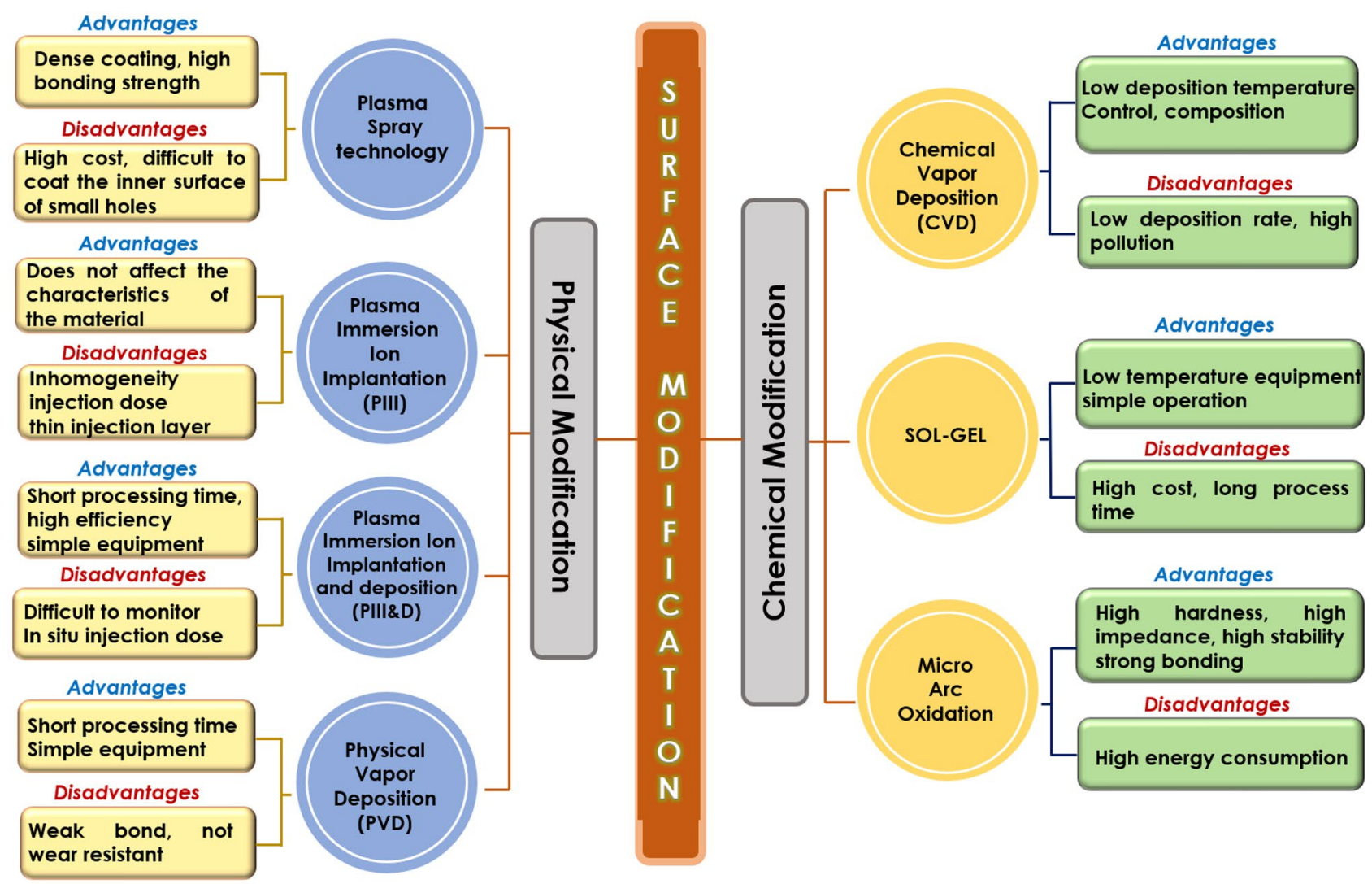

Fig. 11 Various surface modification methods with their respective advantages, disadvantages, and applications [73]

achieve a favorable and considerable surface modification on the surface of biomaterial/implant/device primarily via severe plastic deformation (SPD) and development of a passivating layer on the machined surface [75-77]. The process economy accompanying a massive output makes subtractive manufacturing or machining techniques such as milling, turning, and drilling the primary choice of the manufacturers. However, the surface defects (such as thermal cracks and corrosion pits) found on the finally produced medical implant can lead to failure or faster degradation under the joint influence of stress and corrosive environment. This gives rise to fatigue cracking and wear at defective sites [78]. Therefore, a manufactured part's functional behavior can be predicted primarily by those attributes that ultimately quantify the surface integrity and the magnitude of manufacturing-induced compressive residual stresses (induced by more mechanical deformation and less thermal influence). These residual stresses are responsible for enhanced surface hardness, leading to improved corrosion features. The physical, mechanical, chemical, and metallurgical aspects can be tailored during a particular manufacturing process of interest. Finally, surface integrity on the implant's surface can ascertain the probability of its success or failure. A generalized range of typical values of surface roughness expected on biomedical implants or parts is 1.5 to $4 \mu \mathrm{m}[79,80]$.
In addition, the physiochemical properties such as topography, wetting behavior, and elemental composition on the topmost layer of an implant surface basically ascertain its effectiveness in a biological setting. Thus, even slight changes in such properties are able to cause considerable variations in the reactivities of the implant as well as the cell at the point of their interaction [81, 82]. However, the topographical features such as surface roughness are mainly responsible for the cells' response such as osteogenic differentiation of cells, cell growth, and proliferation rates $[82,83]$. In this regard, cutting speed, feed rate, cutting tool pressure, and lubrication and their various levels were identified as some of the major machining factors inducing specific topographies on the machined metallic biomaterials [84].

\subsubsection{Effect of cutting tool's properties and lubrication/ cooling (lubri-coolant) during machining}

Traditional subtractive manufacturing techniques are best defined as subtracting excess material from the workpiece in the form of chips using a sharp-edged cutting tool by applying forces on the workpiece, thus removing the material under suitable manufacturing conditions. The process input variables should be adequately selected to achieve the 


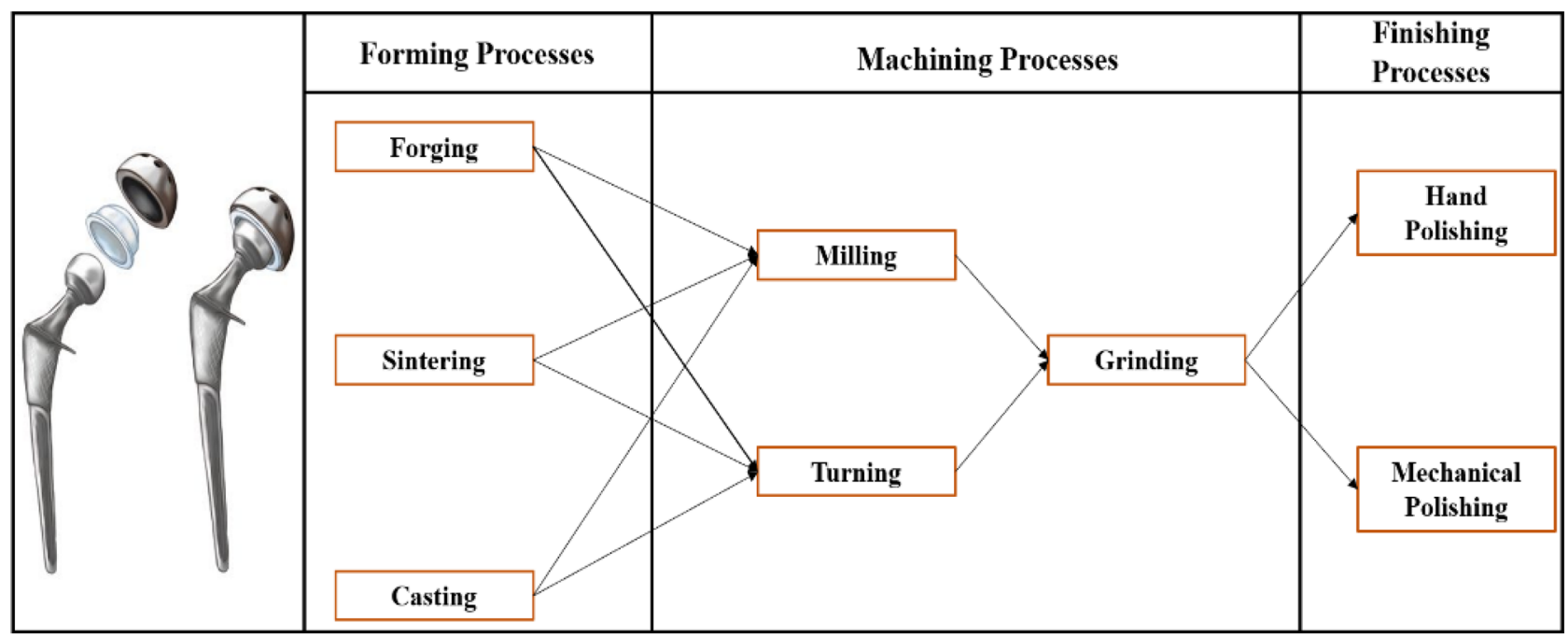

Fig. 12 Fabrication process plan for metallic components of the prosthesis

desired outcomes during the traditional subtractive manufacturing of biomaterials. Figure 12 shows the inclusion of some forming processes and machining techniques, followed by finishing processes, in attaining the prosthesis's metallic components [85].

However, due to undesirable properties such as low thermal conductivity and elastic modulus, chemical reactivity (with a cutting tool), high hot hardness, and flammability, the difficult-to-cut biomaterials exhibit poor machinability, challenging their effective machining [86]. Hence, to deal with the issue, several latest investigations optimizing machining input variables, researching chip-morphology, evaluating vibration and forces at the tool-biomaterial interface, studying the impact and behavior of cryogenically treated (cryo-treated) cutting tool, applying various types of cooling techniques were included and elaborated by a review based on Ti alloys [87]. The survey of the recent literature indicated the application of non-coated and coated cutting tools, which also play an important role [88, 89]. Moreover, cutting tools with coating such as AlTiN, TiAlN, AlCrN, TiAlSiN, and $\mathrm{NbN}$ and without coating were also used in some recent studies [89-92]. Besides, the applications of cryogenics as a treatment medium to enhance the existing properties (such as mechanical, chemical, metallurgical, thermal, and electrical) of uncoated as well as coated cutting tools and as a cooling agent amid machining of difficult to machine Ti alloys, were elucidated by several recent articles [92-95]. In addition, the wear properties of the carbide cutting tools were significantly improved as a result of cryogenic treatment that led a uniform spread of carbides [96-99]. Further, as highlighted by one of the latest reviews, cutting tools with textured surfaces are some leading tribological research fronts, improving the ease of machining.
Since a considerable number of metallic biomaterials fall in the category of difficult-to-machine materials, the variation in tool texture's features such as width, depth, and density, may lead to remarkable enhancements in chip-formation, cutting force, generated heat, lubri-cooling action, surface finish quality, and consequently, tool life. The textures comprising linear-grooves and dimple-geometries (obtained by laser ablation) were identified as the most competent textures [100]. However, so far, the literature has reported the use of textured cutting tools only with Ti-based biomaterials [101]. Two recent articles presented the effective use of microtextured tungsten and cemented carbide cutting tools with MO disulfide + SAE 40 oil and ZJ846 lubri-coolants, respectively, against Ti-6Al-4 V alloy. In both the studies, a notable improvement in cutting force, surface roughness, chip-morphology, and tool life were witnessed [102]. Besides this, the exceptionally excellent cutting abilities of the advanced cutting tool materials such as cermet, polycrystalline cubic boron nitride (PCBN), ceramic, and polycrystalline diamond (PCD), are nowadays popularly known in the manufacturing community. As demonstrated by several studies, stainless steel and Ti-6Al-4 V alloy were quite easily machined with PCBN [103-107], PCD [105, 107-109] with enhanced cutting force, chip-behavior, tool safety, and surface quality. However, the ultra-high hardness (around 10,000 HV) of these cutting tools always challenges their manufacturing techniques [110]. In this regard, traditional abrasive-grinding and non-traditional electric discharge grinding (EDG) were identified as two effective methods to develop such ultra-hard cutting tools. EDG, being the variant of a conventional electric discharge machining (EDM) technique, erodes the excess material from the facial cutting tool such as PCD [111] and PCBN [112], via unceasing and repeated sparks 


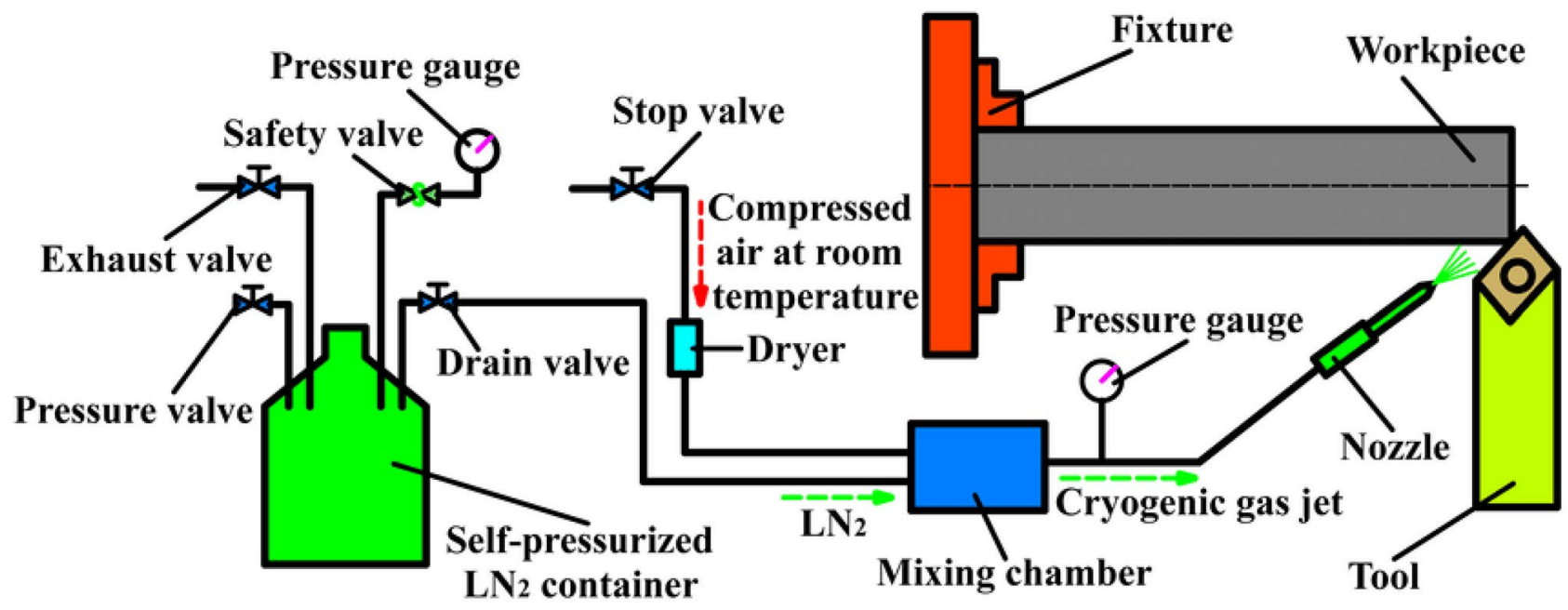

Fig. 13 Schematic display of cryogenic machining system [115]

generally with the assistance of a rotary copper-nickel alloy wheel (electrode). The rotary electrode simultaneously channelizes the dielectric into the space between electrode and workpiece and expels the debris from the same [109]. This leads to obtain an increased material removal and reduced wear and short-circuiting (by decreasing the probability of arcing and non-uniform sparking) [113]. Moreover, an EDG process achieves a superior material subtraction (up to $400 \mathrm{~mm}^{3} / \mathrm{min}$ ) to a traditional abrasive-grinding process [111]. A study revealed that the wheel rotation could notably influence the heat affected layer, surface finish, and edgeundercut [113].

Further, an immense use of cryogenic cooling strategies, noticeably decreasing the machining temperatures (developed due to the cutting tool and workpiece surface interaction), was witnessed by the past couple of decades. However, the heat removal capacity and produced surface finish are determined using the direction and approach angle of the cryo-lubri-coolant. The cryo-lubri-coolant might hit the cutting tool-chip interface or cutting tool flank-workpiece interface [114]. Figure 13 diagrammatically shows a cryogenic machining-system with several components when a Ti-6Al-4 V alloy was being turned [115].

An improved heat-transfer (forty-notch higher) and cooling rate (up to $8{ }^{\circ} \mathrm{C} / \mathrm{ms}$ ) was witnessed as the gas was eliminated in the released jet (found in the sub-cooled boiling zone) comprising partial liquid-phase/drops at the exit of nozzle and with approximately 50\% liquid when arrives at the target [116-118]. Moreover, the cryo-lubri-coolants displayed higher dynamic viscosity and specific heat in their liquid phase than gaseous phase $[119,120]$. In addition, the heat-transfer coefficients with numeric values as $20,000 \mathrm{~W} / \mathrm{m}^{2} \mathrm{~K}, 2000 \mathrm{~W} / \mathrm{m}^{2} \mathrm{~K}$, and $20 \mathrm{~W} /$ $\mathrm{m}^{2} \mathrm{~K}$ were noticed during the cutting of Ti-6Al-4 V alloy using cryo-lubri-coolant, dry compressed air, and free convection, respectively [114]. Also, being environment-friendly, healthfriendly, and cost-effective, the cryo-lubri-coolant-assisted machining is identified as sustainable manufacturing [121]. Further, the machining of Ti alloys was reviewed in detail that consisted of application of several cooling strategies. It was found that conventional cutting fluid did reduce the formation of burrs and built-up edge (BUE) but ended up with chipping and flank wear of the cutting tool. Therefore, the application of minimum quantity lubrication (MQL), hybridized MQL + nano-fluids $\left(\mathrm{Al}_{2} \mathrm{O}_{3}\right.$, graphite, and molybdenum disulfide), minimum quantity cooling lubrication (MQCL), cold-water mist jet (CWMJ), cooled air-lubrication, vegetable oil + cooled-air, graphene-doped nanofluid mist-spray cooling, hybridized MQL + graphene nanoparticles and cryogenic machining (using either $\mathrm{CO}_{2}$ or $\mathrm{LN}_{2}$ ) were enumerated [122]. For example, greater amount of heat transfer and superior surface quality were noticed while TC9 alloy was being turned using CWMJ. Besides, at low cutting speeds and feed rates, a superior performance of MQL was observed over wet, cooled air-lubrication, hybridized vegetable oil + cooled air, and MQCL environments [123] and also shielded the cutting tool coating [124]. In contrast, the hybridized MQL with graphite nanofluids brought more amount of cutting temperatures down than the hybridized $\mathrm{Al}_{2} \mathrm{O}_{3}$ and molybdenum disulfide [114, 125]. In addition, cryogenic cooling noticeably dissipated the heat, however, the hybridized $\mathrm{MQL}+\mathrm{Al}_{2} \mathrm{O}_{3}+$ multi-walled carbon nanotube decreased the cutting forces by $11.8 \%$ [126]. Also, graphene's excellent thermal conductivity in graphenedoped-nanofluid mist spray and its hybrid variant led to notably remove the excess heat [111]. The cryogenic machining again performed better than MQL and its variants in terms of enhanced heat transfer, and cutting tool wear $[122,127]$. 

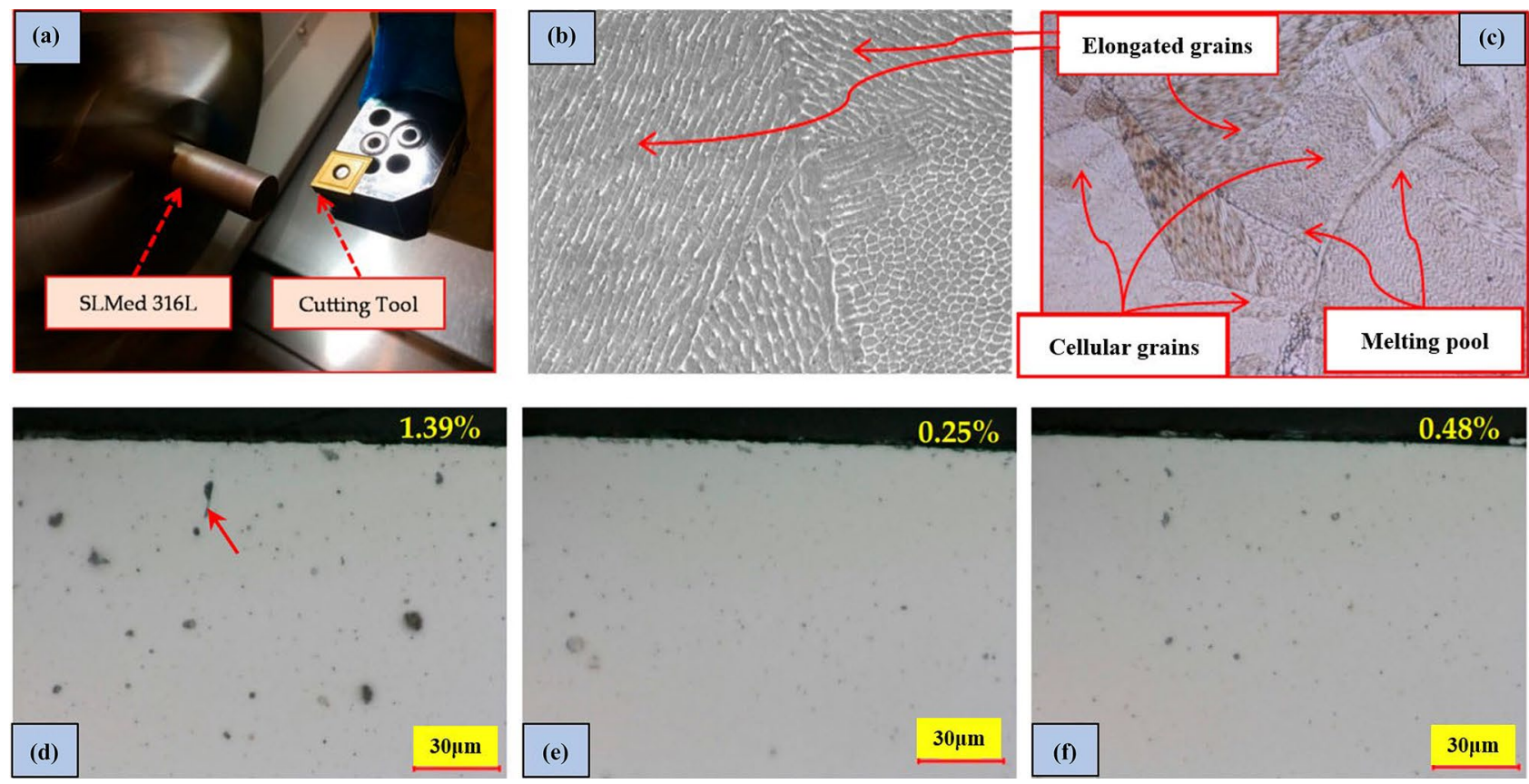

Fig. 14 a Experimental setup, b grain structure, and $\mathbf{c}$ melting pool of as-built SLMed part; $\mathbf{d}$ porosity noticed on as-built SLMed part, $\mathbf{e}$ turned part at $50 \mathrm{~m} / \mathrm{min}$ cutting-speed, and $\mathbf{f}$ turned part at $200 \mathrm{~m} / \mathrm{min}$ cutting speed [128]

\subsubsection{Some relevant findings amid enhanced traditional machining of metallic implant biomaterials}

As outlined by the study, the optimal value of surface roughness $(0.9 \mu \mathrm{m})$ during turning a selective laser melted (SLMed) 316L SS by cementite carbide-cutting tools (SNMG form) was achieved at $200 \mathrm{~m} / \mathrm{min}$ cutting speed $0.1 \mathrm{~mm} / \mathrm{rev}$ feed-rate, and $1.25 \mathrm{~mm}$ depth-of-cut. The surface integrity was improved with the rise in cutting speed, as shown in Fig. 14 [128]. However, the same became worse with the rise in depth-of-cut and feed rate. The tensile residual stresses were more affected by cutting speed and feed rate [129].

Concerning the subtractive manufacturing of 316L SS, based on recent findings, researchers' interest is slowly shifting towards hybrid manufacturing (additive followed by subtractive manufacturing). In this regard, the hybrid manufacturing of 316L SS biomedical parts using additive (SLM) followed by subtractive manufacturing (finish turning) resulted in $88 \%$ surface roughness reduction. Moreover, the post-turned SLMed surface and subsurface were noticed with substantially reduced porosity density and considerably refined grains and strain-hardened layer [128]. Some latest research stated the significant role of macro and micromilling in the subtractive processing of 316L SS for biomedical applications. A study of an additive manufactured 316L SS included cutting forces when the feed direction changed concerning the layer inclination. The resulting melt borders from the additive manufacturing obstruct the dislocation distortion [130]. Another research reported a considerable impact on the anisotropy of powder bed fusion (PBF) micro-manufactured 316L SS with the alteration in feed direction and surface roughness values. The larger tool diameter $(800 \mu \mathrm{m})$ achieved improved results [131]. In the case of SS, one of the prime complexities in machining SS is that it characteristically produces high cutting temperatures, which results in the depletion of part life and weakening of the workpiece's surface properties. Moreover, the traditional cooling methods are ineffectual in restraining these critical issues of quick tool wear and high cutting temperature. In a comparative investigation of wet and cryogenic turning, the results came out to favor cryogenic cooling when $44-51 \%$ reduction in cutting temperature, $16 \%$ reduction in cutting force, and $22-34 \%$ reduction in surface roughness were recorded [132].

Besides, titanium and its alloys are other categories of metallic implant biomaterials challenging to be machined. The premier obstacles in machining this material are the elevated cutting temperatures and instant tool deterioration at the machining time. Undeniably, several tool materials express instant wear and tear even when operated at adequate cutting speed. In the present scenario, the machining practice is cutting speed is reduced to less than $1 \mathrm{~m} / \mathrm{s}$ so that the tool deterioration may be minimized. A single layer coating of $\mathrm{Al}_{2} \mathrm{O}_{3}$ is preferred due to its lower thermal conductivity than a tungsten carbide insert. This layer avoids heat dissipation from the intense temperature and stress at the cutting point. There are other options for machining 

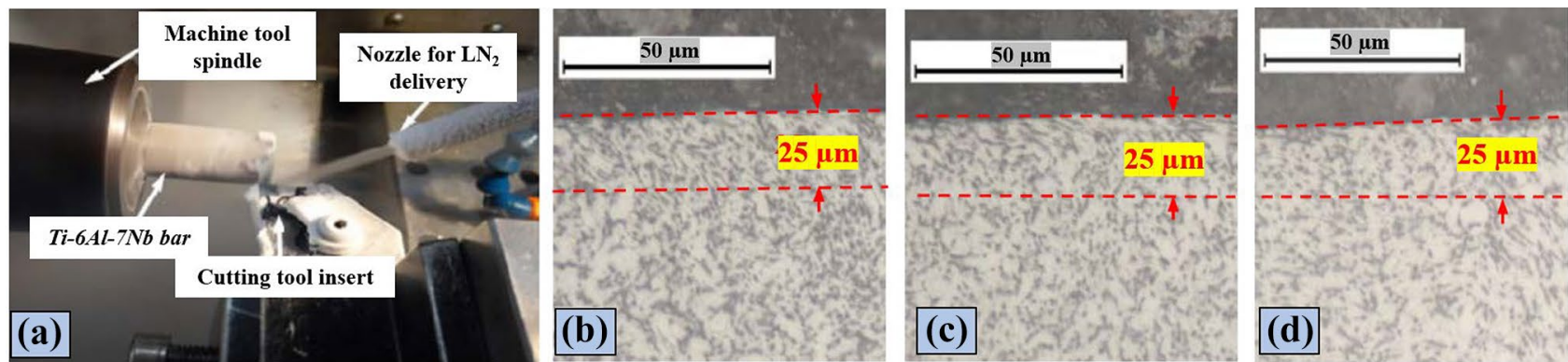

Fig. 15 a Cryogenic turning setup. Microstructure of surface and subsurface amid $\mathbf{b}$ cryogenic, $\mathbf{c}$ flood cooled, and $\mathbf{d}$ dry turning [77]

titanium alloys, such as carbide and nitride, yet they are not employed due to their chemical resemblance. Therefore, the cryogenic machining practice is employed for its twofold excellence in enriching chemical stability and reducing the cutting temperature while machining hard-to-machine metallic biomaterials. This practice is effective enough to increase the efficiency of titanium machining [133].

Further, it was depicted that cryogenic machining was the alternative to dry and flood machining of Ti-6Al-7Nb, resulting in an improved surface finish to be used as biocompatible medical implants [77]. It was also realized that the machined surface degraded because of adhesion formed as a product of dry machining and softening of the constructed surface due to the rapid rise in penetrating temperature. Due to some slight variations between dry and flood-cooled machining in terms of micro-level firmness of the surface and its underlying area, the best surface roughness was noticed in the case of cryogenic machining, which was $35 \%$ better than dry and $6 \%$ than flood-cooled machining as a result of SPD (as illustrated in Fig. 15).

Sun et al. [134] discussed the ramification of cryogenic compressed air cooling on the tool wear and the subsequent progression of cutting forces amid the turning of Ti6Al-4 V alloy using two different speeds. A carbide insert (CNMX1204A2-SMH13A) was used to conduct the process of turning at an approach angle of $45^{\circ}$, the rake angle of $+15^{\circ}$, the effective rake angle of $+9^{\circ}$, and inclination of $-6^{\circ}$. Due to the dimensions of the built-up edge, chip and flank wear were reduced significantly by the cutting forces at more values of cutting speed. Therefore, cryogenic compressed air cooling was comparatively found better. Orthogonal cutting of Ti-6Al-4 V alloy having a more effective feed rate $(0.1-0.25 \mathrm{~mm})$ at high speed was examined in terms of the dynamics and generation of chip geometry. Implants were manufactured through turning with the help of a displaceable cutting plate made of coated cemented carbide. It was concluded that depth of cut and chip design play essential roles in mainly turning hard metallic biomaterials. A recent study on the dry turning of biomedical Ti-6Al-4 V-ELI with SNMA120408 uncoated inserts via experimentation and finite element modeling obtained phenomenal results. In Fig. 16, the SEM micrographs demonstrated the major fractures leading to chipping segment generation and the plastic flow of the workpiece surface via observed feed marks on the turned samples. Moreover, the subsurface analysis revealed that the substantial microstructural changes occurred due to the differently produced high heat energies with variation in cutting speed [135].

In a study on ultrasonic assisted-drilling of Ti-6Al-4 V, Pujana et al. [136] observed a 10-20\% reduction in feed force. However, the drill bit experienced a higher temperature than the conventional drilling setup. Figure 17 presents
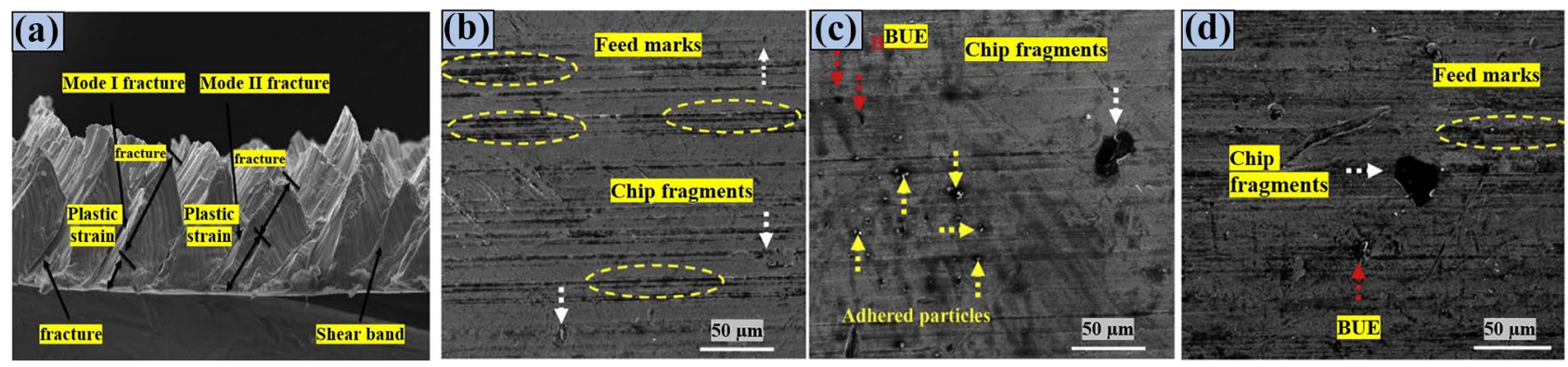

Fig. 16 a Major fractures leading to chipping segment generation. Machining induced imperfections on biomedical Ti-6Al-4 V-ELI surface at b $65 \mathrm{~m} / \mathrm{min}, \mathbf{c} 112 \mathrm{~m} / \mathrm{min}$, and $\mathbf{d} 124 \mathrm{~m} / \mathrm{min}$ cutting speed [135] 

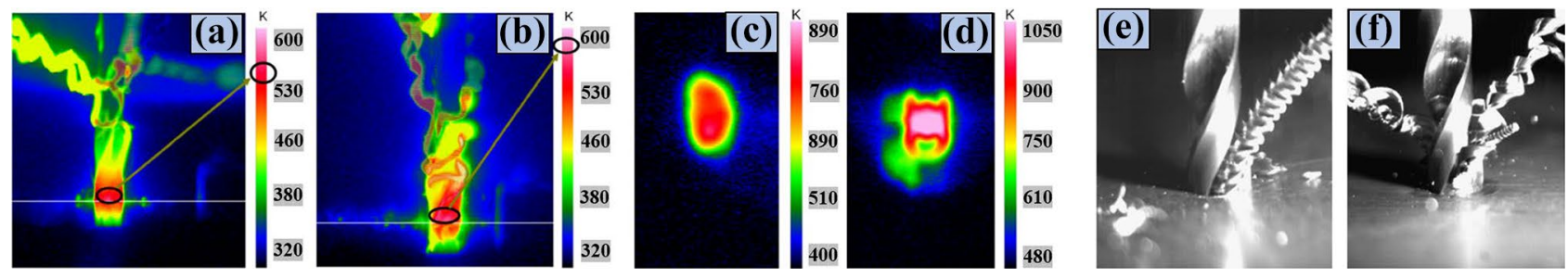

Fig. 17 Drill thermograms a without and $\mathbf{b}$ with ultrasonic assistance while entering into the Ti-6Al-4 V specimen. Drill thermograms $\mathbf{c}$ without and $\mathbf{d}$ with ultrasonic assistance while exiting the Ti-6Al-4 V specimen. Chip generation $\mathbf{e}$ without and $\mathbf{f}$ with ultrasonic assistance [136]

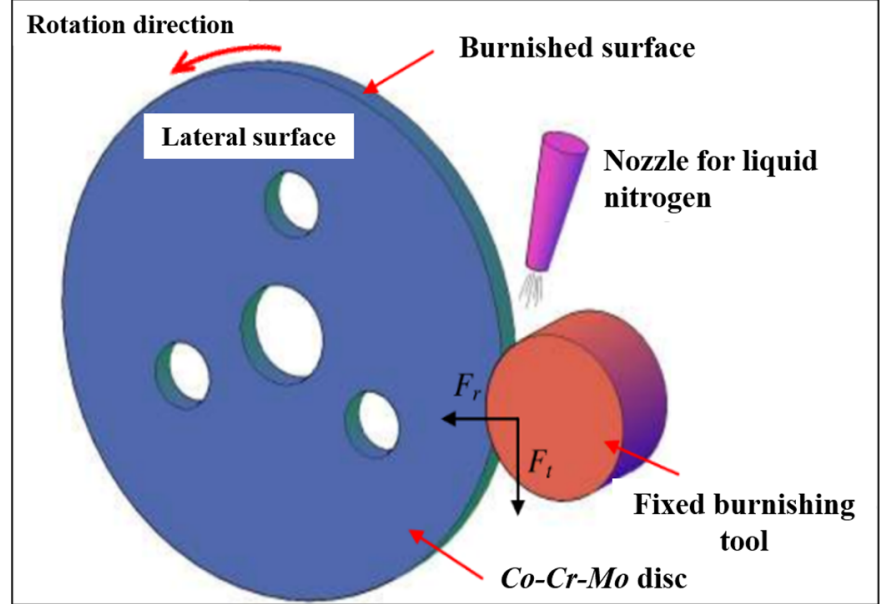

(a)

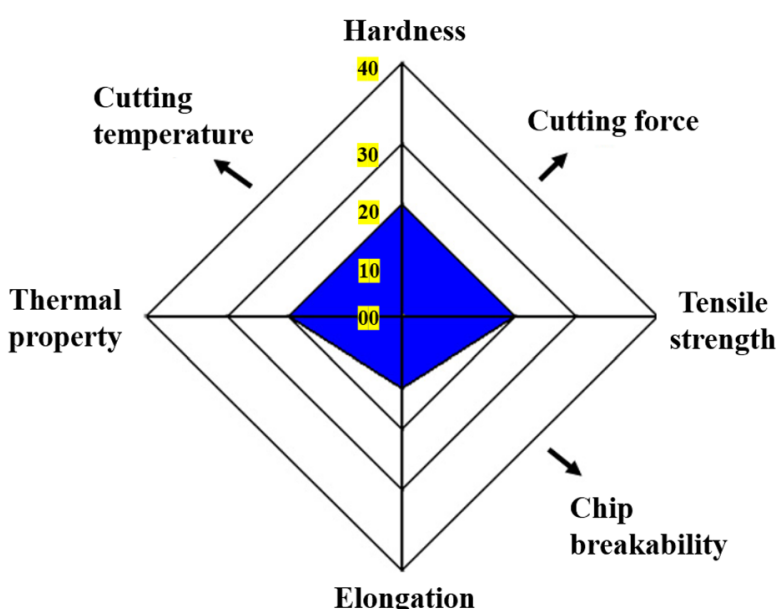

Elongation

(b)

Fig. 18 a Schematic diagram of the burnishing of Co-Cr-Mo alloy [75] and b properties of Co-Cr-Mo alloys [137]
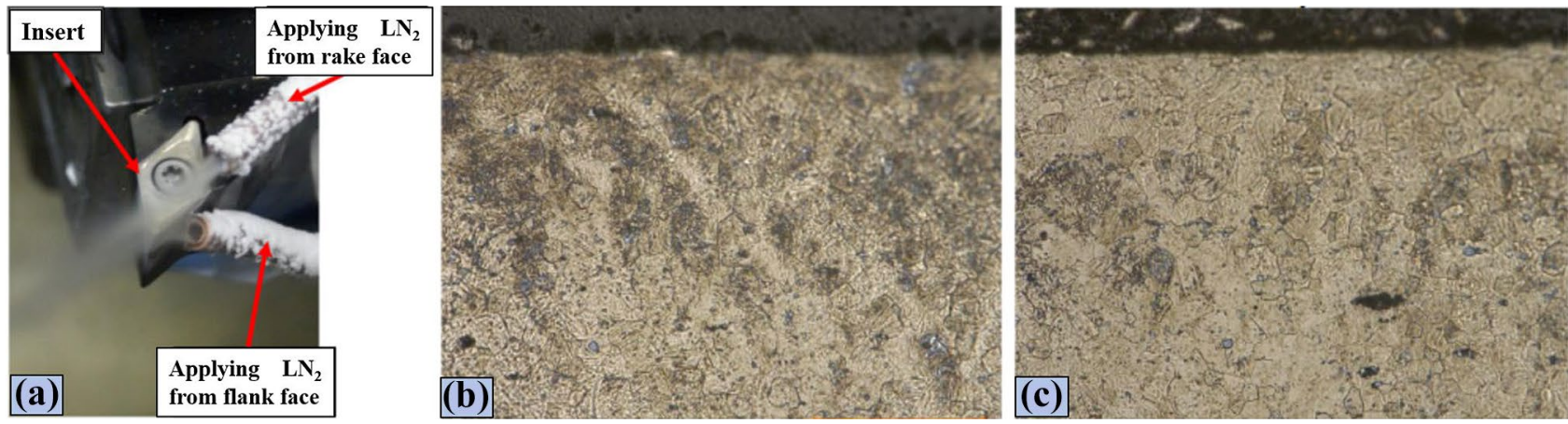

Fig. 19 a Cryo-turning; SEM micrograph of surface and sub-surface of the turned surface of NiTi alloy during $\mathbf{b}$ dry and $\mathbf{c}$ cryo-turning [139]

the thermograms of the observations without and with the assistance of ultrasonic vibrations.

Further, in the case of cobalt alloys, it was reported by Yang et al. [75] that under both conditions, either dry or cryogenic, when the refinement of grains occurs in the surface layer of Co-Cr-Mo (ASTM F75 cast alloy), the respective microstructures also change (Fig. 18). Also, on the surface, which was cryogenically burnished, a noteworthy increment in the relative intensity was achieved, which could considerably improve the erode defiance of $\mathrm{Co}-\mathrm{Cr}-\mathrm{Mo}$ alloy presents burnishing (with the assistance of liquid nitrogen and burnishing tool) and Co-Cr-Mo alloy properties. Another study conducted by Ferreira et al. [137] milled the Co-28Cr-6Mo alloys at varying speeds to observe the changes in the thermal gradients, roughness, cutting forces, and hardness. The 

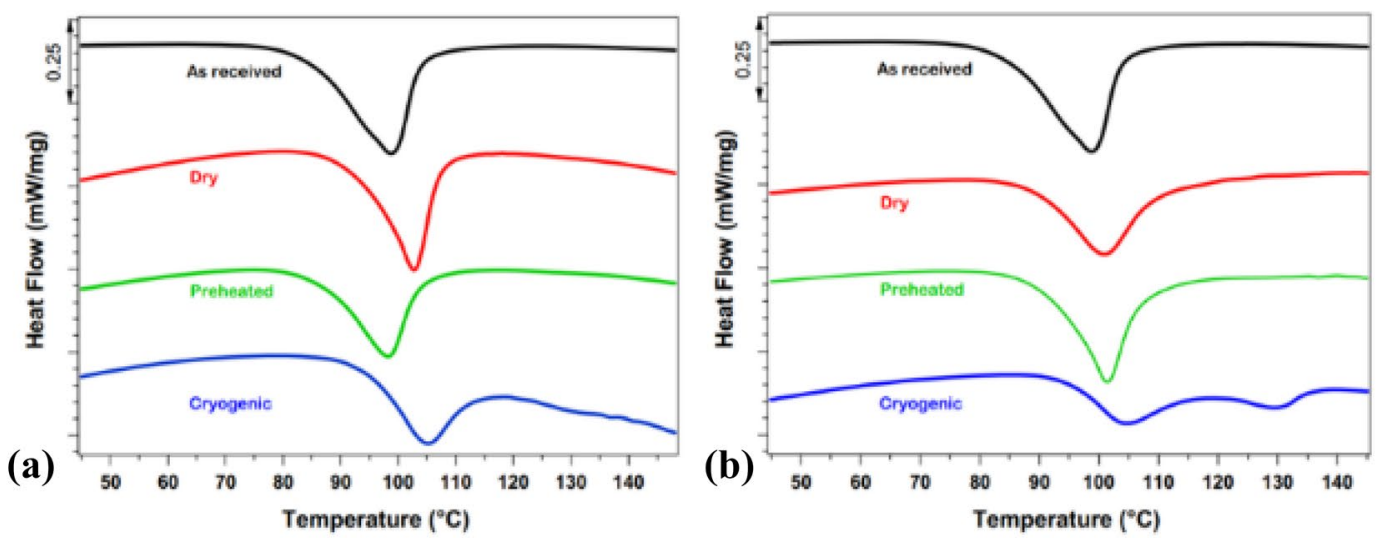

DSC results of samples machined under different conditions at (a) $12.5 \mathrm{~m} / \mathrm{min}$, (b) $100 \mathrm{~m} / \mathrm{min}$ cutting speed
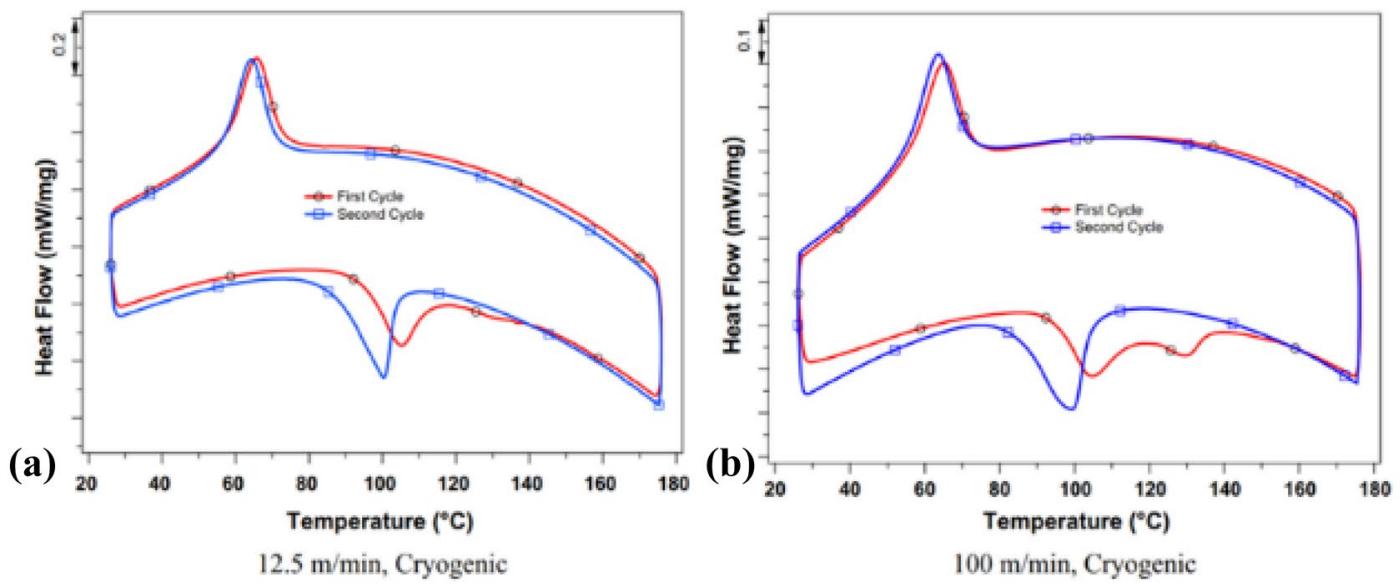

DSC response of machined NiTi specimens at the first and second cycles, (a) $12.5 \mathrm{~m} / \mathrm{min}$ cryogenically machined sample and (b) $100 \mathrm{~m} / \mathrm{min}$ cryogenically machined sample

Fig. 20 DSC plots show machining operations' nature under varying heat flow, temperature, and cutting speed [140]

results endorsed a high impact of higher cutting speeds on the response outcome.

Besides, Nitinol SMAs possess some unique traits such as the transformation of phase, shape memory, and superelasticity, through which they are significantly employed in various industries. An experimental study conducted by Kaynak et al. [138] examined several dry and cryogenic machining considerations, named quality and roughness of surface, topography, phase transformation, and microstructure of induced surface integrity in SMA's machining. The study concluded that the machined components' surface eminence was significantly enriched in cryogenic machining compared to dry machining. Figure 19 presents the cryo-turning view and SEM micrographs of dry and cryo-turned surfaces. In cryo-turned specimen, relatively higher temperatures and broader peaks were observed when matched with the specimen undergoing dry machining (during the transformation from martensite to austenite). This result gestures that the influence of cryogenic machining is denser on the surface principal aspects of SMAs because high disconnection density and residual stresses are introduced on their surfaces and sub-surfaces, as shown in Fig. 19.

Kaynak et al. [140] focused on turning NiTi alloy under dry, preheated, and cryogenic conditions and highlighted the influence of cryo-turning on phase state and transformation, which was evident in the form of broader peaks and $29 \%$ bigger austenite finish transformation temperature at high cutting speed. However, the total conversion of martensite to austenite took place in dry turning at each speed. In Fig. 20, the broader peaks and higher transformation temperature are easily noticeable in cryo-turned samples than other turned samples. Moreover, the variation in peak and transformation nature with a change in cutting speed is also clearly visible, as shown in Fig. 20.

Further, when considering magnesium and its alloys as the potential degradable metallic implant biomaterials, corrosion resistance is one of the prime documented aspects that need to be dealt with since the manufactured 


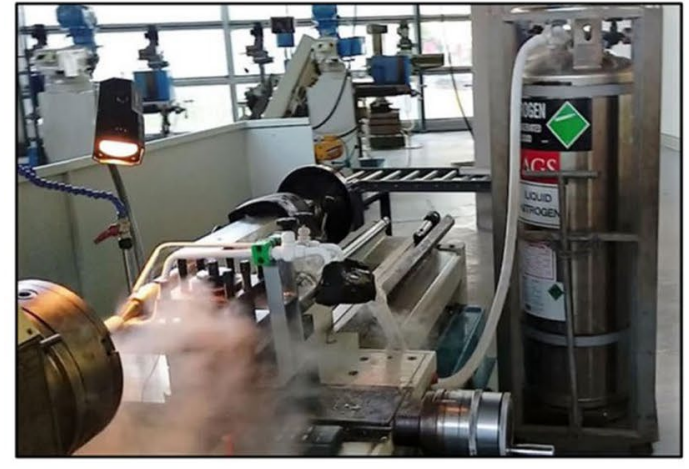

(i)

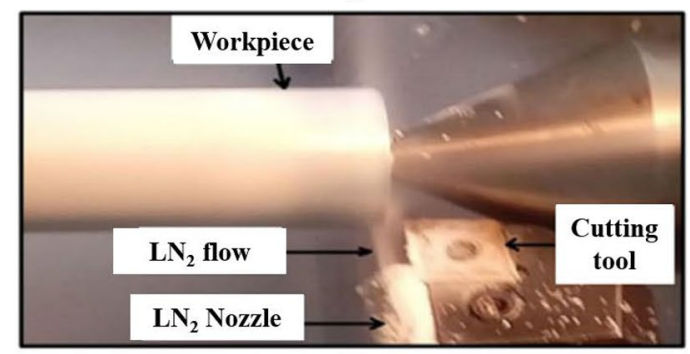

(ii)

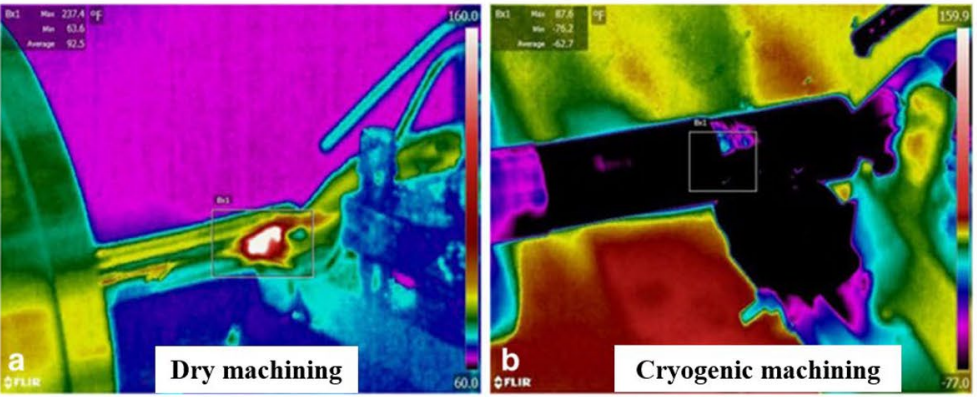

(iii) Thermal images of AZ31 magnesium alloy at $\mathrm{Vc}=150 \mathrm{~m} / \mathrm{min}, \mathrm{f}=0.14 \mathrm{~mm} / \mathrm{rev}$, and $\mathrm{d}=0.4 \mathrm{~mm}$ during (a) dry and (b) cryogenic machining

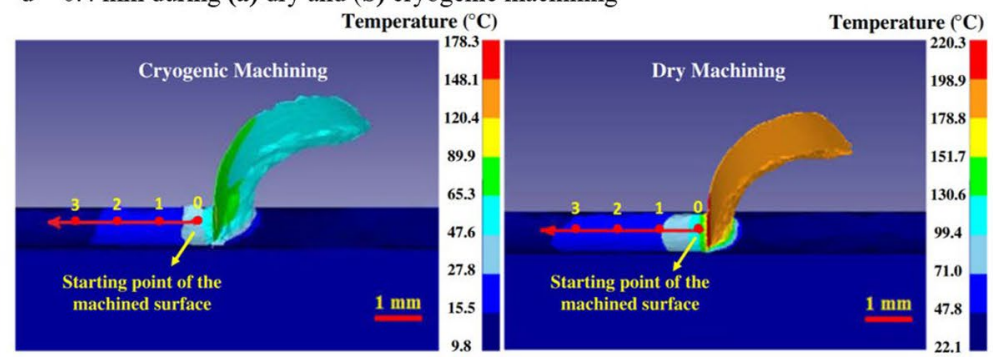

(iv) Temperature distribution at the machined surface during cryogenic and dry machining ( $\mathrm{Vc}=150 \mathrm{~m} / \mathrm{min}, \mathrm{f}=0.14 \mathrm{~mm} / \mathrm{rev}$, and $\mathrm{d}=0.4 \mathrm{~mm}$ )

Fig. 21 (i) Cryogenic turning setup, (ii) cryogenic turning, (iii) thermal images, and (iv) simulated results of temperature distribution amid turning of Mg alloy AZ31 [146]

part/component has to deal with the human body. In addition, during $\mathrm{Mg}$ alloy implants' subtractive manufacturing, another common challenge that the manufacturers face is their low melting point. Therefore, there are chances of ignition or even explosion as soon as the machining zone temperature reaches around $450{ }^{\circ} \mathrm{C}[141]$. Moreover, not every coolant can be used during magnesium's machining and its alloys to reduce this temperature since some can unexpectedly react and cause explosions by forming gases such as hydrogen [142]. Hence, the traditional subtractive manufacturing of $\mathrm{Mg}$ and its alloys is preferred under specific cooling environments. In this regard, cryogenic machining simplified the complexities of corrosion and ignition in some recent literature [143-145]. Danish et al. [146] conducted a simulated and comparative study on cryogenic assisted and dry turning of Mg alloy AZ31. They demonstrated the efficient and faster elimination of generated heat (up to 60\%), followed by a decrease in surface roughness (by 56\%) amid cryogenic-turning. Figure 21 shows the experimental setup and some findings. In similar studies performed by Bertolini et al. [147] and Davis and Singh [148] on Mg alloy AZ31B and AZ91D, respectively, comprising low-temperature sustainable lubrication/cooling, in addition to superior surface integrity, the cryogenically turned/milled surfaces were also noticed with a featureless layer, suggesting improved passivation against corrosion of that surface. The authors found that the enhanced cooling improved the surface roughness up to $48.07 \%$ and generated a more uniform passivation layer.

Davis and Singh [149] used three different milling environments (wet, cryogenic, and hybrid) and the end mill tool in the untreated and cryo-treated form to mill $\mathrm{Mg}$ alloy AZ31B to improve its surface integrity. The findings improved surface integrity at the high-speed using cryo-treated end mill amid hybrid (wet + cryogenic) cooling. Figure 22 shows the different milling environments, obtained featureless oxide passivation layer on the surface hybrid-milled by cryo-treated end mill, energy-dispersive $\mathrm{X}$-ray spectroscopy (EDS) showing the elements present on the finally manufactured surface, and the worn-out end mill cutting edges. Hybrid milling improved the end mill life, contributing to surface integrity enhancement. In continuation, the latest research performed by Davis et al. [150] machined Ti-6Al-4 $\mathrm{V}$ alloy also used the combination of the cryo-treated carbide end mill and different lubri-cooling environments and consequently achieved improved surface characteristics including morphology, chemistry, roughness, and microhardness. Moreover, the best achievement of this research was the observation reporting a remarkably improved in vitro cell proliferation and growth on the hybrid-lube-coolant-machined surface. In this regard, Fig. 23 compares and displays the modified surface with CpTi alloy and demonstrates the enhanced cell response 


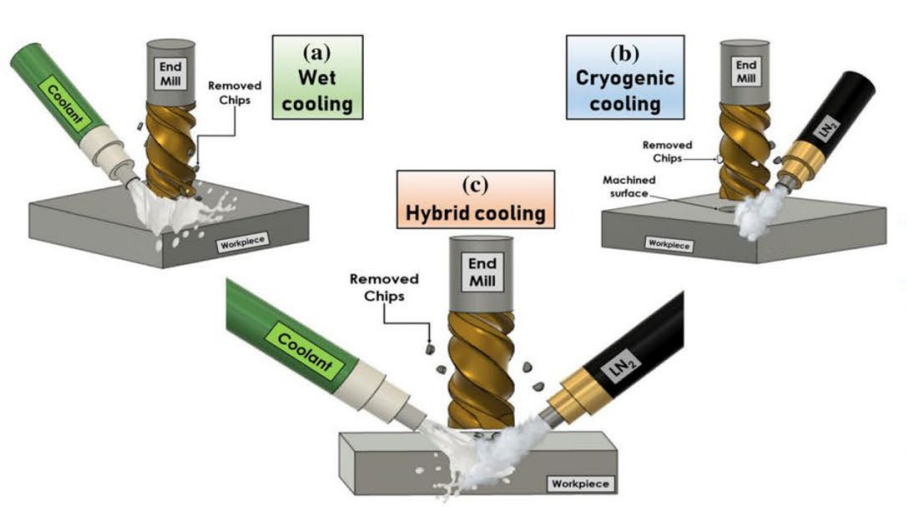

(i)

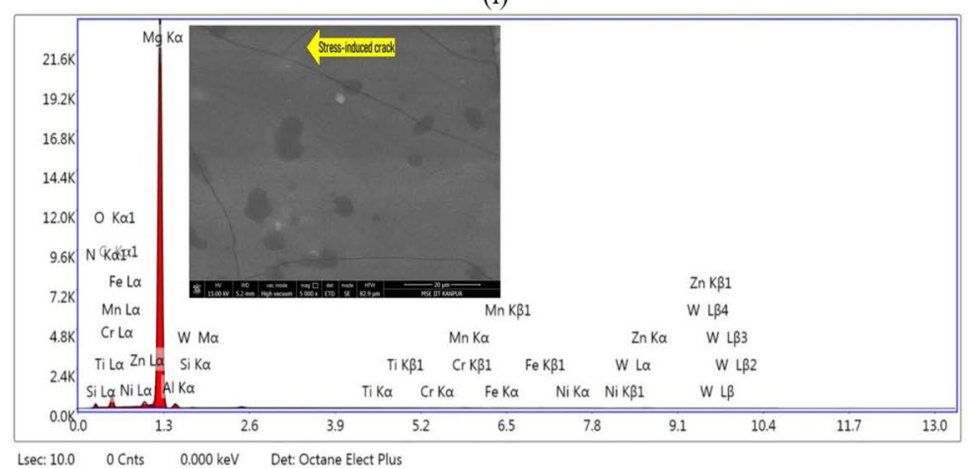

(iii)

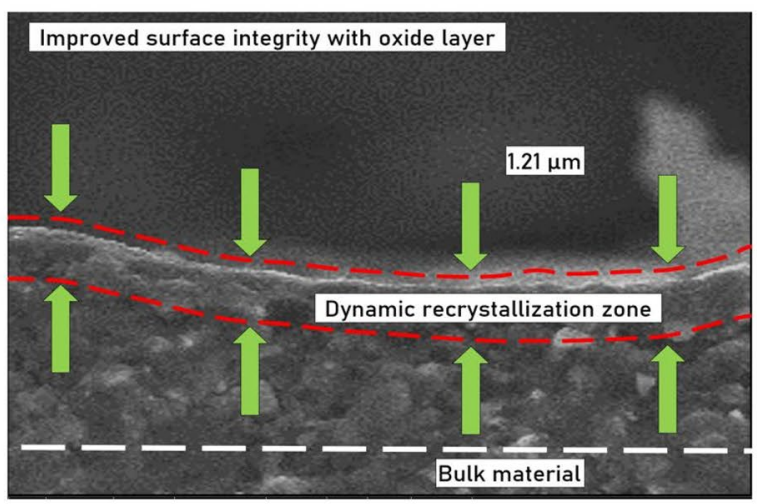

(ii)
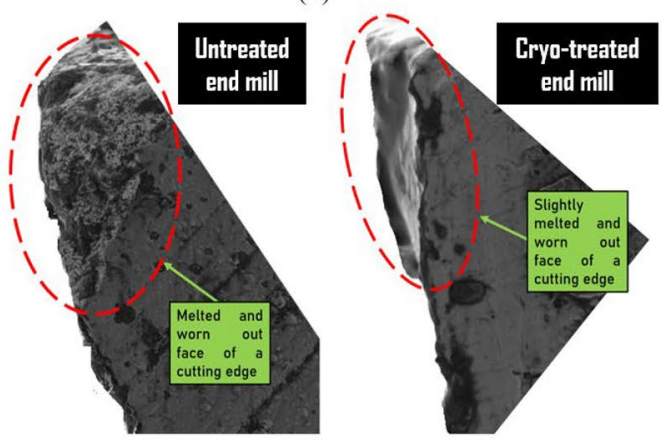

(iv)
Fig. 22 (i) Schematic diagram of three different milling environments of machining $\mathrm{Mg}$ alloy AZ31B, (ii) SEM demonstration of the featureless oxide layer on the surface hybrid-milled (wet + cryo) by cryo- treated end mill, (iii) EDS and SEM image of the surface hybridmilled by cryo-treated end mill, and (iv) SEM images displaying tool wear in both the end mills [149]
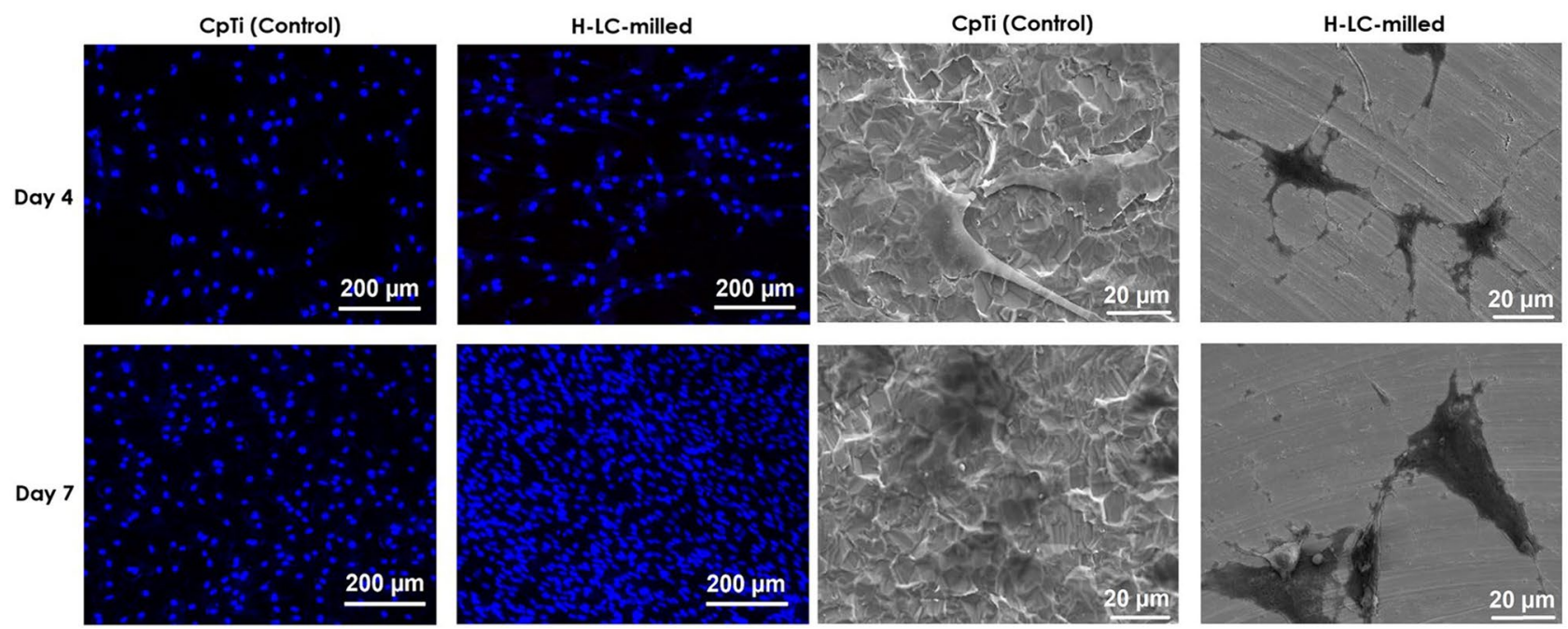

Fig. 23 Fluorescence (stained with DAPI (blue)) and SEM images are presenting ADSCs after 4 and 7 days of cell culture on CpTi and hybridlubri-coolant-milled surfaces (obtained with cryo-treated end mill) [150] 


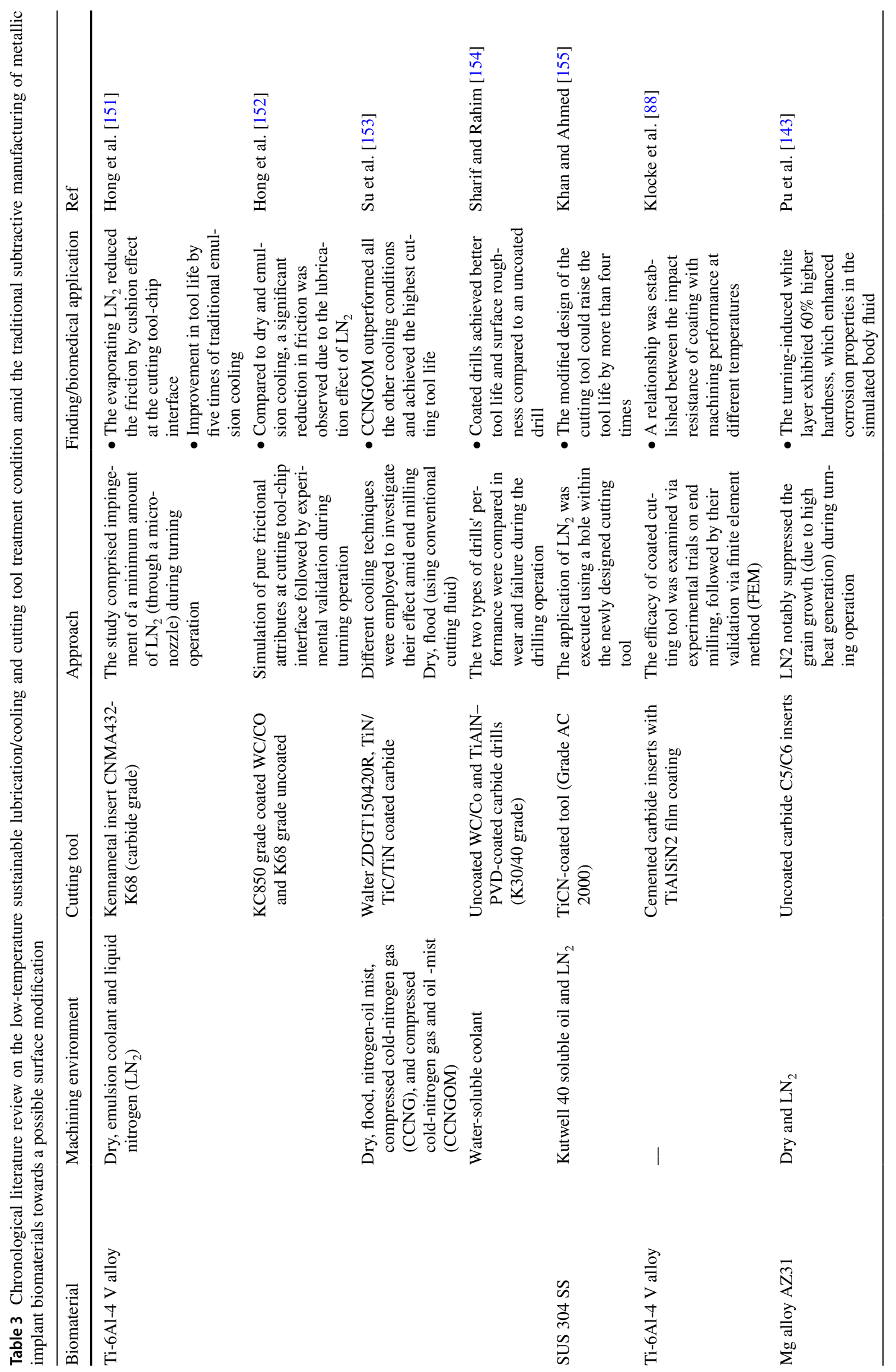




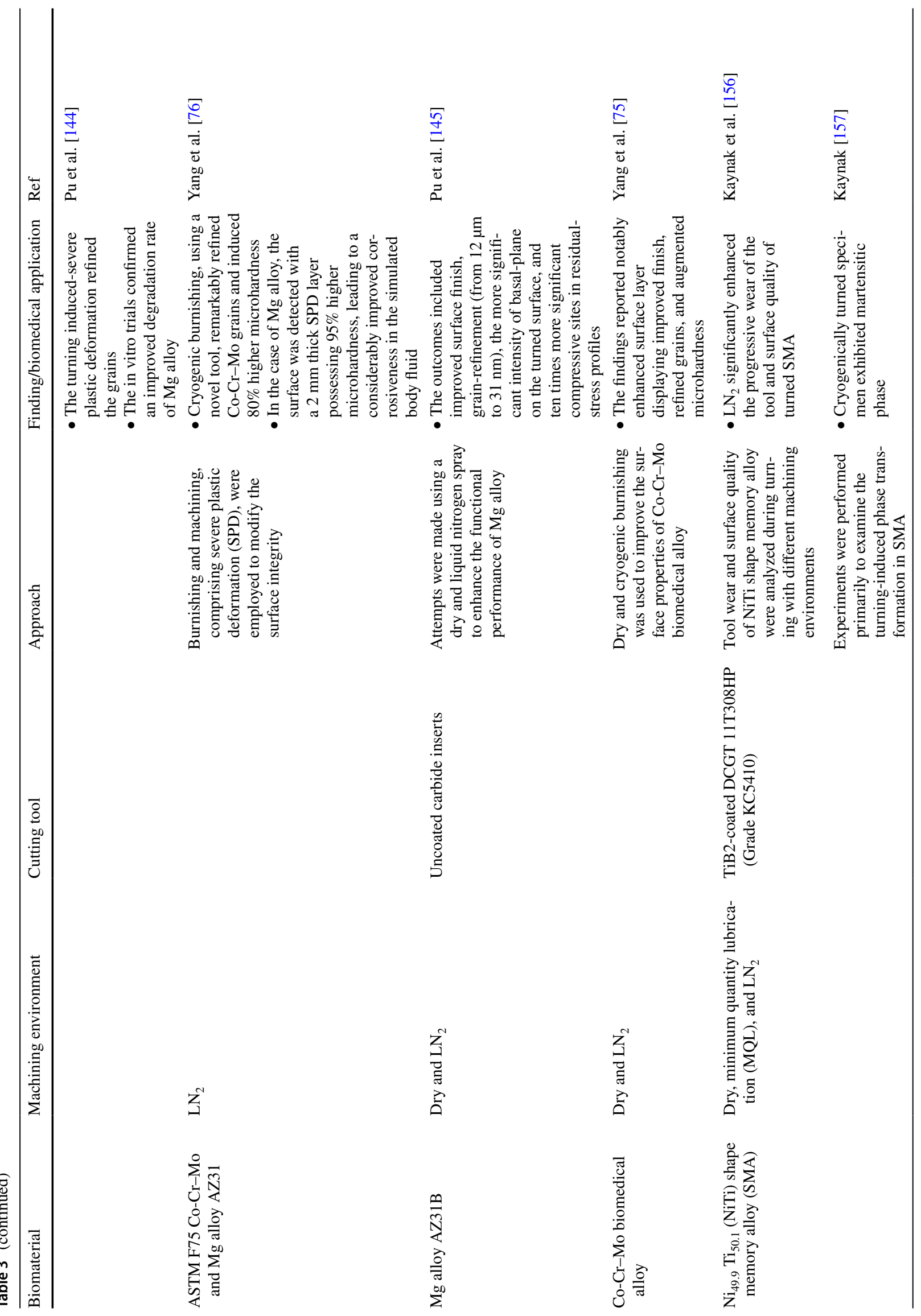




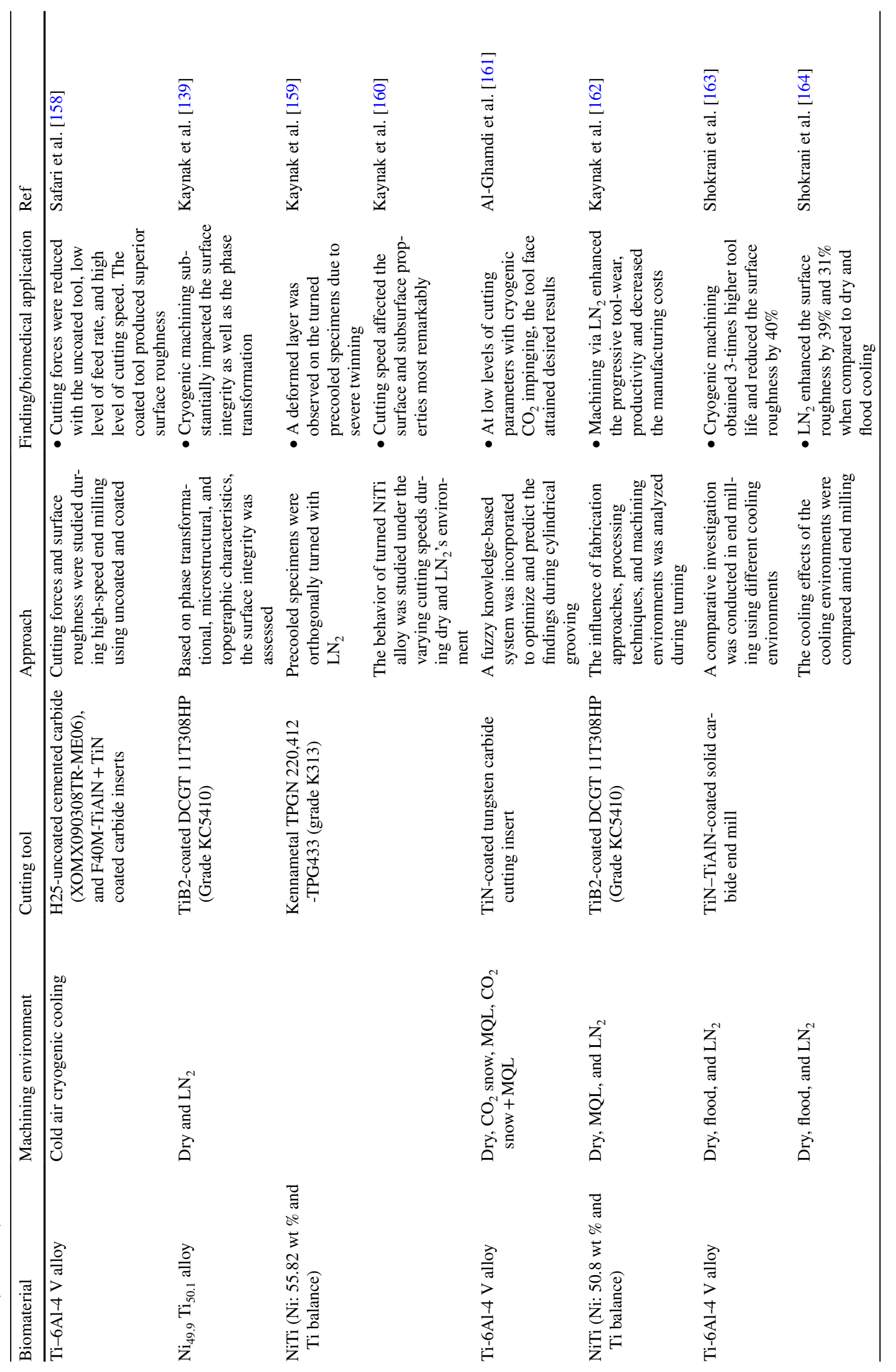




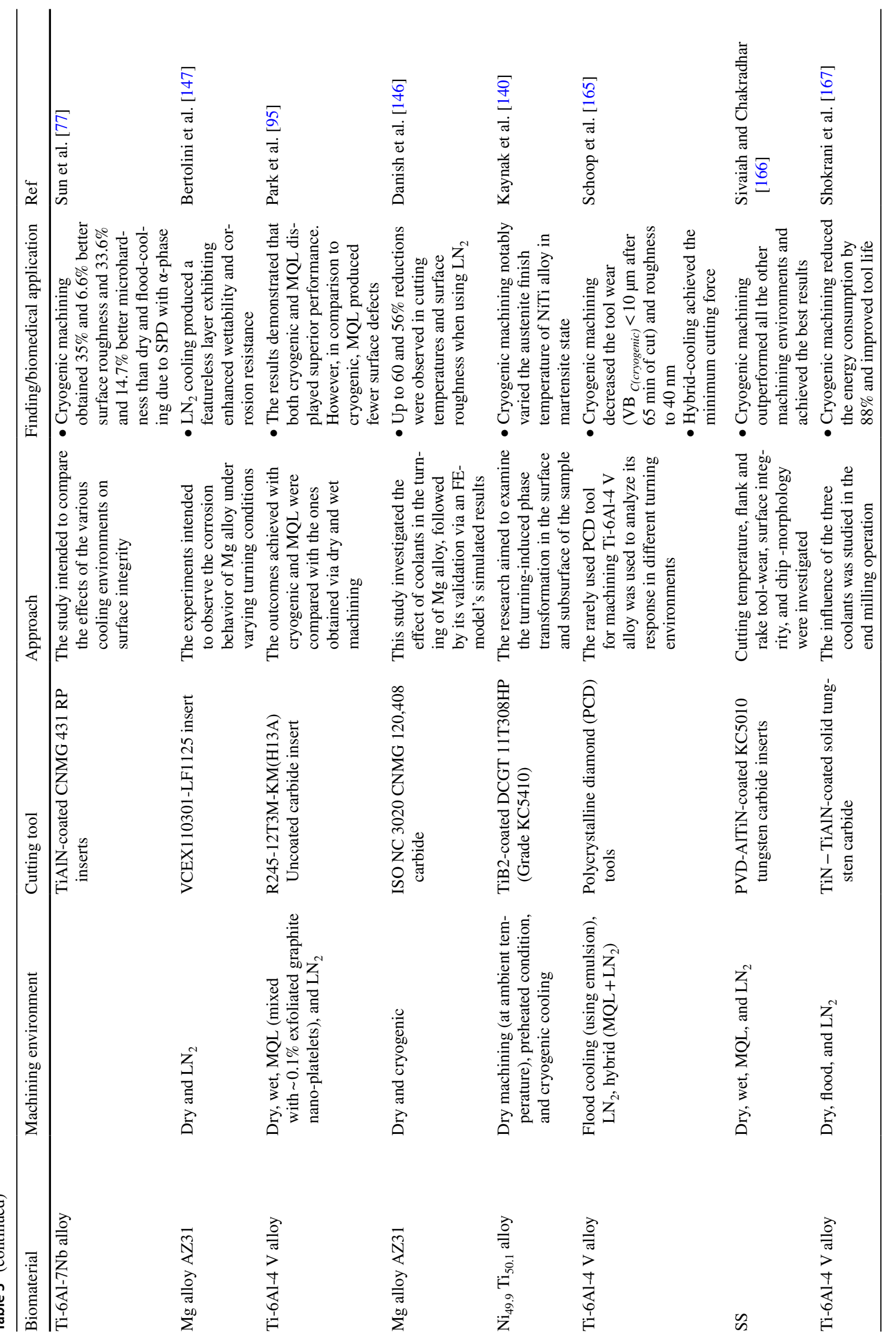




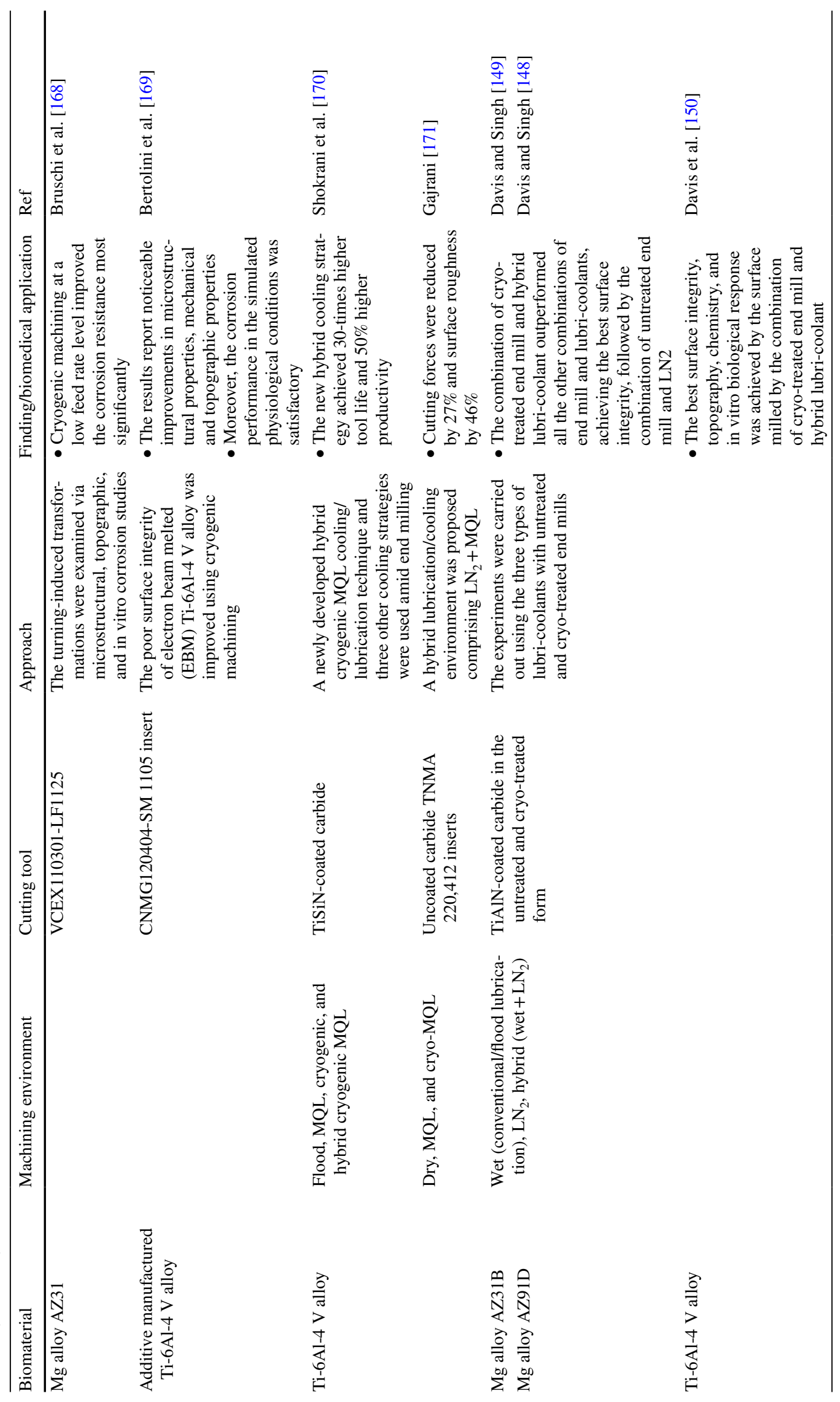




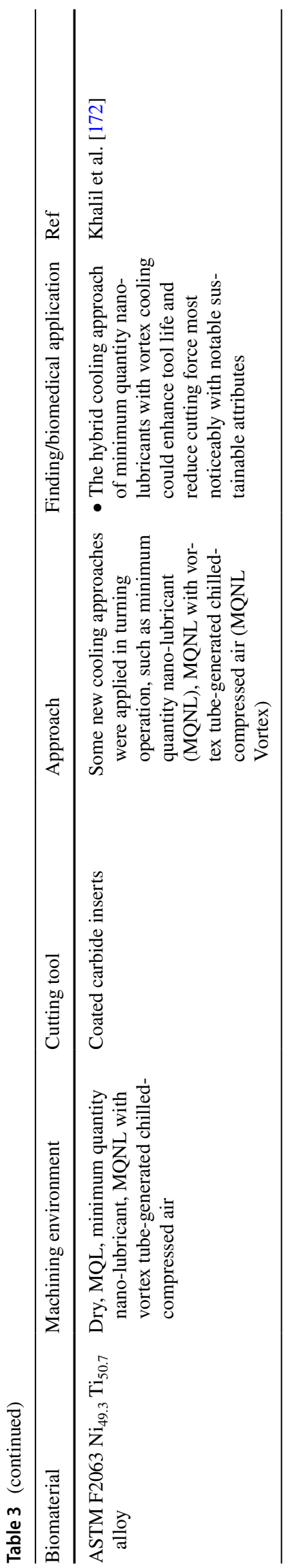

after 4 and 7 days on the machined surface with the superior performance of the end milling.

\subsubsection{A rigorous chronological survey on the strategies used to modify the metallic implant biomaterials using traditional machining techniques}

This section presents an elaborated review focused on some significant attempts made in the last 20 years (in chronological order) to achieve surface modification on metallic implant biomaterials via traditional machining approaches. In this regard, Table 3 and Fig. 24 demonstrate the primary approaches (in terms of lubrication/cooling and cutting tool) adopted to modify the metallic implant biomaterials via traditional machining techniques substantially. The significant findings have been pointed. However, only a few studies report an improvement in the biological behaviors of the traditionally machined workpiece biomaterials. Based on the findings observed in the previous literature recorded in Table 3 and graphical analysis of Fig. 24, the chiefly used metallic implant biomaterials for biomedical implant applications and manufactured by traditional subtractive manufacturing techniques were Ti-based alloys, followed by NiTibased, Mg-based, SS, and Co-Cr-based alloys. However, a tremendously increasing trend in using NiTi-based and Mg-based alloys as implant biomaterial could be witnessed easily in the last ten years in Table 3. Moreover, according to Fig. 24, the low-temperature sustainable approach of cryogenic machining has appeared with its dominant use over the conventionally used cutting fluids.

In addition, a slow but notable rise in the incorporation of hybrid lubrication/cooling (lubri-cooling) methods could also be observed, indicating the increasing scope of the same in the days to come. Hence, some of the main merits/applications, demerits, challenges, and possible solutions amid the traditional machining of $\mathrm{Mg}$, NiTi, and Ti-based metallic implant biomaterials, can be further elucidated with the help of Table 4 .

\subsection{Surface modification of metallic implant biomaterials via non-traditional subtractive manufacturing techniques}

Besides high toughness and strength, some of the significant challenges in the traditional machining of metallic implant biomaterials lie in the extreme sensitivity of these materials such as $\mathrm{Mg}$ (due to high flammability), NiTi (due to susceptibility to the temperature-induced transition of phase), and Ti-based alloys (due to high hardness) towards cutting-induced temperature variations, high strain-rate, and consequent phase transformations [54, 135, 176]. In this regard, the advanced manufacturing processes constituting the non-traditional subtractive manufacturing techniques 


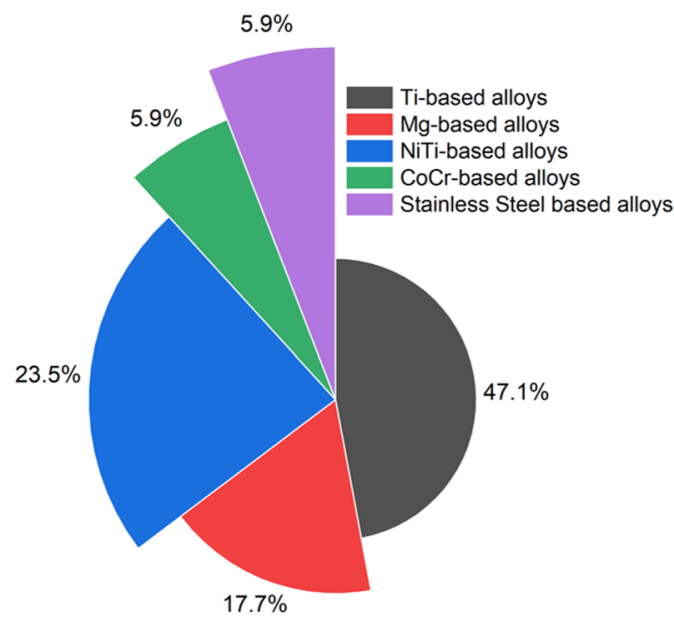

(a)
Conventional-lubri-coolant Hybrid-lubri-coolant

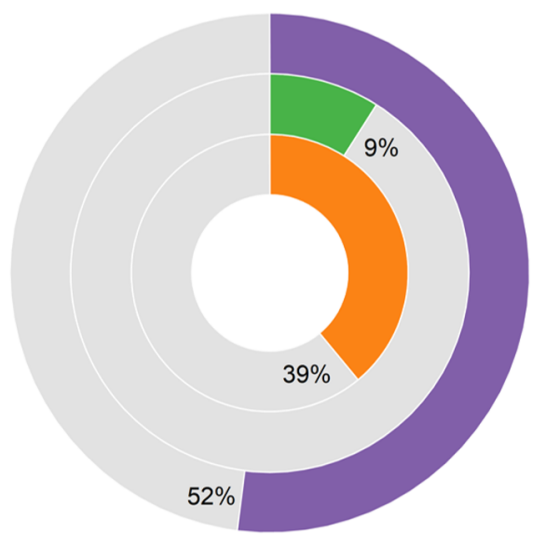

(b)

Fig. 24 Percentage of published research articles in the last 20 years on a traditional machining of metallic implant biomaterials $\mathbf{b}$ using different lubri-coolants/machining environments

such as laser machining (LM), waterjet machining (WJM), and electric discharge machining (EDM) are the potential alternatives for effective machining of Nitinol [177, 178]. The non-traditional subtractive manufacturing techniques subtract unwanted and surplus material by different electrical, chemical, mechanical, thermal, or combinations of these energies without applying the cutting tools used in traditional machining techniques. Following are some commonly employed non-traditional machining techniques to modify the metallic implant biomaterials' surfaces for implant applications.

\subsubsection{AWJM technique}

Abrasive water jet machining (AWJM) is a cold processing technique that comprises efficient shaping tools and fulfils the necessities of material removal structuring for metallic implant biomaterials. Silica sand, garnet, silicon carbide, and aluminum oxide commonly use abrasive particles in AWJM. The AWJM favors high flexibility with a relatively sensitive material removal rate, amicability with the ambient conditions, and exhibits inexpensive and high machining adaptability. In this type of subtractive manufacturing, the ultra-high pressurized water is forced through a very tiny opening, generating a high speed $(800 \mathrm{~m} / \mathrm{s})$ water flow [179]. The inclusion of abrasive particles in this high-speed water flow raises the standard of machining capability considerably. In this relation, a review revealed the versatility of AWJ on all the commonly used metallic implant biomaterials, including stainless steel, Ti-based, Co-based, NiTi, and Mg-based alloys [180]. Also, an experimental study achieved enhanced fatigue life, compressive residual stress, and surface finish after AWJ assisted peening in the orthopedic application of stainless steel 304 and Ti-6Al-4 V alloy.

Moreover, a recent investigation on AWJ-milling on stainless steel 304 was carried out to produce an implant rough

Table 4 A comparative study of the major applications, demerits, challenges, and possible solutions during the traditional machining of Mg, NiTi, and Ti-based alloys

\begin{tabular}{llll}
\hline Metallic implant biomaterial & Implant application & $\begin{array}{l}\text { Demerit/risk involved amid tradi- } \\
\text { tional machining }\end{array}$ & Possible solution \\
\hline Mg-based alloys & Cardiovascular stent & Flame-ignition & Low depth of cut and speed [173] \\
& Orthopedic device & Flank-built-up & Cryogenic machining [145] \\
& Implantable screw & Early degradation & High-speed machining with \\
NiTi-based alloys & Bone plate & Excessive burrs and chip-forma- & cryogenic cooling [162] \\
& Osteosynthesis plate & tion, and tool-wear & Low-temperature coolant [134] \\
Ti-based alloys & Spherical-prosthesis & Chip-thickness variations & Cryogenic cooling [174] \\
& Dental screws & Heat-stress & Coated carbide cutting tool [175] \\
\hline
\end{tabular}




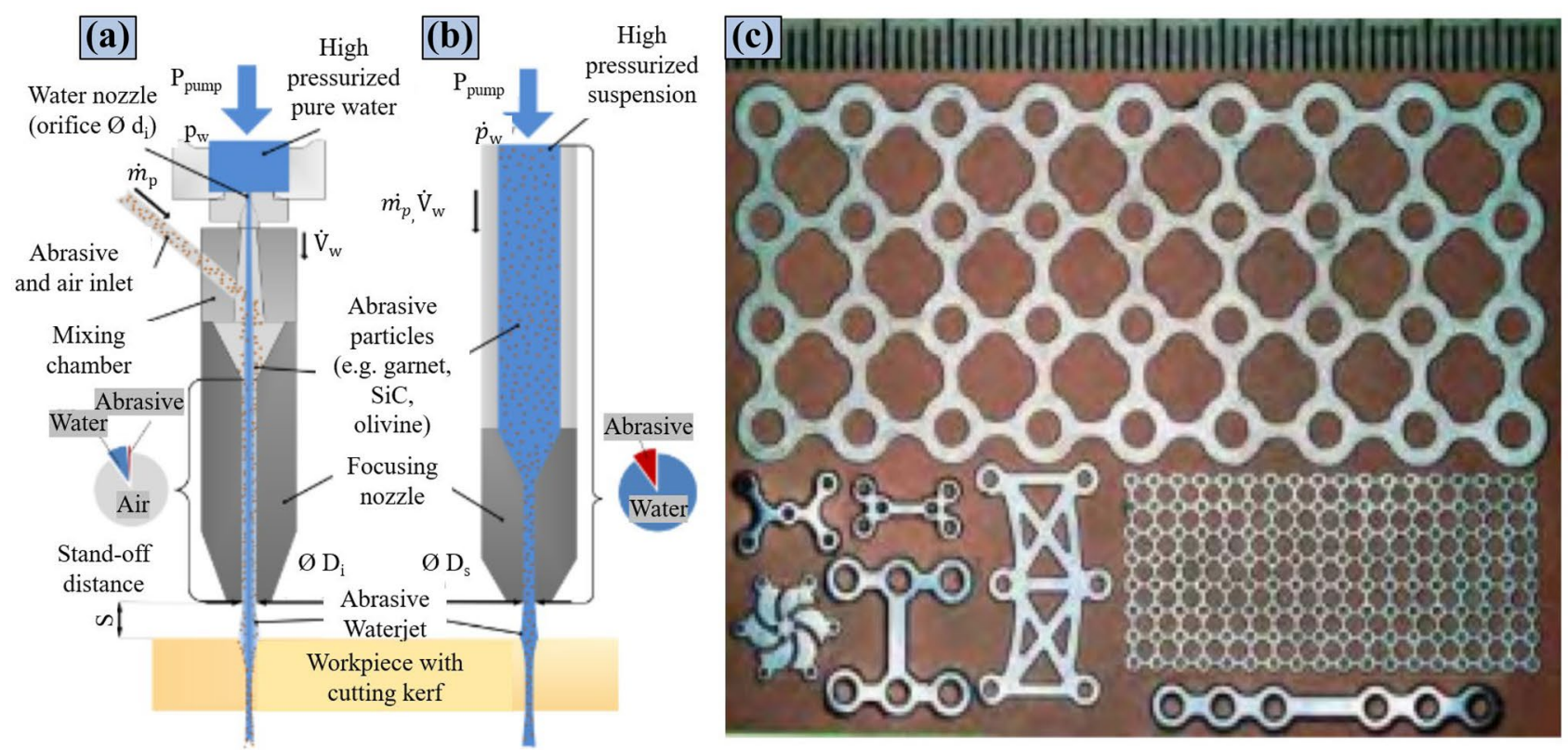

Fig. 25 (a) Injection and (b) suspension type of AWJ; (c) orthopedic implants made up of titanium alloys and stainless steel [185]

spot groove surface pattern [181]. In another study, the surface roughness and irregularities improved using artificial neural networks amid AWJM of Mg alloy AZ91D. Abrasive flow rate and jet feed-velocity primarily affected the surface characteristics [182].

Further, abrasive water jet machining at micro-level ( $\mu$-AWJM) using \#220 to \#320 abrasive mesh size is a recent state-of-the-art subtractive micro-manufacturing technique. Unlike many other thermally manufactured products, the $\mu$-AWJMed products not only exhibit a high degree of surface integrity and profile geometry, but they are also free from stresses and heat-affected zone(s), which can further improve the functionality of metallic implants. $\mu$-AWJM consumes lesser processing time than many other microsubtractive manufacturing processes, such as micro-electric discharge machining $(\mu \mathrm{EDM})$. However, it consumes more time than macro-AWJM and $\mu$-AWJM set up developed by $\mathrm{M} / \mathrm{s}$. OMAX corporation can miniaturize the products in the domain of 200 to $300 \mu \mathrm{m}$ with the aid of a nozzle with a tiny diameter $(<200 \mu \mathrm{m})$ [183]. Figure 25 demonstrates the schematic diagrams of two different AWJ setups and $\mu$-AWJMed orthopedic implants. One recent research conducted on $\mu$-AWJM of Co-Cr-Mo to produce micro-channels concluded $\mu$-AWJM as one of the most potential and promising techniques for the tribological surface texturing of artificial joints. Figure 26 shows some essential technical details of the strategic parameters and desired outcome, followed by the achieved findings [184].

Since AWJM is known for inducing imperceptible temperature variation in the produced parts, NiTi alloys' mechanical and metallurgical responses drastically change even with a slight change in the phase transition. Therefore, it became essential to validate the influence of AWJM on the phase transition of NiTi alloys. In this relation, a comparative experimental work included water jet machining (WJM) of $\mathrm{Ni}_{49.8} \mathrm{Ti}_{50.2}$ with and without garnet abrasive particles of \#80 mesh size. Figure 27 presents a phase transformation diagram, SEM image of one of the surfaces exhibiting martensitic transformation, and finally achieved improved results. The joint evaluation of operating temperatures (of the two WJM processes) and NiTi alloys' phase transformation temperatures revealed a significant AWJM approach for controlled-depth milling. The application of high-speed abrasives on a particular spot could raise the localized temperature above $86{ }^{\circ} \mathrm{C}\left(\mathrm{A}_{\mathrm{s}}\right)$, leading to the transformation of martensite into austenite. However, the temperature beyond $\mathrm{A}_{\mathrm{f}}\left(110^{\circ} \mathrm{C}\right)$ reversed (pseudoelasticity) due to stress-induced transformation. The literature does not report much research on AWJM of NiTi alloys since its most effective variant AWJ-milling loses the surface quality due to grit embedment with increasing penetration depth, which weakens fatigue strength in $\mathrm{Ti}$ alloys [186].

\subsubsection{LBM}

The last four decades have recorded industrial subtractive manufacturing via laser beam machining (LBM) as one of the most dominating non-traditional material subtraction processes for achieving complex geometrical features on the product. However, some investigations on LBM of biocompatible Ti-6Al-4 V and 316L stainless steel revealed that 


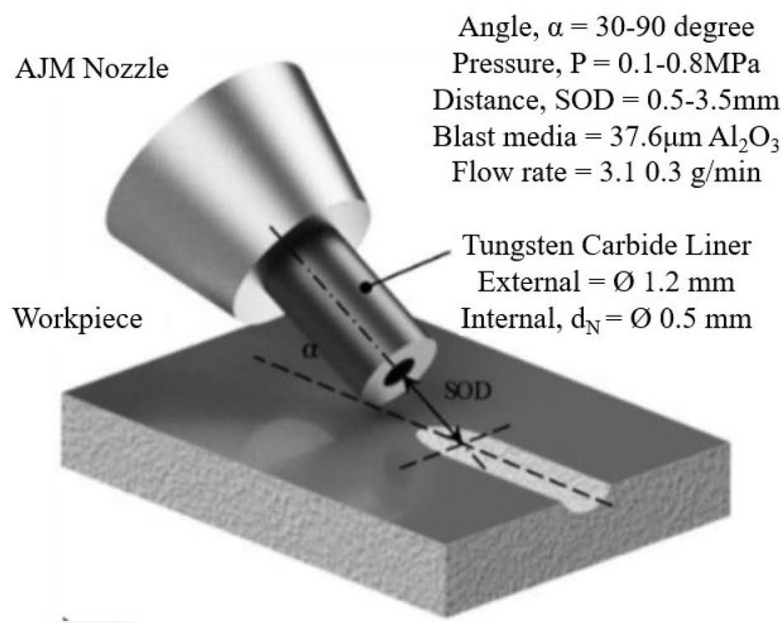

(a) Process schema and parameters

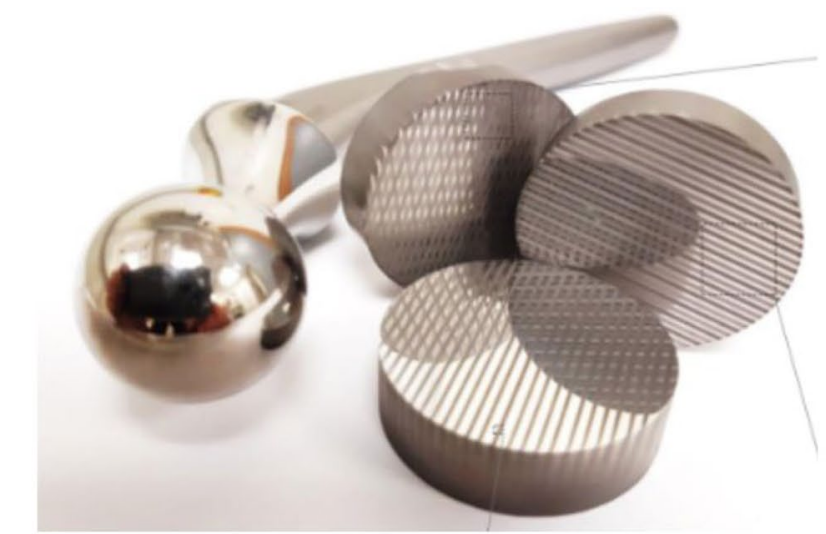

(c) Texturing of Ø30-mm Co-Cr-Mo disks with cross-hatched $550-\mu \mathrm{m} \times 5-\mu \mathrm{m}$ channels
Mounted and polished cross sections of the hip implant
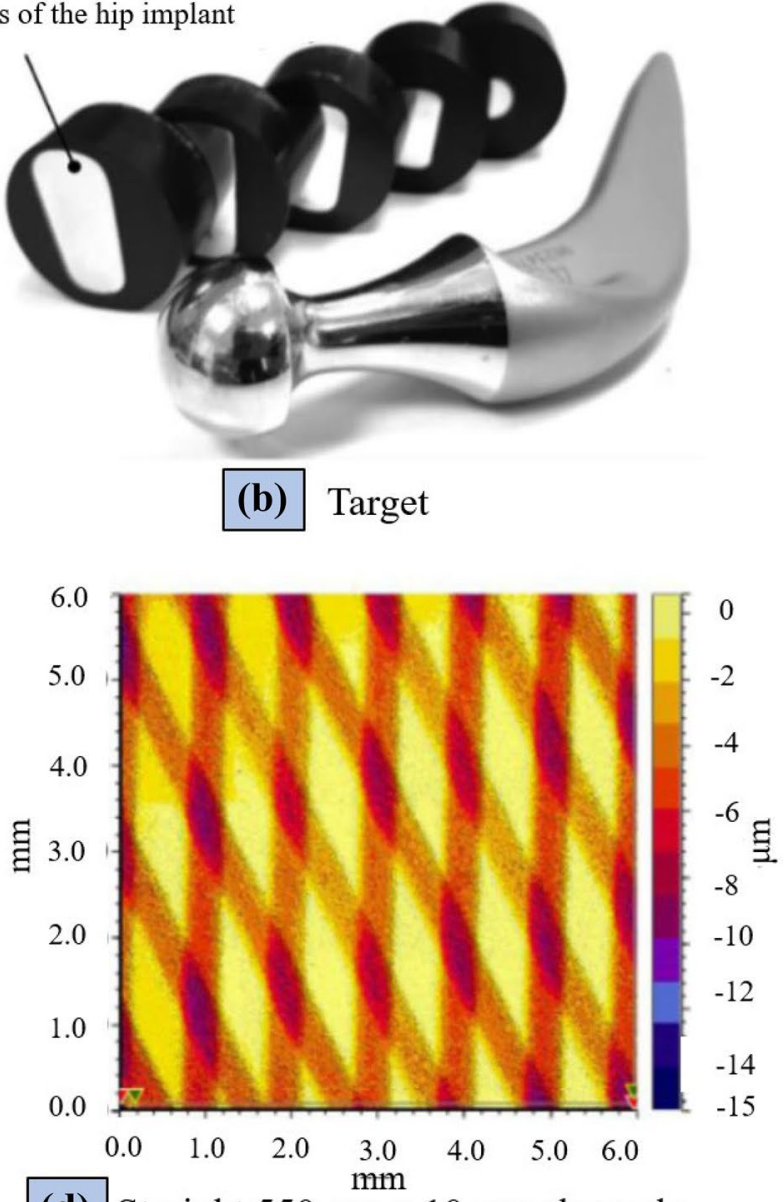

(d) Straight $550-\mu \mathrm{m} \times 10-\mu \mathrm{m}$ channels

Fig. 26 Experimental plan and outcome [184]

the laser beam's unwanted and undesired convergence and divergence, especially during low-power application fiber laser, resulted in the formation of large kerf taper. Moreover, cracks and a rise in the grain size (present in the heataffected zone) were reported [187, 188]. Therefore, such failures in machining metallic implant materials can limit their implant applications seeking tight dimensional fit. Hence, in this relation, attempts were made in an experimental work where a 50-W fiber laser was used to machine $316 \mathrm{~L}$ stainless steel to apply an additional process variable, known as cutting wedge angle. The increase in cutting wedge angle widens the kerf and reveals the kerf taper. Hence, by obtaining optimum settings of all the process variables, the most crucial cutting wedge angle, 316 stainless steel, could be machined with high dimensional accuracy [189].

Additionally, recent research on laser (Q-switched Nd: YAG pulsed laser) milling could decrease the surface roughness of micro-impressions (with slot depth of $12 \mu \mathrm{m}$ ) of
Ti-6Al-4 V from $6.38 \mu \mathrm{m}$ to $0.965 \mu \mathrm{m}$ (Ra) with a considerable material subtraction with the help of a mathematical model. It was also observed that the finish of laser-milled surfaces got improved at low levels of current intensity (approx. 75-80\%) and mid-levels of track displacement $(10 \mu \mathrm{m})$, layer thickness $(2 \mu \mathrm{m})$, and scanning speed $(300 \mathrm{~mm} / \mathrm{s})$ [190]. Besides, in the laser subtractive process, the temperature raised by the laser itself can alter the metallurgical, mechanical, physical properties of the targeted spot on the workpiece and thermally damage the same and accumulate ablated debris if it remains ungovernable. Moreover, such thermal deterioration becomes a prime and pivotal concern in micro-machining. A recent study compared the water and ice-assisted laser micro-machining of Ti-6Al-4 V alloy, keeping the inexpensive, safe, and recyclable water features in mind. Figure 28 shows schematic and SEM images of some of the significant findings. This work's outcome divulged that the water-assisted laser ablation could achieve 


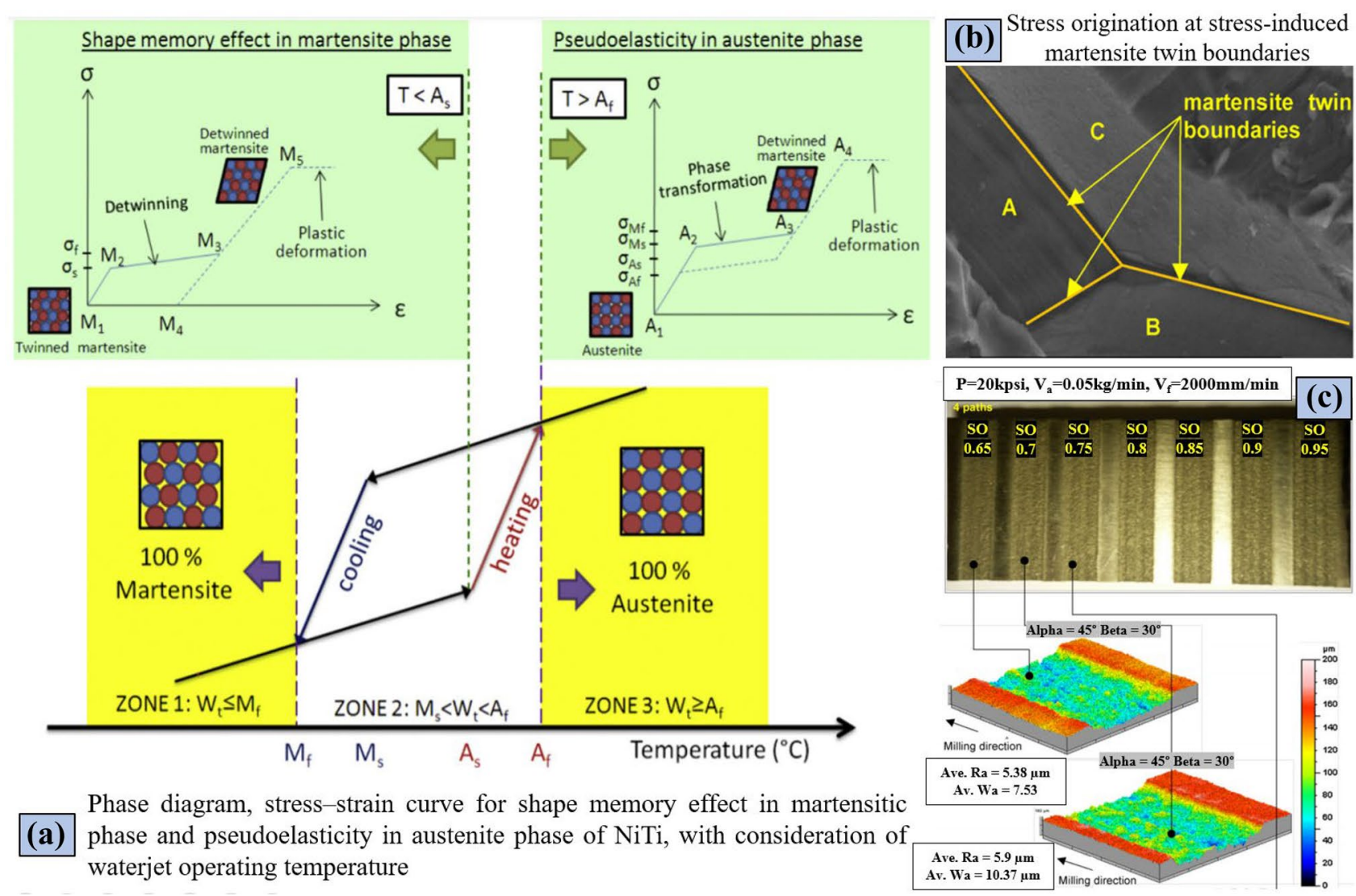

Fig. 27 a Phase diagram and stress-strain curve, b transformed martensite on AWJ-milled surface, and c AWJ-milled actual and simulated results with improved surface finish [186]

the cleaner machined groove with slower laser traverse speed and more passes than the ice-assisted one. However, the gas bubble generation water wave and high refractive index value caused more laser beam dispersion [191].
In the case of subtractive manufacturing of NiTi alloys via LBM, this machining process can manufacture the mechanical stress-free cardiac stents and fabricate microchannels in the medical implants. Moreover, it can also enhance the

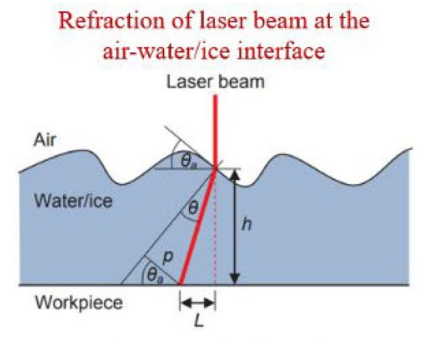

SEM images of titanium alloy surface after the laser ablation in ice

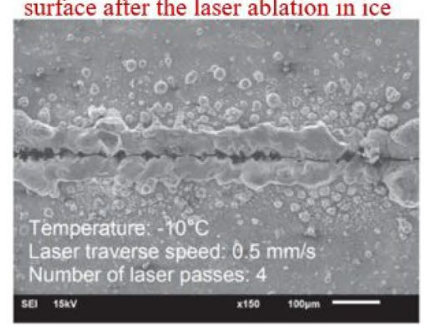

Laser micromachining process in a water/ice layer

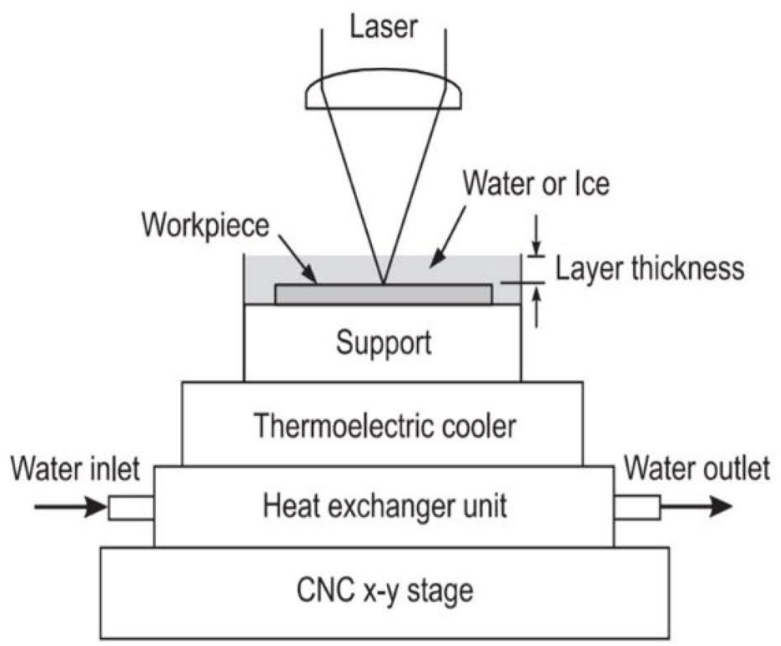

Refraction of laser beam at the bubble/void surface in water/ice

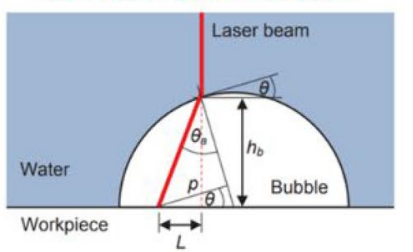

SEM images of titanium alloy surface after the laser ablation in water

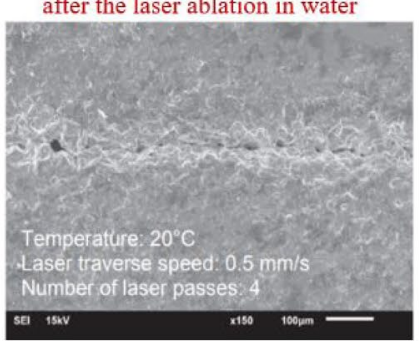

Fig. 28 Laser micromachining of Ti-6Al-4 V using ice and water [191] 

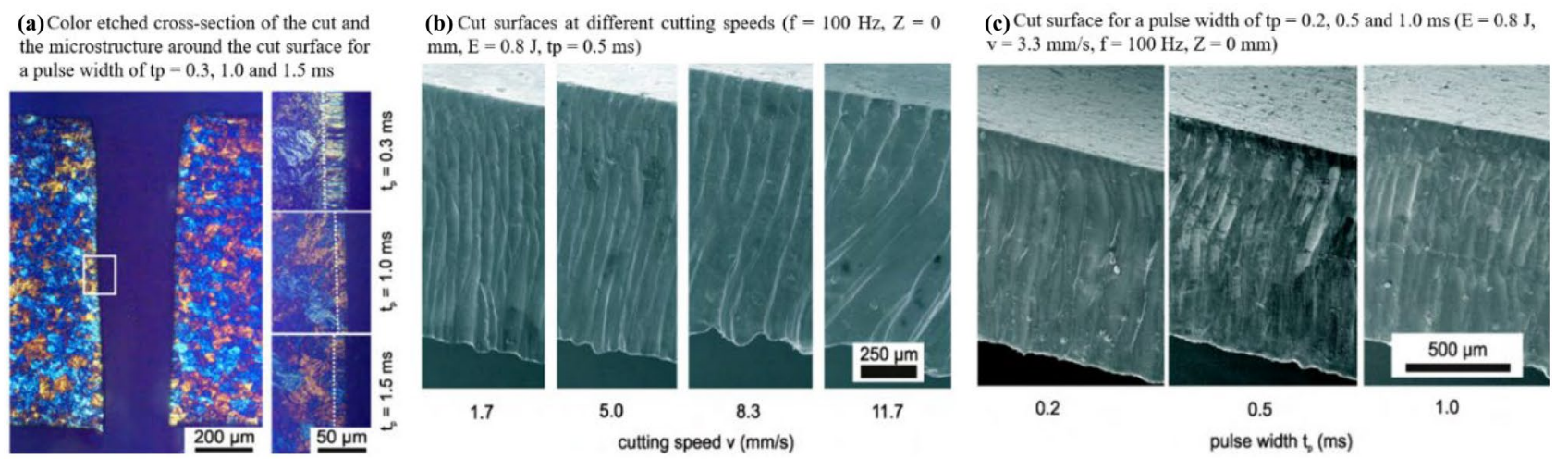

Fig. 29 Representation of various cut surfaces under the influence of variation in process variables [195]

osseointegration of orthopedic implants morphologically [192, 193]. However, as a result of high heat application and setting of process variables of LBM, heat affected zone (influencing the strain restoration), hysteresis, high ablation rate, recast layer, and burr formation are some of the significant challenges while machining NiTi alloys using LBM [194, 195]. A previous study reported the micro-cutting on NiTi alloy sheets ( $350 \mu \mathrm{m}$ thick) via an Nd:YAG laser $(355 \mathrm{~nm})$. The taper angle could be substantially reduced. Another research consisted of pulsed Nd:YAG laser precision cutting of NiTi alloy sheet for biomedical implant application. The influence of LBM process variables on surface integrity and dimensional accuracy was examined. The results revealed the finally achieved kerf width in the range of 150 to $300 \mu \mathrm{m}$ and a taper angle less than $2^{\circ}$. Moreover, the machined quality was achieved in the range of 10-30 $\mu \mathrm{m}$ [195] presents the images displaying the outcome due to variation in input variables (Fig. 29).

Besides, a recent experimental investigation using the response surface method (RSM) and genetic algorithm (GA) found the considerable influence of layer thickness on the taper angle, top-width error (TWE), and spatter thickness during the laser subtractive manufacturing of NiTi microchannel. Besides, scan speed and strategy also substantially affected the output parameters (taper and spatter). Figure 30 presents some of the significant observations via SEM micrographs during the study. Figure $30 \mathrm{~g}$ displays a 3D bubble chart towards maximizing the output parameters' objective function. The lower extreme in the solution space projects the optimal solution. 12.5 and $30.8 \mu \mathrm{m}$ were the minimized optimal taper values and spattered, respectively [196].

\subsubsection{USM}

Unlike many other non-traditional subtractive manufacturing techniques, ultrasonic machining (USM) is neither a chemical nor a thermal process, and therefore, it brings neither chemical nor metallurgical changes on the machined surface. USM can machine any hard-tomachine material irrespective of its hardness (>40HRC) and electrical conductivity or insulation properties. The
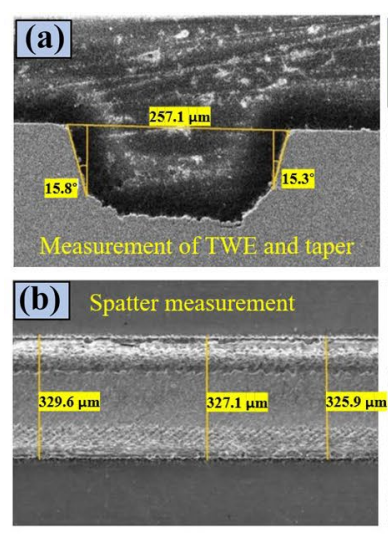
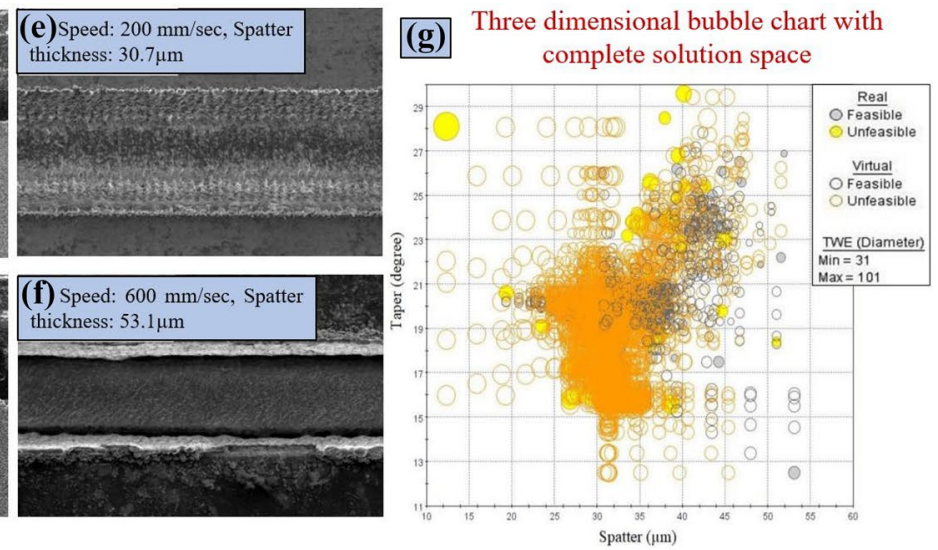

Fig. 30 SEM micrographs showing the measurement of $\mathbf{a}$ TWE and taper and $\mathbf{b}$ spatter [196] 


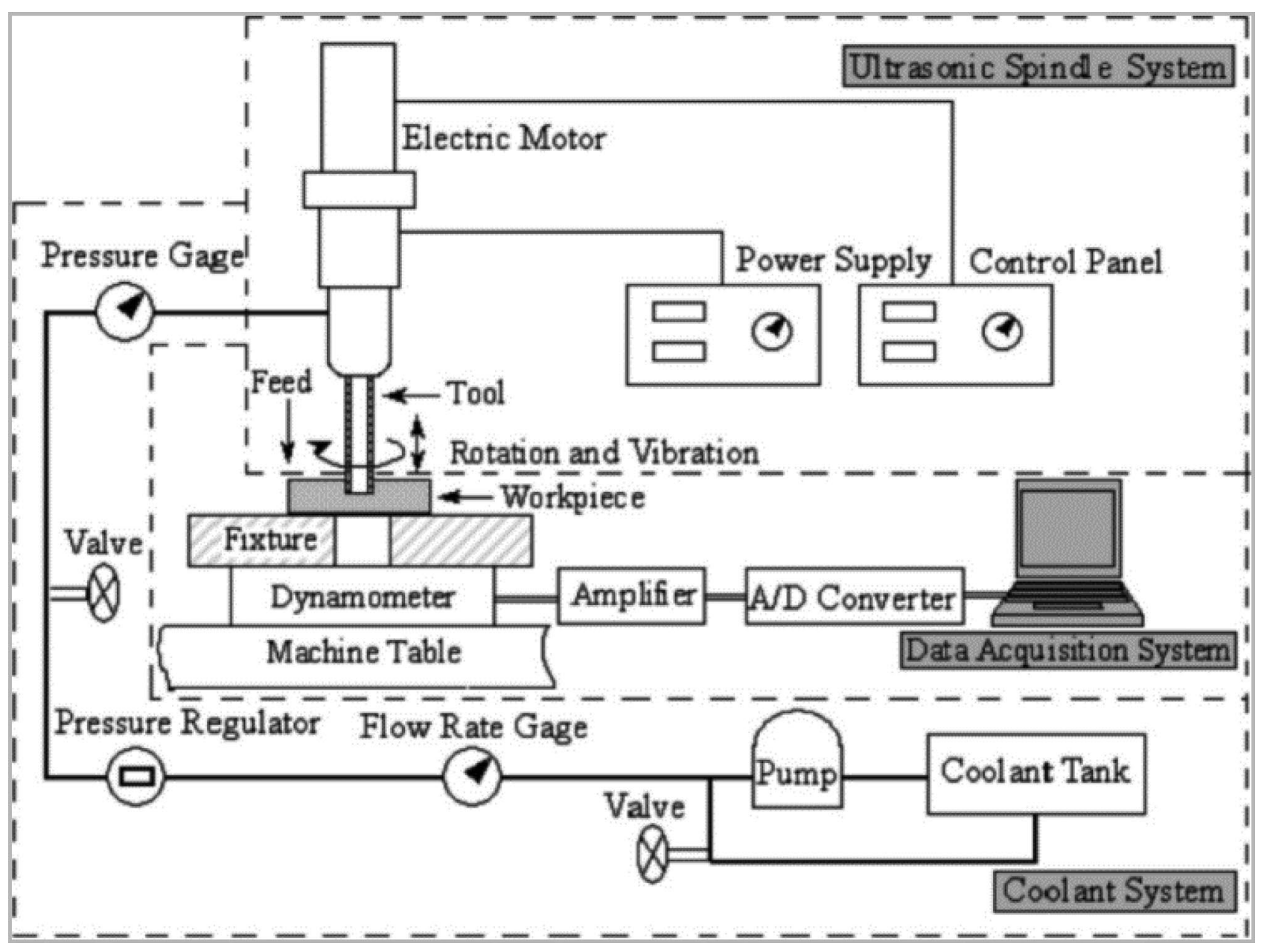

Fig. 31 RUM setup [199]

transformation of electrical energy with low frequency into an electrical signal with high frequency is the primary mode of working of USM. Further, the transformed signal is supplied to the transducer, transfiguring the same into mechanical vibrations. The next stage consists of transmitting these vibrations to the tool via an energy-focusing unit. The USM setup also comprises an abrasive slurry (a blend of abrasive particles such as $\mathrm{Al}_{2} \mathrm{O}_{3}$ and $\mathrm{SiC}$ in oil or water) circulated in the system impinged in the machining zone. The material subtraction occurs through microchipping as a result of joint hammering action of tool (subjected to a static load) vibration and abrasive slurry's (which is between the tool and workpiece) abrasion characteristics [197].

Rotary-USM (RUM) is one of the commonly used variants of USM. A study investigated the effect of various input process variables ultrasonic power, feed rate, and spindle speed primarily on stainless steel's surface integrity amid RUM. The surface finish was noticed with acceptable values at 30\% ultrasonic power and lower feed rate and spindle speed. Additionally, the experimental setup consisted of a fiber optic sensing and data acquisition system and a coolant system [198]. As outlined by research on the RUM of Ti- $6 \mathrm{Al}-4 \mathrm{~V}$, unlike feed rate, a rise in ultrasonic power and spindle speed led to a considerable reduction in surface roughness [199] (Fig. 31). Another investigation observed a noticeable influence of slurry concentration and grit size during ultrasonic drilling of Ti-6Al-4 V [200].

\subsubsection{EDM}

Electric discharge machining (EDM) is often identified as one of the most adequate non-traditional machining processes engaged to machine difficult-to-process metallic biomaterials under tight tolerances [201, 202]. EDM's working principle is based on spark erosion since it uses electrical energy to generate an electric spark, followed by the removal of excess material. The process involves huge amount of heat induced by the thermal energy. EDM is able 
to produce refined micro-structures, 3D (three-dimensional) shapes, complex intricacies, reduce cracks and burr formation, and create high tolerances [203, 204].

Among various non-traditional machining approaches, EDM is known for its unique ability to achieve an elemental composition comprising considerable oxides and carbides on the produced surfaces of metallic biomaterials. Such a surface chemistry in addition to improved morphological and topographical features, can be obtained by an EDM possesses. Further, the EDMed surfaces are often detected with enhanced biocompatibility, hardness, and resistance to wear and corrosion [205, 206]. The significance of EDMed biomaterial surface is often observed in the produced nanostructures, favoring enhanced human osteoblastic cell's biological attachment [207]. A study discovered that the EDMed surface exhibited noticeably improved bone-forming cell response, leading to enhanced cell differentiation and attachment due to the high hydrophilicity of the produced surfaces [208]. Besides the biocompatibility attributes (highlighted in the recent literature), EDM can handle the temperature issues with the $\mathrm{Mg}$ alloy workpiece by using the dielectric medium [209]. The significance of electric discharge machining (EDM) was acknowledged in manufacturing the biocompatible surface of nano-structure. Its influence on the human osteoblastic cell's biological attachment was also mentioned [207]. EDM can generate three-dimensional shapes and complicated geometries and does not require any preparation beforehand. Instead, it can convert the layer to be machined into a layer of oxide and coat considerable carbides of predetermined thicknesses. It improves biocompatibility, provides a more effective means for cell growth, and enhances hardness and thus resistance to wear and corrosion. EDM can be defined as a non-traditional machining technique that works on the principle of spark erosion as it utilizes electrical energy to produce an electric spark and removes the material by immense heat caused by the thermal energy. In an EDM process, the heat flux or thermal energy gets developed due to electrons and ions' interaction with the workpiece and tool surface. An extreme and instantaneous rise in the temperature from 10,000 to $20,000{ }^{\circ} \mathrm{C}$ is observed [180]. An intense localized heat flux basically results in material subtraction. In a previous study, the best results for surface roughness amid machining of Ti-6Al-4 V alloy were obtained at the tool electrode's negative polarity [210].

Exploring EDM's optimum machining parameters resulted in a noticeable change in the parameters such as pulse on-time and output response such as surface integrity. EDM produced a more robust layer for the growth and adhesion of cells acquired from human bone than the sprayed alloy plasma of $\mathrm{TiO}_{2}$. The bone-forming cell reaction on the biocompatible titanium surfaces made by EDM and standard machining techniques were compared. As a result, it was discovered that an EDM machined surface leads to better bone-forming cell responses in promoting cell differentiation and attachment due to its high hydrophilicity on the Ti surfaces. However, it did not affect cell proliferation [208]. It was discovered that the EDM process is suitable for developing shapes with aspect ratios and refined microstructures of biocompatible materials. Their reports also confirmed EDM's wire machining of magnesium-alloys or biodegradable and biocompatible orthopedic implants [211].

However, based on the literature reflecting the surface modification of metallic implant biomaterials such as $\mathrm{Ti}$ alloys, the central observation comprised a coating on the modified surface. Therefore, various modifications have been done in the field of technologies induced within the EDM processes to enhance the surface properties and scale back the areas negatively influenced by the high temperatures. In this regard, applying powder mixed EDM (PMEDM) technique can considerably improve the surface properties. For this reason, a comprehensive review critically summarized a large number of studies introducing powder mixed electric discharge machining (PM-EDM) as a cutting-edge technique for executing two simultaneous processes: excess material subtraction and surface modification [212]. A PM-EDM process includes impregnating fine powder particles or additives such as $\mathrm{Al}_{2} \mathrm{O}_{3}, \mathrm{SiC}, \mathrm{Ti}$, $\mathrm{TiC}, \mathrm{B}_{4} \mathrm{C}$, and $\mathrm{W}$ in the dielectric. These powder particles can significantly reduce the dielectric's insulating strength and broaden the tool electrode-workpiece gap, resulting in considerable surface modification due to enhanced process capabilities [213]. The modification on a PM-EDMed surface can be evidenced in the form of a noticeably thick recast layer exhibiting upgraded surface properties such as improved surface integrity, micro-cracks, corrosion resistance, wear resistance, and biocompatibility [214, 215]. In the case of PM-EDM of Ti and Ti alloys, $\mathrm{B}_{4} \mathrm{C}$ [216], surfactant, graphite, $\mathrm{TiO}_{2}$ [217, 218], $\mathrm{SiC}, \mathrm{Al}_{2} \mathrm{O}_{3}$ [219-222], $\mathrm{Si}$ [223], and carbon nanotubes (CNTs) [224] powder particles were primarily used. For instance, with variation in the powder characteristics (particle sizes and concentrations) of $\mathrm{SiC}$ and $\mathrm{Al}_{2} \mathrm{O}_{3}$ powders and dielectric mediums (such as EDM oil, deionized water, and tap water), considerable changes in the surface roughness (SR), recast layer thickness (RLT), material subtraction/removal rate (MRR), and tool wear rate (TWR) were witnessed [225-227]. Besides, the literature also records a noteworthy improvement in the biological response of PM-EDMed Ti alloys when the enhanced biocompatibility, osteoblastic cell activity, and bone-bonding ability were achieved using hydroxyapatite (HA) [228-230]. Two recent articles used silver nanopowder and obtained remarkable improvement in the antibacterial properties of PM-EDMed Ti-6Al-4 V alloy [215, 231]. One of the latest related research on PM-EDM of NiTi-60 SMA used $\mathrm{Al}_{2} \mathrm{O}_{3}$ powder amid an improved surface roughness and tool electrode wear. The $\mathrm{Al}_{2} \mathrm{O}_{3}$ powder could successfully 
reduce the kinetic energy of the ions by filling up the tool electrode-workpiece gap [232].

Exploring EDM's optimum machining parameters resulted in a noticeable change in the parameters such as pulse on-time and output response such as surface integrity. EDM produced a more robust layer for the growth and adhesion of cells acquired from human bone than the sprayed alloy plasma of $\mathrm{TiO}_{2}$. The bone-forming cell reaction on the biocompatible titanium surfaces made by EDM and standard machining techniques were compared. As a result, it was discovered that an EDM machined surface leads to better boneforming cell responses in promoting cell differentiation and attachment due to its high hydrophilicity on the Ti surfaces. However, it did not affect cell proliferation [208]. It was discovered that the EDM process is suitable for developing shapes with aspect ratios and refined microstructures of biocompatible materials. Their reports also confirmed EDM's wire machining of magnesium-alloys for biodegradable and biocompatible orthopedic implants [211].

Besides, in the past few years, a considerable expansion has been noticed in the miniaturization of medical parts and devices with micron dimensions. The technologically advanced designs combined numerous parts of relatively smaller dimensions with augmented potentialities. For instance, the initial design patterns of medical devices with relatively larger sizes, such as drug delivery systems and heart pacemakers, were not readily accepted by the human body [233]. Therefore, researchers have attempted to develop manufacturing processes that can produce miniaturized medical parts and assemblies in recent years, leading to relatively quicker healing and greater patient comfort [234]. Hence, the researchers were led to establish the powder mixed-micro-EDM (PM- $\mu$-EDM), a downscaled form of PM-EDM with a smaller process variables' domain including tool electrode diameter in the submillimeter range, for obtaining miniaturized components of various complex to machine materials, including $\mathrm{Ti}$ and Ti alloys [235]. The most recent study on PM- $\mu$-EDM of TiNi SMA presented the favorable effect of $\mathrm{TiC}$ powder at $5 \mathrm{~g} / \mathrm{l}$ powder particle concentration on the recast layer of improved microhardness $438.7 \mathrm{HV}$, suggesting its use in orthodontic applications [236]. Davis et al. [237] used various powder particle concentrations (PPCs) to obtain remarkable dimensional accuracies and in vitro biocompatible behavior on the PM- $\mu$ EDMed $\mathrm{Ni}_{55.6} \mathrm{Ti}_{44.4}$ alloy. The research finally achieved improved cytocompatibility using $\mathrm{Zn}$ powder (6 g/l PPC) and copper tool. Figure 32 displays some of the significant findings of this work.

Further, with the help of Fig. 33, Davis et al. [238] presented the schematic demonstration of the sparking phenomenon during non-PM- $\mu$-EDM and PM- $\mu$-EDM performed at different PPCs. According to Fig. 33, the spark directly strikes the work surface during non-PM- $\mu$-EDM. The sparking behavior at different PPCs could be observed in the topmost part of Fig. 33a-e. It is evident that all other concentrations, except $4 \mathrm{~g} / \mathrm{l}$ PPC, end up with poor machinability. The possible reasons for the same are discussed in this subsection. At $2 \mathrm{~g} / \mathrm{l}$ PPC, the spark travelled via powder particles but could not strike the machined surface with the desired intensity, possibly due to a weak bridging effect between the tool-workpiece electrodes. As a result, the formation of more craters and heat-affected zone is generally noticed. However, as shown in the middle part of Fig. 33a-c, 4 g/l PPC resulted in shallow, small craters. The possible reason for the same

Table 5 Non-traditional machining techniques, their merits, demerits, and abilities to machine the $\mathrm{Mg}$, NiTi, and Ti-based alloys

\begin{tabular}{|c|c|c|c|c|c|c|c|c|}
\hline \multirow{2}{*}{$\begin{array}{l}\text { Non-traditional } \\
\text { machining } \\
\text { technique }\end{array}$} & \multirow[t]{2}{*}{ Merits } & \multirow[t]{2}{*}{ Ref } & \multirow[t]{2}{*}{ Demerits } & \multirow[t]{2}{*}{ Ref } & \multicolumn{3}{|c|}{$\begin{array}{l}\text { Metallic implant biomateri- } \\
\text { als }\end{array}$} & \multirow[t]{2}{*}{ Ref } \\
\hline & & & & & $\begin{array}{l}\mathrm{Mg}- \\
\text { based } \\
\text { alloys }\end{array}$ & $\begin{array}{l}\text { NiTi- } \\
\text { based } \\
\text { alloys }\end{array}$ & $\begin{array}{l}\text { Ti- } \\
\text { based } \\
\text { alloys }\end{array}$ & \\
\hline AWJM & $\begin{array}{l}\text { Has high productivity at a } \\
\text { cheaper cost with no thermal } \\
\text { influences for machining } \\
\text { biomaterials having high brit- } \\
\text { tleness and hardness }\end{array}$ & {$[240]$} & $\begin{array}{l}\text { Has machining depth-regula- } \\
\text { tion issues }\end{array}$ & [241] & --- & $\checkmark$ & $\checkmark$ & {$[186,240-245]$} \\
\hline USM & $\begin{array}{l}\text { It involves manageable heat and } \\
\text { can effectively machine the } \\
\text { brittle and hard biomaterials }\end{array}$ & [197] & Lacks a high machining rate & {$[246]$} & --- & --- & $\checkmark$ & {$[180,197]$} \\
\hline EDM & $\begin{array}{l}\text { Complex, intricate features can } \\
\text { be achieved with high surface } \\
\text { quality }\end{array}$ & [247] & $\begin{array}{l}\text { Require workpiece to be } \\
\text { considerably conductive } \\
\text { and display adverse thermal }\end{array}$ & {$[248]$} & $\checkmark$ & $\checkmark$ & $\checkmark$ & {$[201,211,247]$} \\
\hline LBM & $\begin{array}{l}\text { Able to machine almost all the } \\
\text { biomaterials, including macro } \\
\text { as well as micro-machining }\end{array}$ & [249] & $\begin{array}{l}\text { effects in heat-affected } \\
\text { zones and excess recast } \\
\text { layer thickness }\end{array}$ & {$[250]$} & $\checkmark$ & $\checkmark$ & $\checkmark$ & {$[251-253]$} \\
\hline
\end{tabular}



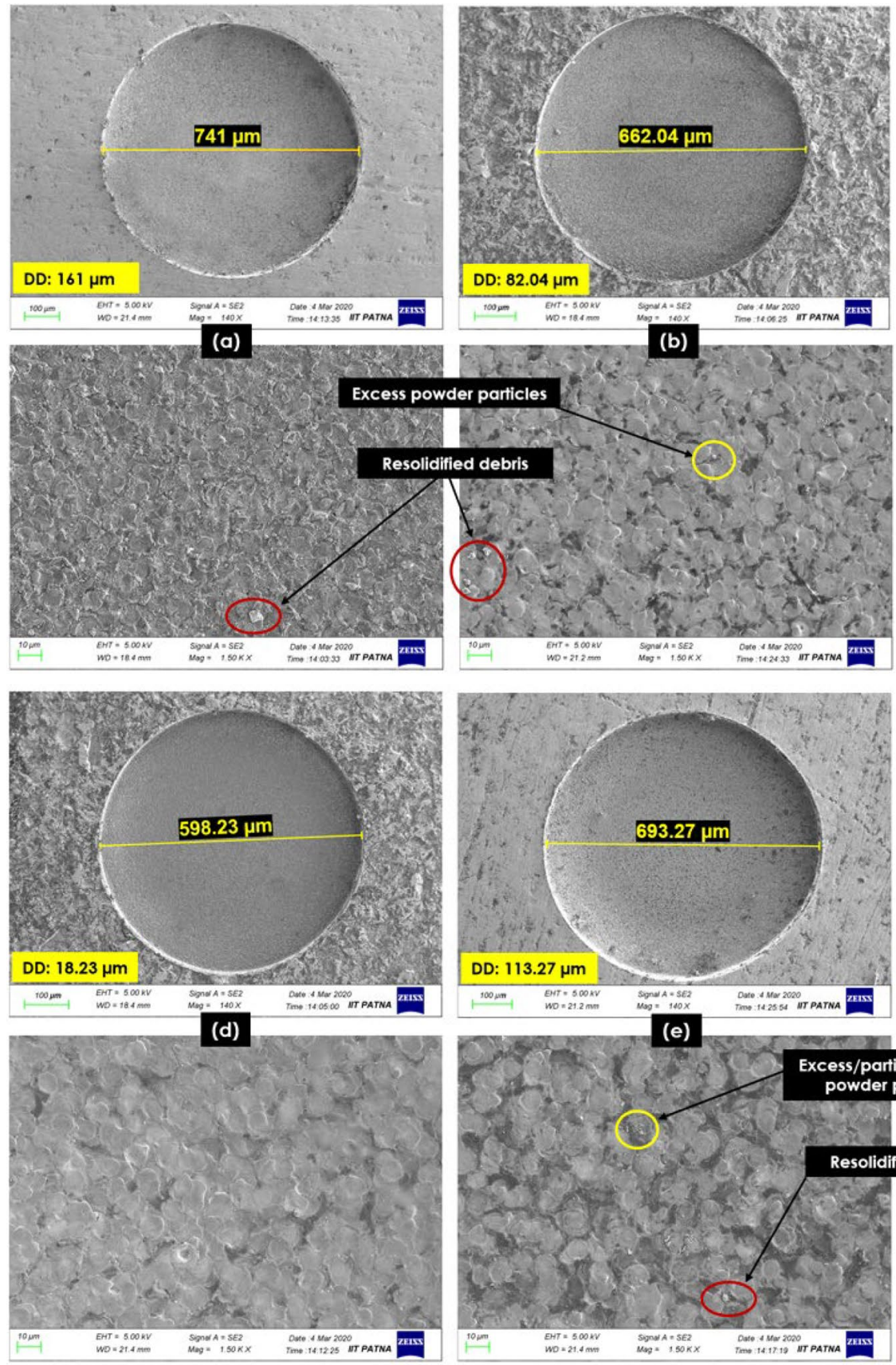

(b)
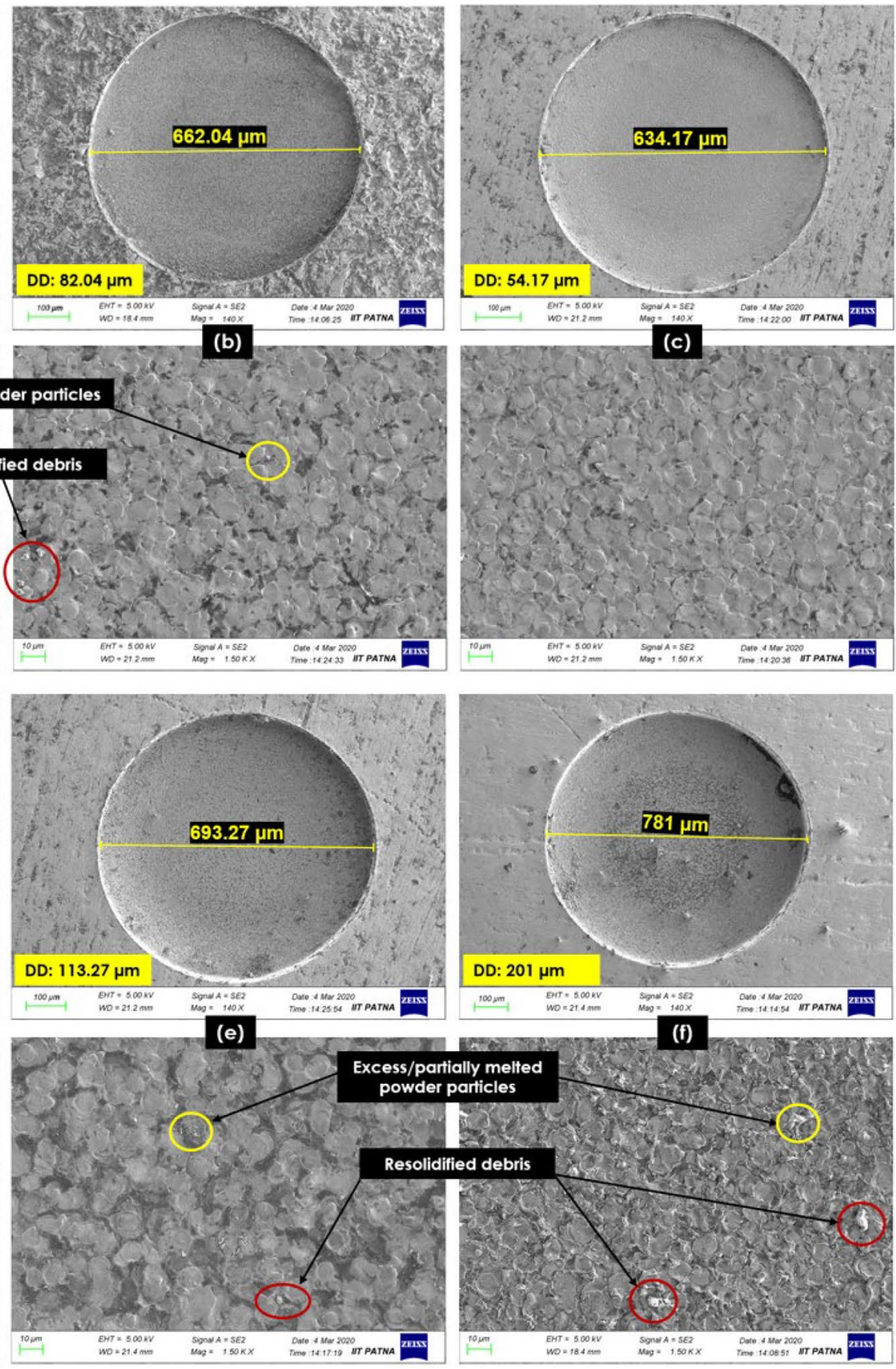

(f)
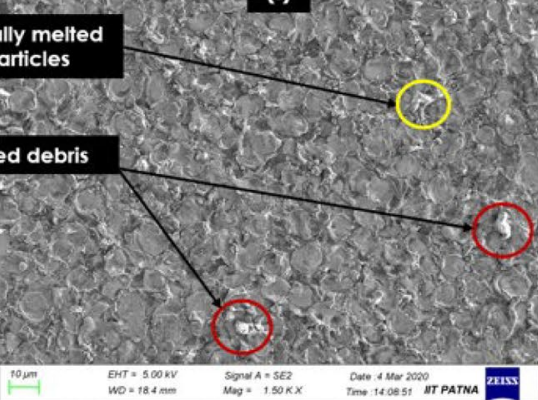

Fig. 32 Dimensional-deviation and surface morphology observed on the $\mathrm{Ni}_{55.6} \mathrm{Ti}_{44.4}$ alloy during PM- $\mu$-EDM with (a) 0 , (b) 2, (c) 4, (d) 6, (e) 8, and (f) $10 \mathrm{~g} / \mathrm{l} \mathrm{PPC} \mathrm{[237]}$

was forming the most effective bridging effect between the tool-workpiece electrodes. Further, it shows the striking of a focused spark via $4 \mathrm{~g} / \mathrm{l}$ PPC to the work surface, followed by the material removal in the form of debris and the modified surface. However, as demonstrated in the down most of Fig. 33a, b, the rise in PPC from 4 to $6 \mathrm{~g} / \mathrm{l}$ and further $8 \mathrm{~g} / \mathrm{l}$, possibly caused more deposition of the powder particles and debris in the craters, resulting in inefficient flushing. These unflushed accumulated powder particles and debris give rise to short-circuiting, and therefore, the occurrence of shortcircuiting (due to increasing PPCs beyond $4 \mathrm{~g} / \mathrm{l}$ ) is displayed at the PPC of 6 and $8 \mathrm{~g} / \mathrm{l}$. The machining with both the $\mu$-tool electrodes was unstable because of short-circuiting at higher PPCs.

Hence, most metallic implant biomaterials exhibiting high hardness, abrasive attributes, ordered-microstructures, and relatively less stiffness often complicate their machinability in terms of high precision and complex geometrical 
Fig. 33 Schematic presentation of the sparking phenomenon with surface modification
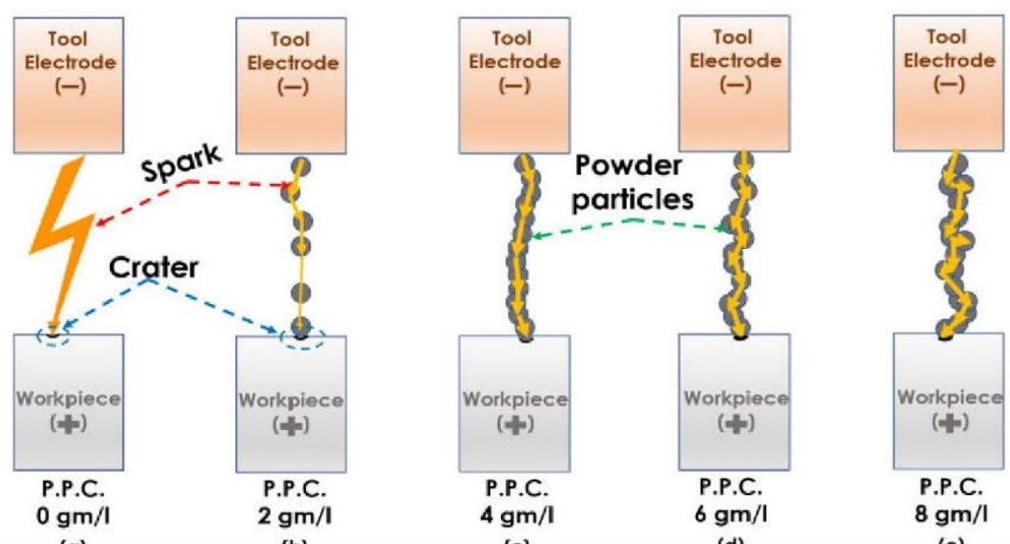

(b)

(c)

(d)
Sparking phenomenon during PM- $\mu$-EDM of Mg alloy AZ91D at different PPCs

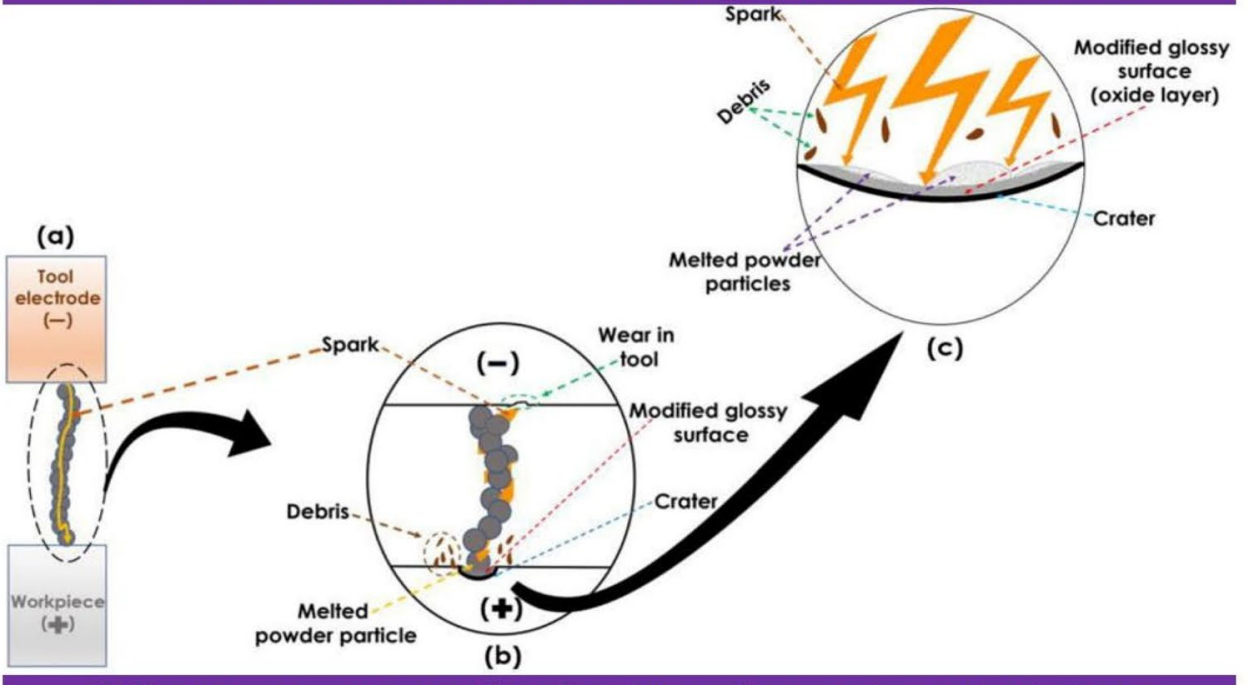

(a) Sparking phenomenon, (b) material removal mechanism, and (c) surface modification amid PM- $\mu$-EDM of Mg alloy AZ91D at $4 \mathrm{~g} / \mathrm{I} \mathrm{PPC}$

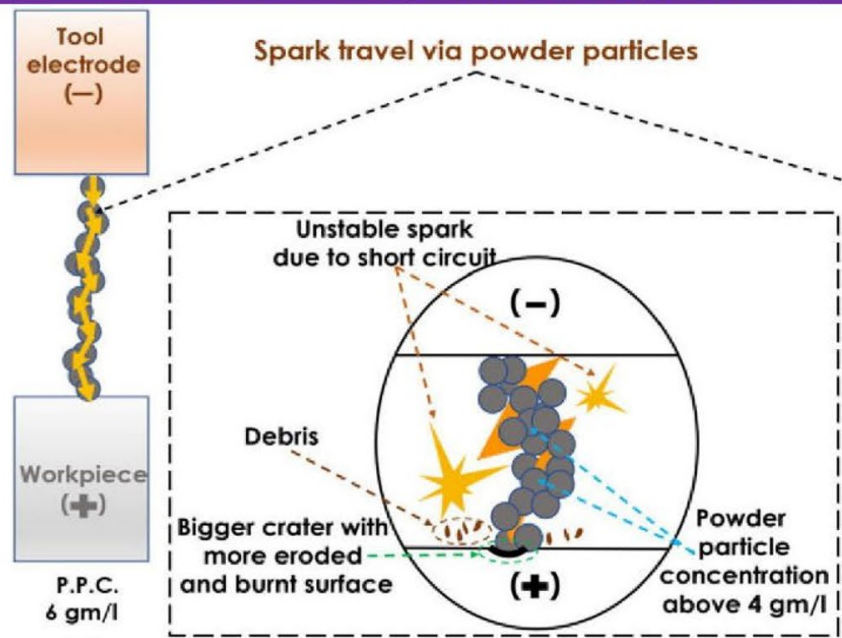

(a)

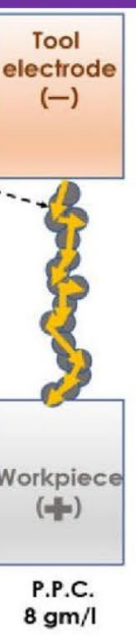

(b)

\section{Short-circuiting during PM- $\mu$-EDM of Mg alloy AZ91D at (a) 6 and (b) $8 \mathrm{~g} / \mathrm{I} \mathrm{PPC}$}

intricacies inappropriate metallurgical and biological properties via traditional means. Therefore, advanced manufacturing methods such as AWJM, LBM, USM, and EDM were found to be some of the well-known non-traditional subtractive manufacturing techniques for machining varieties of metallic implant biomaterials. In this regard, Table 5 


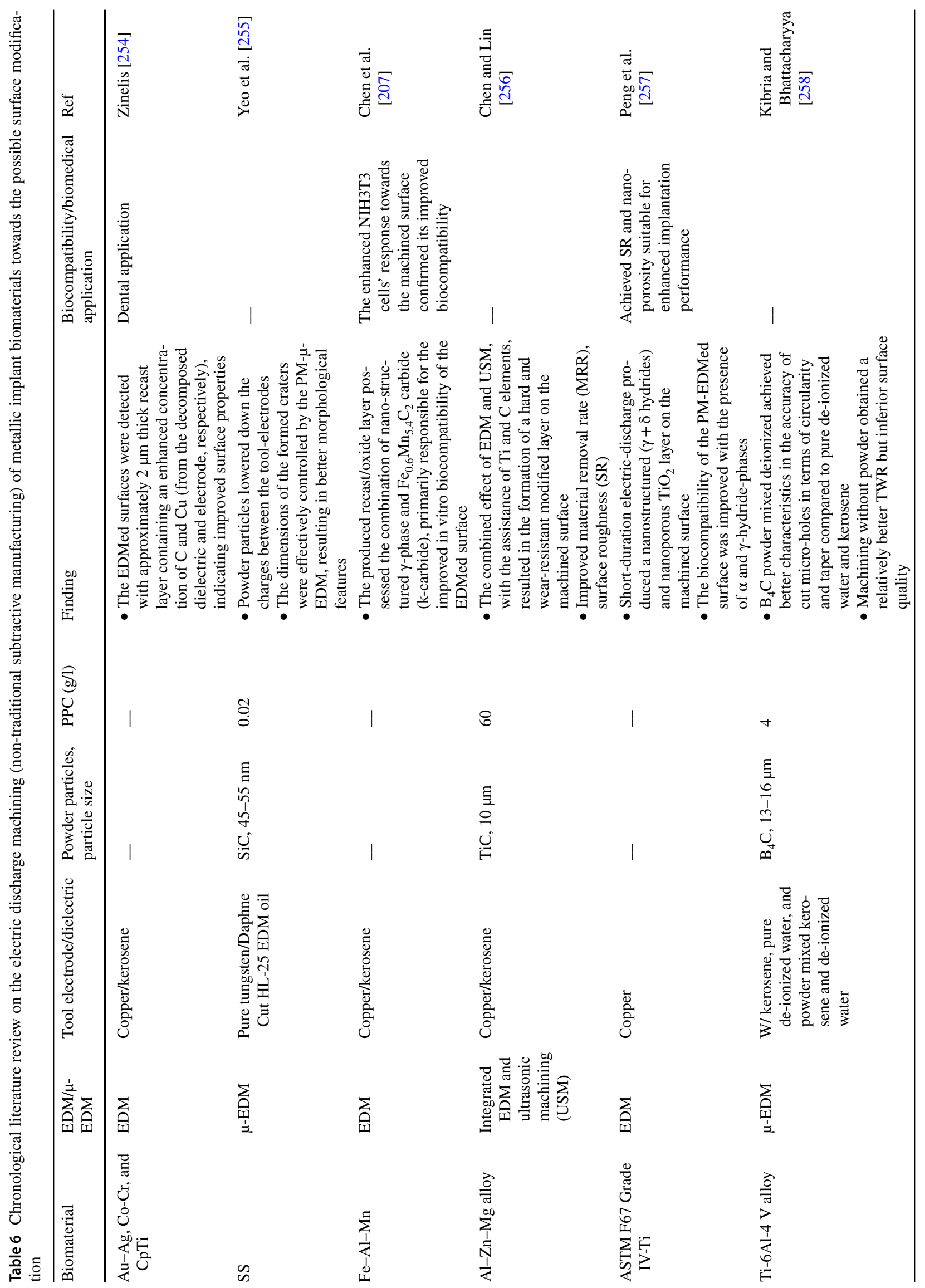




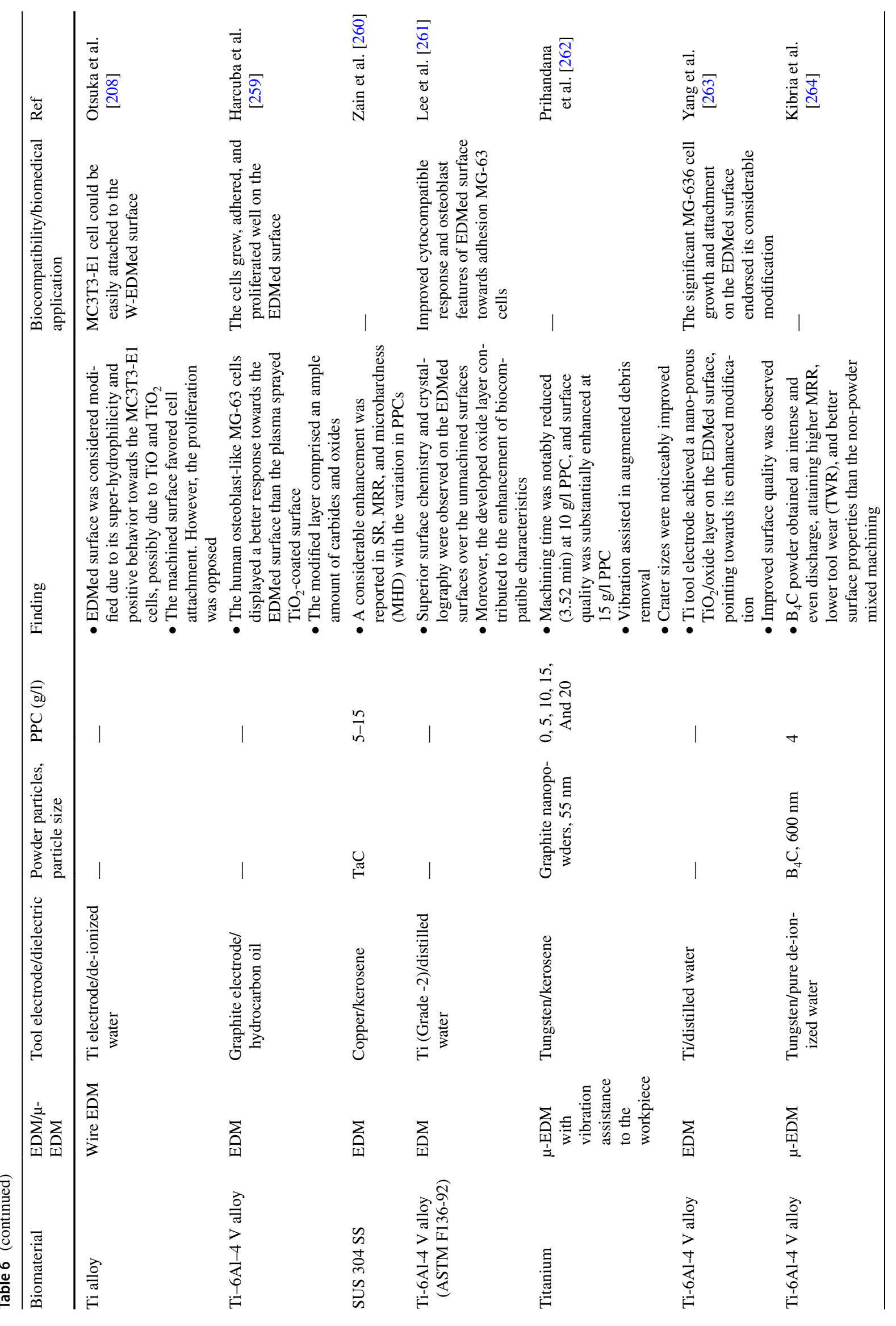




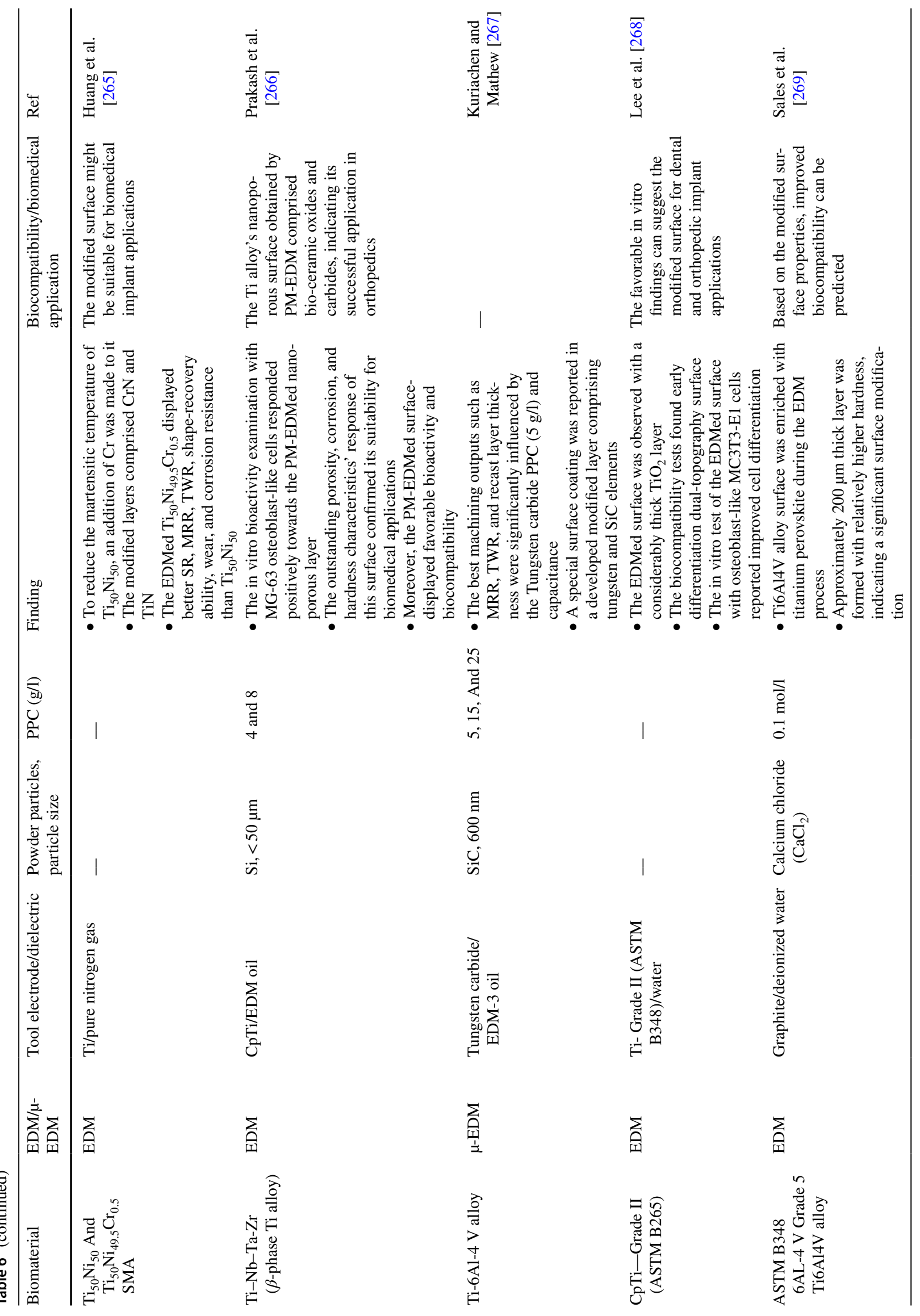




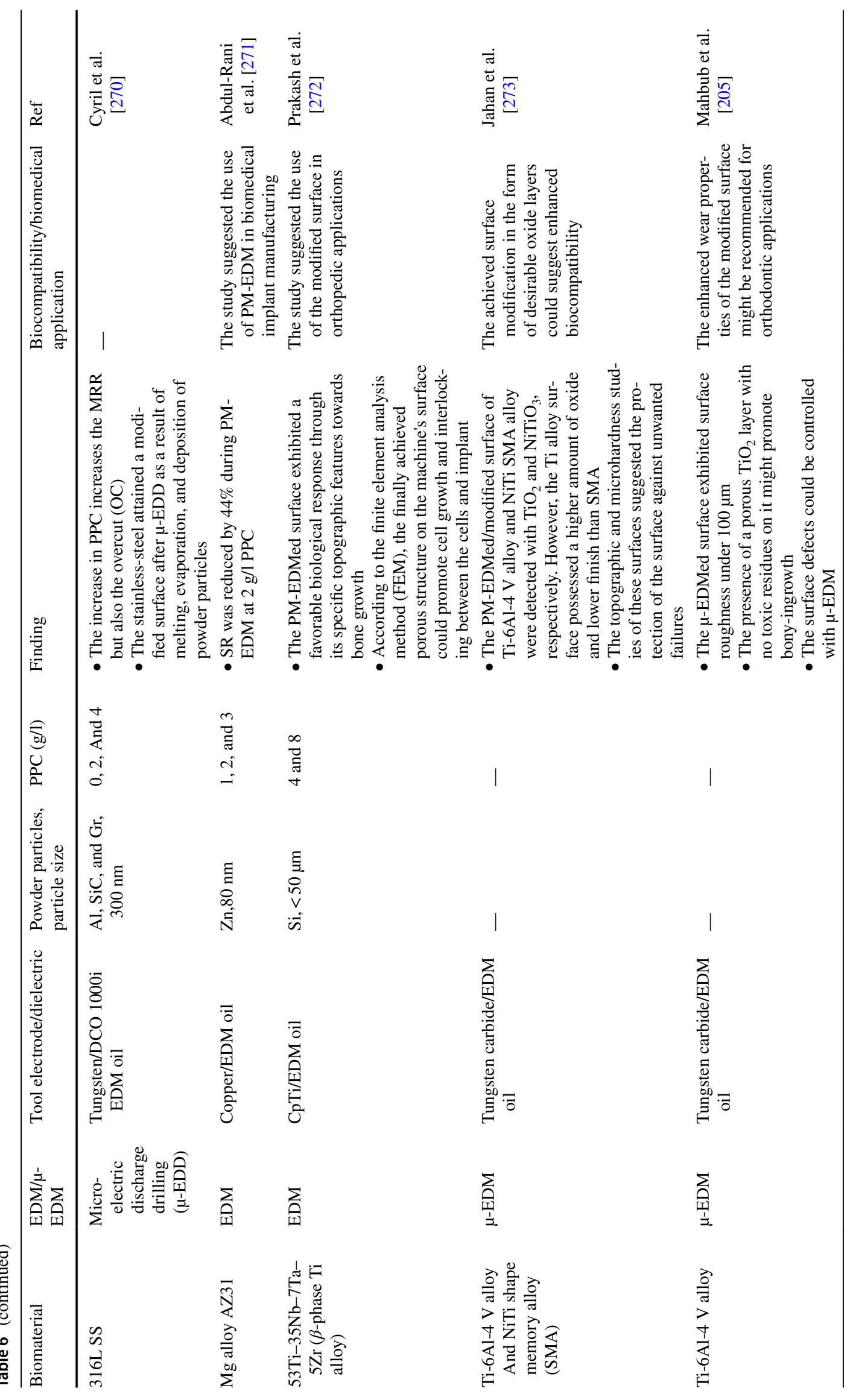




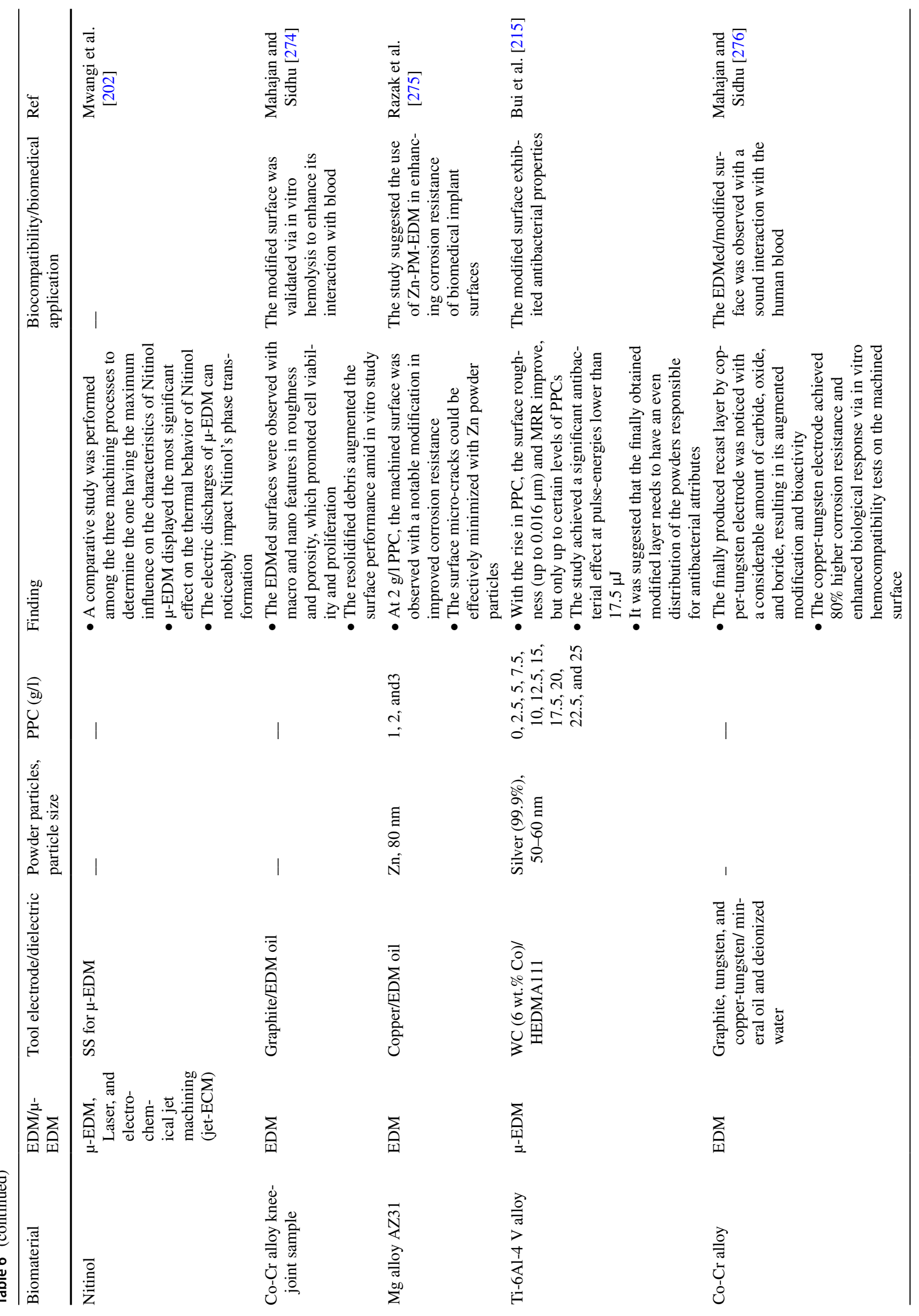




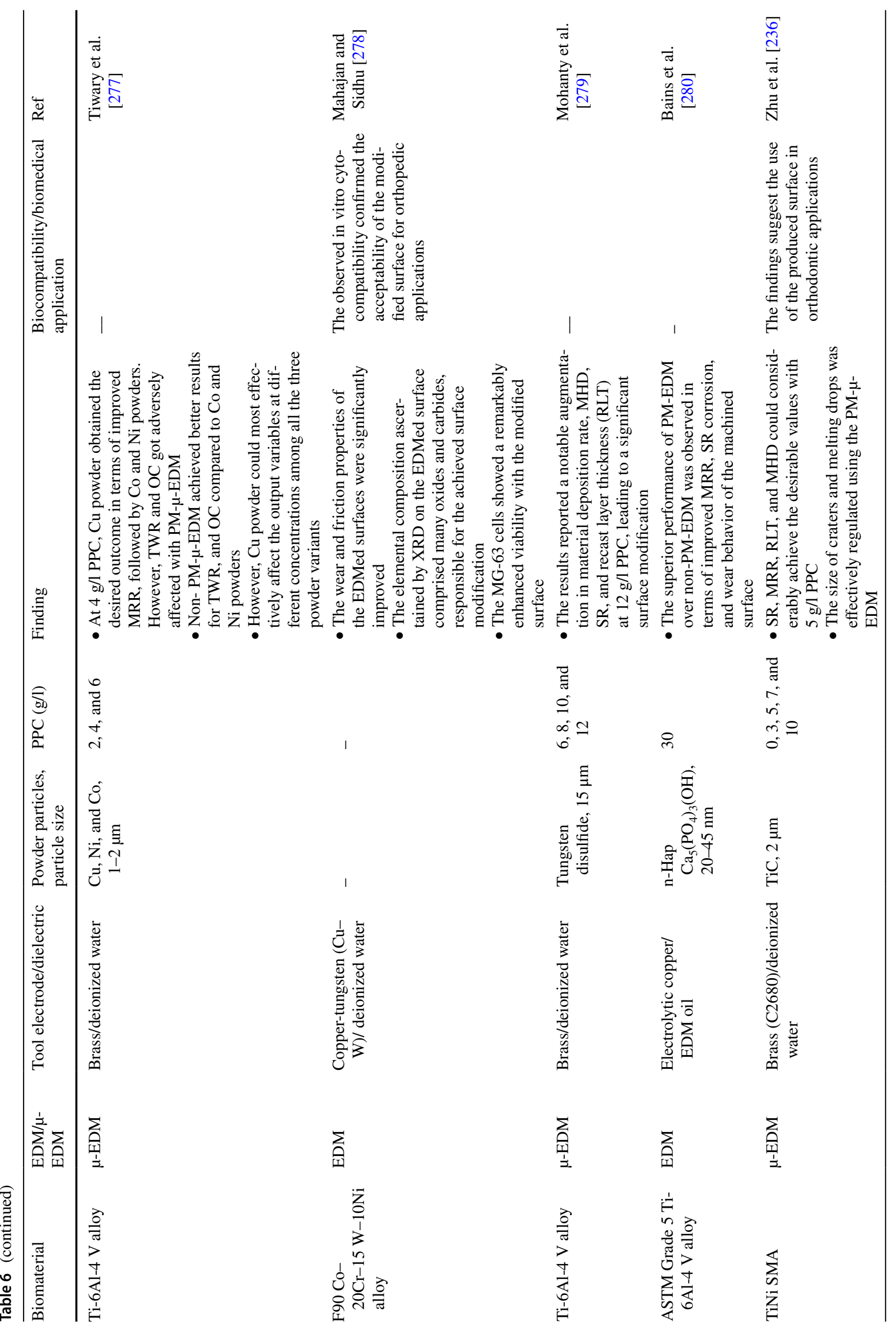




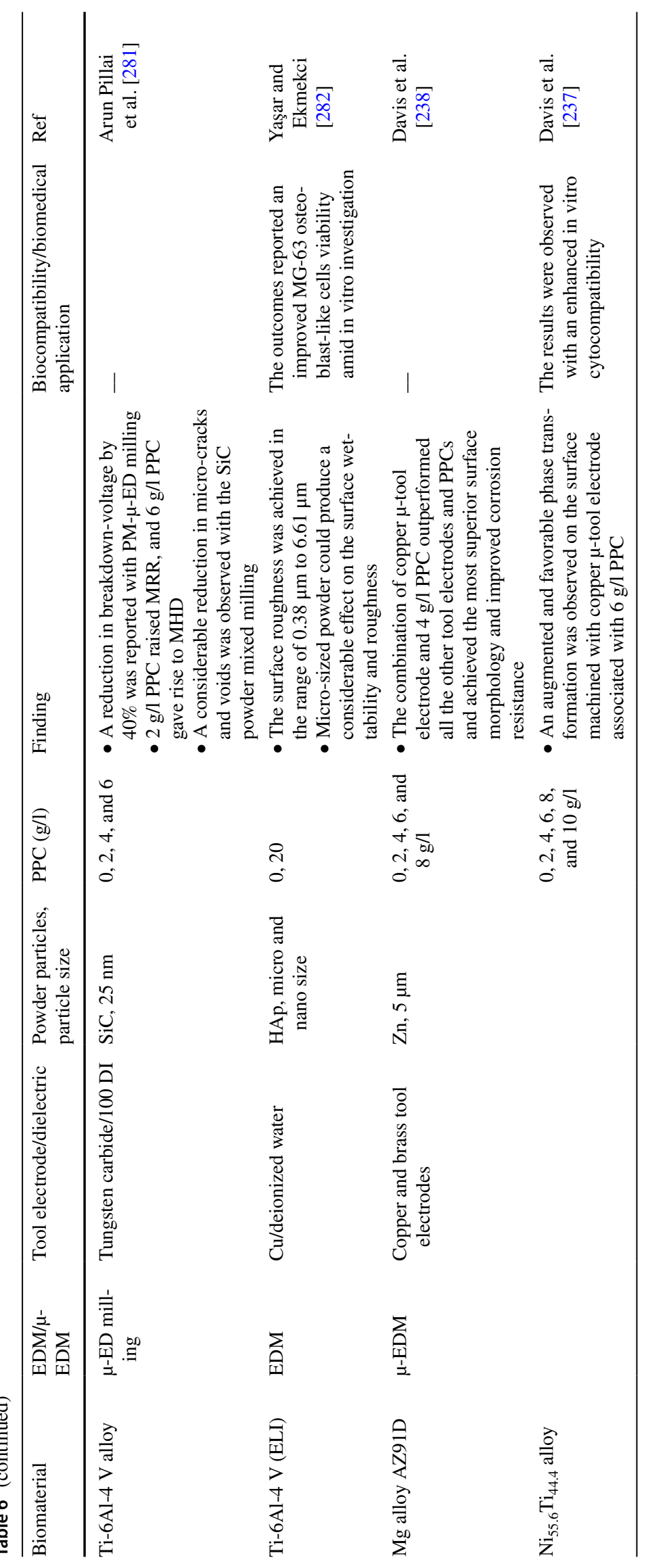


summarizes the literature reporting successful machining only of the $\mathrm{Mg}$, NiTi, and Ti-based metallic implant biomaterials due to their increasing applications. Further, with the help of Table 5, the capabilities of all these commonly used and displayed non-traditional machining techniques could be compared, showing the largest influence of LBM and EDM in this regard. Thus, EDM and LBM may be chosen for the desired response in most cases. However, both of these processes also display almost similar disadvantages. Hence, the final selection from these two might be based on the overall cost and outcome. In this regard, EDM was outlined as a better alternative compared to LBM due to the ease of its modification, overall efficiency, and productivity to achieve the desired results [239].

\subsubsection{A rigorous chronological survey on the strategies used to modify the metallic implant biomaterials using EDM and its variants}

Based on some critical observations in the last subsection regarding non-traditional machining process capabilities for metallic implant biomaterials, the present review further converges the literature to processing only via EDM (at the macro- and micro-scale levels). In this relation,
Table 6 demonstrates the wide use of macro and $\mu$-EDM for machining the various metallic implant biomaterials in the last 15 years, followed by their significant findings. Subsequently, as it could be noted from the literature that the powder mixed variant (PM-EDM) of EDM has been producing superior results for clinical uses in many cases. The PM-EDM setup used different conductive powder particles with varieties of sizes and concentrations and reported unprecedented output variables. In addition to the observations of Table 6, the graphical analysis presented in Fig. 34 also reveals the remarkable percentage rise in the application of PM-EDM at the micro-level (PM- $\mu$-EDM), producing excellent outcomes in terms of significantly enhanced biocompatibility and bioactivity of biomaterials. However, in both Table 6 and Fig. 34, the number of research articles including or attesting the biological response of the EDMed surfaces is comparatively less, but with an increasing trend in the last 5 years, pointing towards the attraction of researchers towards the production of EDMed surfaces supplemented with a specific biocompatibility study. In the literature survey, a more extensive study on the in vitro biocompatibility investigation of the non-traditionally machined biomaterials (Table 6) was observed compared to the traditionally machined biomaterials (Table 3 ).

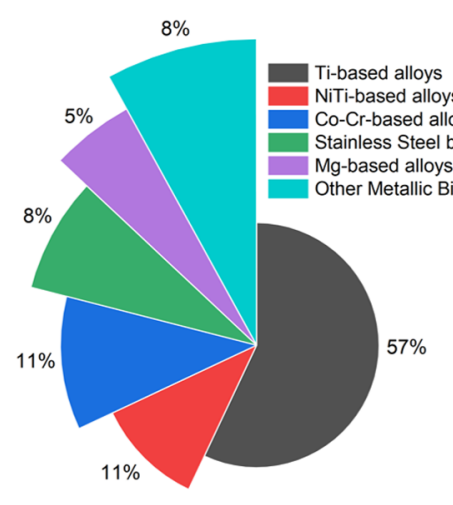

(a) Percentage of published articles on EDM of metallic biomaterials

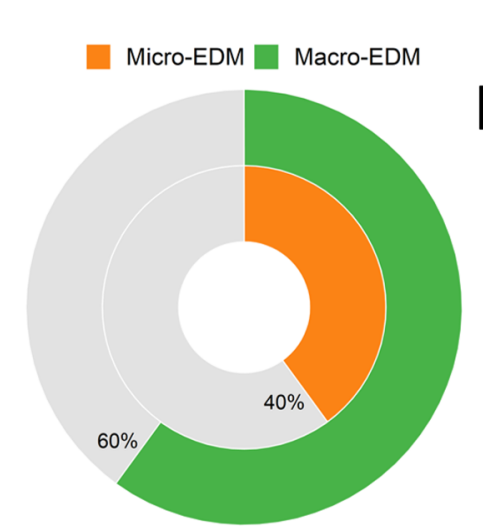

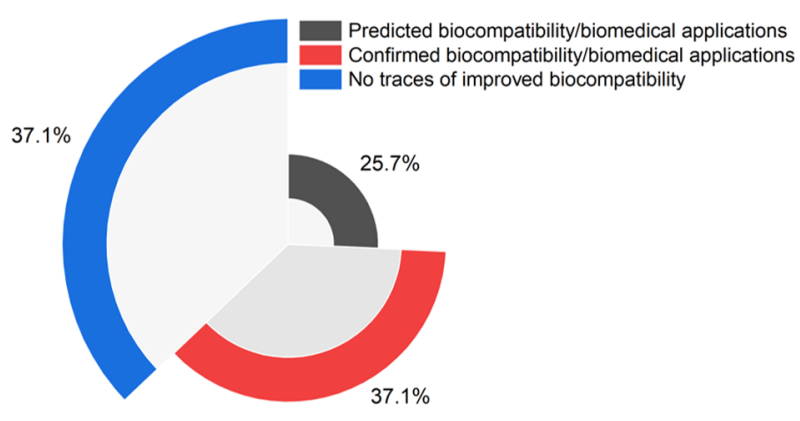

(b) biocompatibility on the biomaterial surfaces modified by EDM

(c) Use of Macro Vs Micro-EDM (during the processing of metallic biomaterials) in terms of published articles

Fig. 34 Graphical analysis of published articles in the last 15 years on EDM of metallic implant biomaterials 


\section{Conclusions}

The biocompatible materials may lack insufficient ability to meet the needed proper bonding between the implant and nearby bones and tissues. Such bonding requires improved implant surface bioactivity, which can be achieved with suitable machining and surface modification techniques. The same can impart greater stability and strength to the implant biologically employing changing the mechanical biocompatibilities (preferably by subtracting or adding the excess material from or to the surface of the work material) for uniform transmission of the stress bone-implant interface. This results in the regeneration and recovery of the damaged tissue or bone. Hence, surface modification enables the metallic implant biomaterials to match the intricacies of a biological environment by enhancing the functional attributes of the biomedical implants or devices.

Moreover, the customizable ease associated with some specific surface modification approaches in attaining the desired surface quality can primarily ascertain the interactive limits of the implant's surface with the adjacent tissues/cells. In this regard, the present review has explored the metallic implant biomaterials, their properties, and the possible techniques to achieve their best applications in making human life more comfortable. Subsequently, the review highlighted the high standard need for an extensive range of practice of various subtractive manufacturing processes as potential means to modify the surfaces of metallic implant biomaterials.

Thus, this review can lead to the following concluding remarks:

- The risk of inflammatory reactions is reduced vastly with the degradable metallic implant biomaterials compared to non-degradable ones. No foreign material is left in the biological system with the application of degradable biomaterials.

- The development of surgical implants of nickel-free stainless steel is still under research, which may open up a greater possibility of human life saving and comfort. Besides this, orthodontics and orthopedics are also using this nickel-free stainless steel.

- The last decade witnessed a significant rise in the use of degradable $\mathrm{Mg}$, and non-degradable NiTi, and Ti-based alloys as competent metallic implant biomaterials. Titanium was one of the best biocompatible materials suitable for the human body, even costlier.

- In the absence of practical traditional machining approaches (in terms of the adequate cutting tool and lubricoolants), the barrier still to be faced for the potential use of $\mathrm{Mg}$-based alloys is their machinability since some biomedical applications require high geometric precision. The feeble traditional machining of $\mathrm{Mg}$-based alloys generally causes notable vibrations, chip-formation with variable sizes, and the appearance of a built-up edge due to the low melting point of $\mathrm{Mg}$ (about $650^{\circ} \mathrm{C}$ ), adversely affecting its stability at high temperatures.

- The poor subtractive processing/machining even increases the oxidation rate of $\mathrm{Mg}$ alloys which are more susceptible to corrosion. Therefore, it is not easy to achieve high precision on the incompetent traditionally machined $\mathrm{Mg}$ surfaces such as $\mathrm{AZ}(\mathrm{Mg}-\mathrm{Al}-\mathrm{Zn})$, WE (Mg-RE-Zr), and ZK (Mg-Zn-Zr), generally developed for clinical applications.

- During the ineffectual traditional machining of highly ductile and elastic NiTi-based alloys, the mechanism of their poor machinability could be explained by the required high cutting forces, leading to increased cutting temperatures and subsequent thermal stresses. This further deforms the cutting tool and causes complex issues, such as stress-induced phase transformations in NiTibased alloys.

- Similarly, the poor machinability characteristics of Tibased alloys, including high chip-thickness, pressureload, spring-back, and developed residual stresses, often hinder the manufacturer from obtaining the desired surface properties.

- As a result of continued use, while machining NiTi and Ti-based alloy, the cutting tool is expected to experience a varying loading and, thus, a severe tool-wear, generation of built-up-edge (BUE), under low-cutting conditions, chip-adhesion, and inferior chip-breaking. Consequently, the worn-out cutting edge instigates several imperfections such as undesirable work-hardening, tearing, feed-marks, micro-cracks, slip-zones, lay-patterns, and grain-deformation on the NiTi and Ti-based alloys' surfaces.

- Hence, to improve the machinability of metallic implant biomaterials such as $\mathrm{Mg}$, NiTi, and Ti-based alloys, the machine operator needs to be highly skilled and experienced to select the optimum process parameters. However, that raises the overall cost of manufacturing.

- The cryogenic and hybrid cooling strategies were found superior approaches over conventional flood (wet)cooling to noticeably improve the efficacy of traditional subtractive manufacturing techniques for machining the degradable and non-degradable metallic implant biomaterials.

- A conventional EDM produces specific geometrical features and improves biocompatibility. However, in an EDM process, under the effect of the tremendous rise in temperature, sudden cooling, and inefficient flushing, the cut, melted, and unflushed workpiece material gets resolidified in the form of a layer (also known as recast or white layer) on the workpiece surface. 
- In the case of biomedical implants, the recast layer of non-uniform thickness with several micro-cracks on the surface may further weaken the workpiece's resistance towards abrasion, corrosion, and wear, resulting in implant failure.

- Although some of the latest studies have also reported this issue in EDM of all the metallic implant biomaterials, they have provided a potential solution in a variant of EDM, known as powder mixed-EDM (PM-EDM).

- However, these studies could not be considered conclusive because the literature has been listing another competent variant of EDM, termed as powder mixedmicro-EDM (PM- $\mu$-EDM), which appears to capture the attention of numerous researchers nowadays gradually.

\section{Future trends}

A closer look at the literature on new cooling approaches and cutting tool treatment conditions in the traditional machining and non-traditional EDM of Mg, NiTi, and Ti-based alloys, reveals a number of vacancies to work within these areas in subsequent studies. Therefore, some of the possible future scopes are as follows:

- The majority of prior research on traditional machining of Mg, NiTi, and Ti-based alloys, which used a different cooling strategy other than the conventional cutting fluid and achieved profound findings, was exclusively noticed with cryogenic cooling. However, the use of hybrid cooling strategies, which could also achieve superior findings, particularly the biological response of the machined surface, was rarely recorded during the machining of these biomaterials. Thus, subsequent in vitro/in vivo biological studies must be conducted to validate the process capability.

- The past research illuminated the extensive use of an untreated cutting tool during dry, wet, and cryogenic machining of these biomaterials. However, as per the available literature, the application of cryo-treated cutting tools during the cryogenic and hybrid machining of these metallic implant biomaterials has been reported only in a minimal most recent study. Hence, there are ample opportunities to explore this area.

- The performance of the cryo-treated end mill seemed to be dependent on the temperature of the machining environment. However, further testing would need to be performed to validate the same.

- Consequently, rare attempts were made to integrate a cryo-treated cutting tool with different low-temperature cooling environments and study its subsequent effect on surface properties, including wettability and biocompatibility.
- The use of more hybrid cooling techniques associated with cryo-treated cutting tools can be strongly suggested for subsequent experimental trials during traditional machining of biomaterials.

- The noteworthy results attained amid the use of CWMJ, vegetable oil, cooled-air, MQL, nano-fluids $\left(\mathrm{Al}_{2} \mathrm{O}_{3}\right.$, graphite, and molybdenum disulfide) MQCL, and graphene-doped nanofluid mist-spray cooling (during traditional machining of biomaterials), etc. encourage the development of newer potential lubri-coolants.

- Moreover, the detailed studies on the application of coated cryo-treated cutting tools in conjunction with these lubri-coolants need to be conducted and promoted. Most importantly, the use of promising hybridized combinations of the existing and newly developed lubri-coolants in conjunction with coated cryo-treated cutting tools achieving considerable biocompatibility features are still unstudied, indicating the need and broad research scope in this area for the present and budding researchers.

- Despite the exceptional cutting performance of advanced cutting tool materials such as cermet, PCD, and PCBN, a very rare studies consisting of the traditional machining of metallic biomaterials by these cutting tool materials showing augmented biological responses are available, prompting the immediate requirement of extensive investigations on the same.

- The textured cutting tools displayed an outstanding performance against stainless steel and Ti-based alloys. However, so far, these studies are limited and therefore, the application of these tools need to be expanded against all the metallic biomaterials.

- The literature observed a dramatic improvement in the performance of textured tools as well when used as selflubricating or with conventional cutting fluid, MQL, and wet + nanoparticles. Hence, more types of lubri-coolants and their hybridized forms will need to be used along for further investigations.

- Additionally, the difficulty of producing ideal texturing on coated and on ultra-hard cutting tools such as ceramic, PCBN, and PCD, signals the necessity of achieving the same for improved machinability.

- Moreover, many current investigations in the broader literature have conducted the cryogenic turning of these biomaterials, whereas a minimal study is available on the cryogenic milling and drilling of these metallic implant biomaterials.

- The optimized input control factors that appeared to be persistent with the macro-PM-EDM of metallic implant biomaterials may turn to be conflicting with PM- $\mu$-EDM. Hence, further investigation is needed to explore the critical precepts of PM- $\mu$-EDM when applied to the metallic implant biomaterials. 
- The excellent use of bioactive powder particles associated with different $\mu$-tool electrode materials amid PM- $\mu$ EDM of a few metallic implant biomaterials has just been addressed. Hence, the unstudied areas and undiscovered facts on the micro-machining of various metallic implant biomaterials for medical applications signal the necessity for further research.

- Due to a minimal study on the biocompatibility investigation of metallic implant biomaterials processed by PM- $\mu$-EDM, the other studies cannot be convincing for the medical applications of these metallic implant biomaterials since a surface modification process substantially alters the topography and chemistry of the modified surface, possibly leading to an increase or development of toxicity on the modified surface towards the associated cells. Hence, further related studies are required.

- PM-EDM (at macro and micro level) via more bioactive powders in conjunction with copper tool electrode needs to be explored to modify the biomaterials' surfaces.

- The biocompatibility study in the latest research evaluated a short-term in vitro biological response of the significantly modified surfaces. However, a more comprehensive in vitro biocompatibility study and in vivo hemocompatibility investigation will be conducted to validate the long-term biological responses and the subsequent clinical use of these modified surfaces.

\subsection{Advances in biocompatible metals and alloys}

The field of metallic implant biomaterials has experienced intense growth in the last decade, and new alloys and manufacturing methods are currently under investigation to improve the performance of biomedical implants inside the human body. Although fundamental advances were achieved for biocompatibility, tensile limits or wear, and fatigue resistance, improving one of these characteristics might still require sacrificing the other or yielding low process productivity. Nevertheless, future trends include porous metallic structures, functionalized metal surfaces, and new biodegradable alloys, intending to improve biocompatibility without losing mechanical and tribological properties.

The most common metal for implants nowadays is, without doubt, the Ti-6Al-4 V alloy, but there are some new promising alternatives. Nagase et al. [283] developed the high-entropy TiZrHfCr0.2Mo and TiZrHfCo0.07Cr0.07Mo alloys with improved mechanical hardness and biocompatibility, even greater than that of commercially-pure Ti. However, the casting method yields ingots that would be usually milled for biomedical use, posing an extra challenge due to the increased hardness. Besides, porous structure metals exhibit another important field of interest. According to Kargozar et al. [284], the open-cell structure with porosity above $60 \%$ yields a lower modulus of elasticity and higher friction, similar to cancellous bone. These interconnected pores also present remarkable future capabilities as scaffolds for tissue engineering in vitro before surgery. Even though they are mainly produced by powder metallurgy [285] and additive manufacturing [286], non-traditional subtractive manufacturing processes may also be implemented for this purpose. Sales et al. [269] were able to produce a porous perovskite layer on the surface of Ti-6Al-4 V alloy through EDM. Calcium insertion into the Ti-6Al-4 V alloy surface was attributed to re-solidification and ion implantation; thus, functionalization was also achieved. The traditional subtractive manufacturing processes should be studied to produce small external channels, holes, or threads for fixation of the part, but with much care, saving from disruption of the microporous features.

Biocompatible Cermets (ceramic-metal composites) is another upcoming trend in biomaterials. Esteban-Tejeda et al. [287] produced mechanically stable biocide glass coatings with $\mathrm{ZnO}$ on $3 \mathrm{Y}-\mathrm{TZP} / \mathrm{Ta}$ and $3 \mathrm{Y}-\mathrm{TZP} / \mathrm{Nb}$ for antimicrobial activity. At the same time, He et al. [288] used spark plasma sintering of bio-Cermet Ti-13Nb-13Zr-HA to improve cell attachment. Just as in the case of porous materials, future works might evaluate the feasibility of traditional milling and drilling, which might be necessary in the case of patient custom devices.

Regarding biodegradability, besides the traditional magnesium alloys, there are several ongoing research for the use of zinc or ferrous biodegradable alloys, which do not present the flame hazard of the former during machining. Also, their degradability rate is lower [289], making them more suitable options for future biodegradable metal implants.

\subsection{Developments in subtractive manufacturing processes}

Traditional cutting processes such as milling, drilling, and turning have already been substantially investigated in several different configurations and techniques, making it harder to innovate in these fields. Although 5 axes machines and cryogenic cooling using $\mathrm{LN}_{2}$ have already been discussed for milling, progress can be achieved by combining them. Romero-Resendiz et al. [285] used these with liquid $\mathrm{CO}_{2}$ for clean manufacturing of Ti-6Al-4 V implants, achieving optimum geometrical tolerance in reduced lead time.

On the other hand, an active cutting fluid could be an exciting idea for the functionalization of an implant surface in milling operations. Shang et al. [290] produced nano-lubricants from nitrogen-doped carbon dots (N-CDs) that adsorbed into the metal surface during tribological tests. Carbon nanotubes and graphene are other possible choices that are being researched nowadays as additives for machining fluids. Also, as shown by Amiril et al. [291], 
biocompatible lubricants based on ionic liquids might be used to reduce tool wear in machining operations due to their non-toxicity. Since Khemchandani et al. [292] also observed uniform deposition of phosphorous compounds on the wear marks of pin-on-disc tests with ionic fluids, there is hope that the lubricant could also perform ion or molecule implantation on the material surface.

Another significant concern that can be addressed through adjusting machining input variables is the achievement of specific crystalline structures in complex implant alloys for orthopedic implants. Depending on the cutting variables, temperature and deformation might induce phases and microstructures beneficial or deleterious for osseointegration in the metal surface. She et al. [293] researched the different responses of biocompatibility in Co-29Cr-5Mo, 316L SS, and Ti-6Al-4 V, finding different responses of biocompatibility depending on the resultant microstructure during surface deformation, which depends not only on input variables but also on each material's capability for martensitic phase transformation, dislocation slipping and mechanical twinning. In this sense, ultrasonic vibration-assisted machining is also an exciting topic for future studies since one of the main advantages of this process is reducing cutting force in elliptic milling and turning. The development of new metalceramic composites might also require this technology due to traditional machining approaches' high tool wear and surface damage [294].

\subsection{Non-traditional subtractive manufacturing processes for surface engineering}

The surface defects present on the finally manufactured degradable biomedical implant can cause an early degradation or failure under the joint influence of stress and corrosive environment inside the human body. A noticeable variation in the biomaterial's physical, mechanical, chemical, metallurgical, and biological properties occurs during manufacturing. In this regard, the upcoming research needs to remarkably improve the existing potentialities of the nontraditional machining processes by incorporating some novel strategies amid machining the metallic implant biomaterials. As explained by Duraccio et al. [295], a machined dental implant, for instance, usually undergoes further processing through plasma spray, grit blasting, etching, anodization, and acid treatment or ion implantation to adjust the surface chemical composition and roughness of dental implants, the essential characteristics for osseointegration. However, it would be highly beneficial if a single manufacturing process could achieve the final product. In this regard, according to Davis et al. [237, 238], powder-mixed EDM (PM-EDM) is a promising technique since it can be used for both roughing and finishing operations. The authors found that PM-EDM reduced machining time and increased dimensional accuracy, two of the critical variables in the machining process of implants. Bains et al. [280] performed nano-HAp powder-mixed EDM (PM-EDM) on Ti alloy surface for producing HAp bio-coatings, for which the wear and corrosion rates were also hampered. However, as Al-Amin et al. [296] discussed, powder mixing still poses challenges in obtaining uniform thickness, proper adhesion, and controlling HAp phase transformation, which must be solved before the widespread use of this method for orthopedic implants. As further explained by Al-Amin et al. [297], the more significant weight of HAp particles and its polar nature produces a heterogeneous mixture with dielectric oil impairs Ca-P ions deposition's regularity. Besides, this creates an uneven discharge and surface energy, which also prejudice coating adhesion. This could be overcome by using new combinations of Ca-P salts and electrolytes together with better control of EDM process parameters, which might be achieved through current research in EDM simulation. Another possibility would be to use particle mixing with EDM milling [298] since the small rotary tool would keep the material removal confined to a smaller region, and calcium phosphate compounds could be flushed more consistently. Additionally, as discussed previously, EDG, owing to its fine cutting propensity, can be incorporated in future research to produce desired surface characteristics primarily on the hard-to-bemachined metallic biomaterials. The absence of flushing and easy removal of debris might make the process economic. Moreover, the rotating wheel of EDG can effectively minimize the heat-affected layer, leading to less damage of the produced surface [299].

Regarding surface preparation, there are several promising non-conventional or hybrid methods to tailor micro or even nano-sized structures favorable to cell adhesion and proliferation. For instance, Bouet et al. [300] has combined femtosecond laser with Selective Laser Melting to reduce product surface roughness and create periodic surface nanostructures due to laser-induced ablation. Additionally, IBM and EBM have been used as subtractive strategies for hardto-cut metals, SMAs and Cermets, but the ongoing research aims to use these techniques for surface modification. Saptaji et al. [180] reviewed these fields and found that controlled heating of the outer metal layer might be used for tempering or relaxing residual stresses. The latter is desired to avoid cracking and delamination while the former may improve wear resistance, both of which contribute to greater adhesion. Although these processes require expensive equipment and possess lower productivity, technological development in the following years might facilitate their use for improving adhesion and cohesion, the most challenging characteristics regarding subtractive processing of biocompatible coatings. 
Author contribution The authors declare that all co-authors participated in all the development stages of this review.

Availability of data and material All the authors declare that this paper has no available data or material.

Code availability All the authors declare that this paper has no available code.

\section{Declarations}

Ethics approval Not applicable to this paper.

Consent to participate Not applicable to this paper.

Consent for publication Not applicable to this paper.

Conflict of interest The authors declare no competing interests.

\section{References}

1. Mordor intelligence (2021) Biomaterials market - growth, trends, COVID-19 impact, and forecasts (2021 - 2026). https://www. mordorintelligence.com/industry-reports/biomaterials-market. Accessed 28 Jun 2021

2. Food and Drug Administration (FDA) (2019) Implants and prosthetics. https://www.fda.gov/medical-devices/products-and-medicalprocedures/implants-and-prosthetics. Accessed 23 May 2021

3. Kashi A, Saha S (2010) Mechanisms of failure of medical implants during long-term use. Biointegration of Medical Implant Materials: Science and Design 326-348 https://doi.org/ 10.1533/9781845699802.3.326

4. Shekhawat D, Singh A, Bhardwaj A, Patnaik A (2021) A short review on polymer, metal and ceramic based implant materials. IOP Conf Ser Mater Sci Eng. https://doi.org/10.1088/1757-899X/1017/1/012038

5. Williams DF (1999) The Williams dictionary of biomaterials. Liverpool University Press

6. Mitsuishi M, Cao J, Bártolo P et al (2013) Biomanufacturing. CIRP Ann 62:585-606. https://doi.org/10.1016/j.cirp.2013.05.001

7. Ghasemi-Mobarakeh L, Kolahreez D, Ramakrishna S, Williams D (2019) Key terminology in biomaterials and biocompatibility. Curr Opin Biomed Eng 10:45-50. https://doi.org/10.1016/j. cobme.2019.02.004

8. U. S. Food \& Drug Administration (2018) ISO 10993-1:2018 - biological evaluation of medical devices - part 1: evaluation and testing within a risk management process. In: International Organization for Standardization. https://www.iso.org/standard/ 68936.html. Accessed 5 Jun 2021

9. Crowley C, Pembroke T, Birkinshaw C (2010) Biomaterials in dentistry and medicine. Biomaterials Developments and Applications. H. Bourg and A. Lisle (Editors), Book Series: Advances in Biology and Medicine, Nova Science Publishers 231-289

10. Roach P, Eglin D, Rohde K, Perry CC (2007) Modern biomaterials: a review-bulk properties and implications of surface modifications( Cell Material interaction BioMat paper). J Mater Sci - Mater Med 18:1263-1277

11. Laurén S (2020) Biocompatibility: biomaterial interaction with the biological surrounding. In: Biolin Scientific. https://www. biolinscientific.com/blog/biocompatibility-biomaterial-inter action-with-the-biological-surrounding. Accessed 12 Jul 2021
12. Rahmati M, Silva EA, Reseland JE et al (2020) Biological responses to physicochemical properties of biomaterial surface. Chem Soc Rev 49:5178-5224. https://doi.org/10.1039/d0cs00103a

13. Bartolo P, Kruth JP, Silva J et al (2012) Biomedical production of implants by additive electro-chemical and physical processes. CIRP Ann Manuf Technol 61:635-655. https://doi.org/10.1016/j. cirp.2012.05.005

14. Khan W, Muntimadugu E, Jaffe M, Domb AJ (2014) Implantable medical devices. pp 33-59

15. Kumar N, Arora NC, Datta B (2014) Bearing surfaces in hip replacement - evolution and likely future. Med J Armed Forces India 70:371-376. https://doi.org/10.1016/j.mjafi.2014.04.015

16. Fua-Nizan R, Abdul Rani AM, Yazid Din M (2017) Manufacturing methods for medical artificial prostheses- a review. Mal J Fund Appl Sci 13:464-469. https://doi.org/10.11113/mjfas. v13n4-2.772

17. Festas AJ, Ramos A, Davim JP (2020) Medical devices biomaterials - a review. Proc Inst Mech Eng L: J Mater: Des Appl 234:218-228. https://doi.org/10.1177/1464420719882458

18. Klocke F (2011) Manufacturing processes 1: Cutting

19. Rony L, Lancigu R, Hubert L (2018) Intraosseous metal implants in orthopedics: a review. Morphologie 102:231-242. https://doi. org/10.1016/j.morpho.2018.09.003

20. SIORA (2019) Orthopedic blog, trauma blog I siora surgicals. https://www.siiora.com/blog/page/2/

21. Jardini AL, Larosaa MA, Filho RM, Zavaglia CAC, Bernardes LF, Lambert CS, Calderoni DR, Kharmandayan P (2014) Cranial reconstruction: 3D biomodel and custom-built implant created using additive manufacturing. J Cranio-Maxillofac Surg 42:1877-1884

22. Trafton A (2016) Successful human tests for first wirelessly controlled drug-delivery chip. In: MIT News Office. https://news. mit.edu/2012/wireless-drug-delivery-0216. Accessed 15 May 2021

23. Loblaw A, George KJ, Misra V (2020) Surgical and radiotherapeutic management of malignant extradural spinal Cord compression. Clin Oncol 32:745-752. https://doi.org/10.1016/j.clon. 2020.07.022

24. Deharo J-C, Martignani C (2020) Prevention of device infection: new implantable devices. Infections of Cardiac Implantable Devices. Springer International Publishing, Cham, pp 153-175

25. Tsai SW, Ma HH, Hsu FW et al (2019) Risk factors for refracture after plate removal for midshaft clavicle fracture after bone union. J Orthop Surg Res. https://doi.org/10.1186/ s13018-019-1516-Z

26. Kessler P (2019) A treatment algorithm in craniofacial reconstruction: patient-specific implants. Craniofacial Trauma. Springer International Publishing, Cham, pp 333-344

27. Doan N, Truong L, Doan J, Reher P (2020) Overcoming single dental implant failure using two small implant support for one crown: five year retrospective study. pp 289-293

28. Katti KS (2004) Biomaterials in total joint replacement. Colloids Surf B 39:133-142. https://doi.org/10.1016/j.colsurfb.2003.12.002

29. Yang K, Ren Y (2010) Nickel-free austenitic stainless steels for medical applications. Sci Technol Adv Mater 11:014105. https:// doi.org/10.1088/1468-6996/11/1/014105

30. Rack HJ, Qazi JI (2006) Titanium alloys for biomedical applications. Mater Sci Eng, C 26:1269-1277. https://doi.org/10.1016/j. msec.2005.08.032

31. Singh R, Singh S, Hashmi MSJ (2016) Implant materials and their processing technologies. Reference Module in Materials Science and Materials Engineering. https://doi.org/10.1016/ b978-0-12-803581-8.04156-4 
32. Tanzi MC, Farè S, Candiani G (2019) Biomaterials and applications. In: Foundations of Biomaterials Engineering. Elsevier, pp 199-287

33. Sankaranarayanan $\mathrm{S}, \mathrm{Ng} \mathrm{BM}$, Jayalakshmi S et al (2015) Microstructure and mechanical properties of a magnesium-aluminiumerbium Alloy. Magnesium Technology 2015:445-449. https:// doi.org/10.1007/978-3-319-48185-2_82

34. Thomann UI, Uggowitzer PJ (2000) Wear-corrosion behavior of biocompatible austenitic stainless steels. Wear 239:48-58. https://doi.org/10.1016/S0043-1648(99)00372-5

35. Raposo H (2009) Stainless steels for small-diameter applications. Adv Mater Processes 167:23-24

36. Kraft CN, Burian B, Perlick L et al (2001) Impact of a nickelreduced stainless steel implant on striated muscle microcirculation: A comparative in vivo study. J Biomed Mater Res 57:404412. https://doi.org/10.1002/1097-4636(20011205)57:3\%3c404:: AID-JBM1183\%3e3.0.CO;2-W

37. Yamamoto A, Kohyama Y, Kuroda D, Hanawa T (2004) Cytocompatibility evaluation of Ni-free stainless steel manufactured by nitrogen adsorption treatment. Mater Sci Eng C 24:737-743. https://doi.org/10.1016/j.msec.2004.08.017

38. Tsuchiyama T, Fukumaru T, Egashira M, Takaki S (2004) Calculation of nitrogen absorption into austenitic stainless steel plate and wire. ISIJ Int 44:1121-1123. https://doi.org/10.2355/isijinternational.44.1121

39. Black J (1982) The education of the biomaterialist: report of a survey, 1980-81. J Biomed Mater Res 16:159-167. https://doi. org/10.1002/jbm. 820160208

40. Shayesteh Moghaddam N, Taheri Andani M, Amerinatanzi A et al (2016) Metals for bone implants: safety, design, and efficacy. Biomanuf Rev. https://doi.org/10.1007/s40898-016-0001-2

41. Zhang LC, Chen LY (2019) A review on biomedical titanium alloys: recent progress and prospect. Adv Eng Mater. https://doi. org/10.1002/adem.201801215

42. Kim T, See CW, Li X, Zhu D (2020) Orthopedic implants and devices for bone fractures and defects: past, present and perspective. Engineered Regeneration 1:6-18. https://doi.org/10.1016/j. engreg.2020.05.003

43. Goharian A, Abdullah MR (2017) Bioinert metals (stainless steel, titanium, cobalt chromium). In: Trauma Plating Systems. Elsevier, pp 115-142

44. Kim KT, Eo MY, Nguyen TTH, Kim SM (2019) General review of titanium toxicity. Int J Implant Dent. https://doi.org/10.1186/ s40729-019-0162-x

45. Shah KN, Walker G, Koruprolu SC, Daniels AH (2018) Biomechanical comparison between titanium and cobalt chromium rods used in a pedicle subtraction osteotomy model. Orthop Rev 10:32-35. https://doi.org/10.4081/or.2018.7541

46. Safranski D, Dupont K, Gall K (2020) Pseudoelastic nitinol in orthopaedic applications. Shape Mem Superelasticity 6:332341. https://doi.org/10.1007/s40830-020-00294-y

47. Guo Y, Klink A, Fu C, Snyder J (2013) Machinability and surface integrity of Nitinol shape memory alloy. CIRP Ann Manuf Technol 62:83-86. https://doi.org/10.1016/j.cirp.2013.03.004

48. Mwangi JW, Nguyen LT, Bui VD et al (2019) Nitinol manufacturing and micromachining: a review of processes and their suitability in processing medical-grade nitinol. J Manuf Process 38:355-369. https://doi.org/10.1016/j.jmapro.2019.01.003

49. Wadood A (2016) Brief overview on nitinol as biomaterial. Adv Mater Sci Eng. https://doi.org/10.1155/2016/4173138

50. Shabalovskaya S, Anderegg J, Van Humbeeck J (2008) Critical overview of nitinol surfaces and their modifications for medical applications. Acta Biomater 4:447-467. https://doi.org/10. 1016/j.actbio.2008.01.013

51. Likibi F, Assad M, Coillard C et al (2005) Bone integration and apposition of porous and non porous metallic orthopaedic biomaterials. Ann Chir 130:235-23541. https://doi.org/10.1016/j. anchir.2004.12.006
52. Pearson OM, Lieberman DE (2004) The aging of Wolff's "law": ontogeny and responses to mechanical loading in cortical bone. Yearb Phys Anthropol 47:63-99. https://doi.org/10.1002/ajpa.20155

53. Ozan S, Munir K, Biesiekierski A et al (2020) Titanium alloys, including nitinol. Biomater Sci. https://doi.org/10.1016/b978-012-816137-1.00018-0

54. Uddin MS, Rosman H, Hall C, Murphy P (2017) Enhancing the corrosion resistance of biodegradable Mg-based alloy by machining-induced surface integrity: influence of machining parameters on surface roughness and hardness. Int J Adv Manuf Technol 90:2095-2108. https://doi.org/10.1007/s00170-016-9536-x

55. Wang F, Cai S, Shen S et al (2017) Preparation of phytic acid/silane hybrid coating on magnesium alloy and its corrosion resistance in simulated body fluid. J Mater Eng Perform 26:4282-4290. https://doi.org/10.1007/s11665-017-2897-y

56. Chen J, Tan L, Yu X et al (2018) Mechanical properties of magnesium alloys for medical application: A review. J Mech Behav Biomed Mater 87:68-79

57. Liu C, Ren Z, Xu Y et al (2018) Biodegradable magnesium alloys developed as bone repair materials: a review. Scanning. https:// doi.org/10.1155/2018/9216314

58. Meagher P, O'Cearbhaill ED, Byrne JH, Browne DJ (2016) Bulk metallic glasses for implantable medical devices and surgical tools. Adv Mater 28:5755-5762. https://doi.org/10.1002/adma.201505347

59. Geetha M, Singh AK, Asokamani R, Gogia AK (2009) Ti based biomaterials, the ultimate choice for orthopaedic implants - a review. Prog Mater Sci 54:397-425. https://doi.org/10.1016/j. pmatsci.2008.06.004

60. Wennerberg A, Jimbo R, Albrektsson T (2015) Implant surfaces and their biological and clinical impact. Implant Surfaces and their Biological and Clinical Impact 1-182. https://doi.org/10. 1007/978-3-662-45379-7

61. Niinomi M (2008) Metallic biomaterials. J Artif Organs 11:105110. https://doi.org/10.1007/s10047-008-0422-7

62. Ohidul Alam M, Haseeb ASMA (2002) Response of Ti-6Al-4V and $\mathrm{Ti}-24 \mathrm{Al}-11 \mathrm{Nb}$ alloys to dry sliding wear against hardened steel. Tribol Int 35:357-362

63. Henriques VAR, Galvani ET, Petroni SLG et al (2010) Production of Ti-13Nb-13Zr alloy for surgical implants by powder metallurgy. J Mater Sci 45:5844-5850. https://doi.org/10.1007/ s10853-010-4660-8

64. Ribeiro ALR, Junior RC, Cardoso FF et al (2009) Mechanical, physical, and chemical characterization of Ti-35Nb-5Zr and Ti-35Nb-10Zr casting alloys. J Mater Sci - Mater Med 20:1629_ 1636. https://doi.org/10.1007/s10856-009-3737-x

65. Koch CC, Whittenberger JD (1996) Mechanical milling/alloying of intermetallics. Intermetallics 4:339-355. https://doi.org/10. 1016/0966-9795(96)00001-5

66. Petrini L, Migliavacca F (2011) Biomedical applications of shape memory alloys. J Metall 2011:1-15. https://doi.org/10.1155/ 2011/501483

67. Wen C, Yu X, Zeng W et al (2018) Mechanical behaviors and biomedical applications of shape memory materials: A review. AIMS Mater Sci 5:559-590. https://doi.org/10.3934/matersci. 2018.4.559

68. Hänzi AC, Gerber I, Schinhammer M et al (2010) On the in vitro and in vivo degradation performance and biological response of new biodegradable Mg-Y-Zn alloys. Acta Biomater 6:18241833. https://doi.org/10.1016/j.actbio.2009.10.008

69. ASTM International (2018) Medical device standards and implant standards. https://www.astm.org/Standards/medicaldevice-and-implant-standards.html. Accessed 2 Jun 2021

70. Ratner BD, Hoffman AS, Schoen FJ, Lemons JE (2013) Biomaterials science: an evolving, multidisciplinary endeavor. In: Biomaterials Science. Elsevier, pp xxv-xxxix 
71. Fukuda A, Takemoto M, Saito T et al (2011) Bone bonding bioactivity of Ti metal and $\mathrm{Ti}-\mathrm{Zr}-\mathrm{Nb}-\mathrm{Ta}$ alloys with $\mathrm{Ca}$ ions incorporated on their surfaces by simple chemical and heat treatments. Acta Biomater 7:1379-1386. https://doi.org/10.1016/j.actbio.2010.09.026

72. Oshida Y (2013) Surface modifications. In: Bioscience and Bioengineering of Titanium Materials. Elsevier, pp 341-456

73. Xue T, Attarilar S, Liu S et al (2020) Surface modification techniques of titanium and its alloys to functionally optimize their biomedical properties: Thematic review. Front Bioeng Biotechnol. https://doi.org/10.3389/fbioe.2020.603072

74. Cooper BG, Bordeianu C, Nazarian A et al (2018) Active agents, biomaterials, and technologies to improve biolubrication and strengthen soft tissues. Biomaterials 181:210-226. https://doi. org/10.1016/j.biomaterials.2018.07.040

75. Yang S, Dillon OW, Puleo DA, Jawahir IS (2013) Effect of cryogenic burnishing on surface integrity modifications of CoCr-Mo biomedical alloy. J Biomed Mater Res B Appl Biomater 101B:139-152. https://doi.org/10.1002/jbm.b.32827

76. Yang S, Pu Z, Puleo DA et al (2011) Cryogenic processing of biomaterials for improved surface integrity and product sustainability. Adv Sustain Manuf. https://doi.org/10.1007/978-3-64220183-7_26

77. Sun Y, Huang B, Puleo DA et al (2016) Improved surface integrity from cryogenic machining of Ti-6Al-7Nb alloy for biomedical applications. Procedia CIRP 45:63-66. https://doi.org/10. 1016/j.procir.2016.02.362

78. Zahoor S, Saleem MQ, Abdul-Kader W et al (2019) Improving surface integrity aspects of AISI $316 \mathrm{~L}$ in the context of bioimplant applications. Int J Adv Manuf Technol 105:2857-2867. https://doi.org/10.1007/s00170-019-04444-0

79. Rønold HJ, Lyngstadaas SP, Ellingsen JE (2003) Analysing the optimal value for titanium implant roughness in bone attachment using a tensile test. Biomaterials 24:4559-4564. https://doi.org/ 10.1016/S0142-9612(03)00256-4

80. Shalabi MM, Gortemaker A, Van't Hof MA, et al (2006) Implant surface roughness and bone healing: A systematic review. J Dent Res 85:496-500. https://doi.org/10.1177/154405910608500603

81. Damiati L, Eales MG, Nobbs AH et al (2018) Impact of surface topography and coating on osteogenesis and bacterial attachment on titanium implants. J Tissue Eng 9:204173141879069. https:// doi.org/10.1177/2041731418790694

82. Stepanovska J, Matejka R, Otahal M et al (2020) The effect of various surface treatments of Ti6Al4V on the growth and osteogenic differentiation of adipose tissue-derived stem cells. Coatings 10:762. https://doi.org/10.3390/coatings 10080762

83. Gittens RA, McLachlan T, Olivares-Navarrete R et al (2011) The effects of combined micron-/submicron-scale surface roughness and nanoscale features on cell proliferation and differentiation. Biomaterials 32:3395-3403. https://doi.org/10.1016/j.biomaterials.2011. 01.029

84. Ellingsen JE, Thomsen P (2000) Lyngstadaas SP (2006) Advances in dental implant materials and tissue regeneration. Periodontol 41:136-156. https://doi.org/10.1111/j.1600-0757. 2006.00175.x

85. Abellán-Nebot JV, Siller HR, Vila C, Rodríguez CA (2012) An experimental study of process variables in turning operations of Ti-6Al-4V and Cr-Co spherical prostheses. Int J Adv Manuf Technol 63:887-902. https://doi.org/10.1007/s00170-012-3955-0

86. Saini A, Chauhan P, Pabla BS, Dhami SS (2018) Multi-process parameter optimization in face milling of Ti6A14V alloy using response surface methodology. Proc Inst Mech Eng B J Eng Manuf 232:1590-1602. https://doi.org/10.1177/0954405416 673682

87. Saini A, Pabla BS, Dhami SS (2016) Developments in cutting tool technology in improving machinability of Ti6Al4V alloy: a review. Proc Inst Mech Eng B J Eng Manuf 230:1977-1989. https://doi.org/10.1177/0954405416640176

88. Klocke F, Michailidis N, Bouzakis KD et al (2010) Investigation of coated tools' cutting performance in milling Ti6Al4V and its correlation to the temperature dependent impact resistance of the film. Prod Eng Res Devel 4:509-514. https://doi.org/10.1007/ s11740-010-0235-4

89. Polini W, Turchetta S (2016) Cutting force, tool life and surface integrity in milling of titanium alloy Ti-6Al-4V with coated carbide tools. Proc Inst Mech Eng B J Eng Manuf 230:694-700. https://doi.org/10.1177/0954405414558732

90. Safari H, Sharif S, Izman S et al (2014) Cutting force and surface roughness characterization in cryogenic high-speed end milling of Ti-6Al-4V ELI. Mater Manuf Processes 29:350-356. https:// doi.org/10.1080/10426914.2013.872257

91. Saini A, Pabla B, Dhami S (2016) Developments in cutting tool technology in improving machinability of Ti6Al4V alloy: A review. Proc Inst Mech Eng B J Eng Manuf. https://doi.org/10. $1177 / 0954405416640176$

92. Vadivel K, Rudramoorthy R (2009) Performance analysis of cryogenically treated coated carbide inserts. Int J Adv Manuf Technol 42:222-232. https://doi.org/10.1007/s00170-008-1597-z

93. Dogra M, Sharma VS, Sachdeva A et al (2011) Performance evaluation of CBN, coated carbide, cryogenically treated uncoated/coated carbide inserts in finish-turning of hardened steel. Int J Adv Manuf Technol 57:541-553. https://doi.org/10.1007/s00170-011-3320-8

94. Poomari A, Mohan B, Rajadurai A, Senthilkumar A (2012) Study on tool life of coated, cryogenically treated and coated and plain cermet cutting tools while machining steel. Eur J Sci Res 85:394-407

95. Park K-H, Suhaimi MA, Yang G-D et al (2017) Milling of titanium alloy with cryogenic cooling and minimum quantity lubrication (MQL). Int J Precis Eng Manuf 18:5-14. https://doi.org/ 10.1007/s12541-017-0001-z

96. Yong AYL, Seah KHW, Rahman M (2007) Performance of cryogenically treated tungsten carbide tools in milling operations. Int J Adv Manuf Technol 32:638-643. https://doi.org/10.1007/ s00170-005-0379-0

97. Çiçek A, Kara F, Kıvak T et al (2015) Effects of deep cryogenic treatment on the wear resistance and mechanical properties of AISI H13 hot-work tool steel. J Mater Eng Perform 24:44314439. https://doi.org/10.1007/s11665-015-1712-x

98. Sivalingam V, Sun J, Yang B et al (2018) Machining performance and tool wear analysis on cryogenic treated insert during end milling of Ti-6Al-4V alloy. J Manuf Process 36:188-196. https:// doi.org/10.1016/j.jmapro.2018.10.010

99. Strano M, Albertelli P, Chiappini E, Tirelli S (2015) Wear behaviour of PVD coated and cryogenically treated tools for Ti-6Al$4 \mathrm{~V}$ turning. IntJ Mater Form 8:601-611. https://doi.org/10.1007/ s12289-014-1215-6

100. Machado AR, da Silva LRR, de Souza FCR et al (2021) State of the art of tool texturing in machining. J Mater Process Technol 293:117096. https://doi.org/10.1016/j.jmatprotec.2021.117096

101. Sharma V, Pandey PM (2016) Recent advances in turning with textured cutting tools: A review. J Clean Prod 137:701-715. https://doi.org/10.1016/j.jclepro.2016.07.138

102. Zheng K, Yang F, Zhang N et al (2020) Study on the cutting performance of micro textured tools on cutting Ti-6Al-4V titanium alloy. Micromachines 11:137

103. Zoya ZA, Krishnamurthy R (2000) The performance of CBN tools in the machining of titanium alloys. J Mater Process Technol 100:80-86. https://doi.org/10.1016/S0924-0136(99)00464-1

104. Ezugwu EO, da Silva RB, Bonney J, Machado ÁR (2005) Evaluation of the performance of CBN tools when turning Ti-6Al$4 \mathrm{~V}$ alloy with high pressure coolant supplies. Int J Mach Tools 
Manuf 45:1009-1014. https://doi.org/10.1016/j.ijmachtools. 2004.11.027

105. Sun FJ, Qu SG, Pan YX et al (2015) Effects of cutting parameters on dry machining Ti-6Al-4V alloy with ultra-hard tools. Int J Adv Manuf Technol 79:351-360. https://doi.org/10.1007/ s00170-014-6717-3

106. Abbas AT, Al Bahkali EA, Alqahtani SM et al (2021) Fundamental investigation into tool wear and surface quality in high-speed machining of Ti6Al4V alloy. Materials 14:7128

107. Zhou M, Eow YT, Ngoi BKA, Lim EN (2003) Vibration-assisted precision machining of steel with PCD tools. Mater Manuf Processes 18:825-834. https://doi.org/10.1081/AMP-120024978

108. Ezugwu EO, Bonney J, da Silva RB, Çakir O (2007) Surface integrity of finished turned Ti-6Al-4V alloy with PCD tools using conventional and high pressure coolant supplies. Int J Mach Tools Manuf 47:884-891. https://doi.org/10.1016/j.ijmachtools. 2006.08.005

109. Li G, Wu G, Pan W et al (2021) The performance of polycrystalline diamond (PCD) tools machined by abrasive grinding and electrical discharge grinding (EDG) in high-speed turning. $\mathrm{J}$ Manuf Mater Process 5:34

110. Schaefer D, Cheung WM (2018) Smart packaging: opportunities and challenges. Procedia CIRP 72:1022-1027

111. Jingyu P, Guo C, Hu D (2004) Electrical discharge grinding of polycrystalline diamond. Mater Sci Forum 471-472:457-461. https://doi.org/10.4028/www.scientific.net/MSF.471-472.457

112. Jia Y, Zhu L (2018) Research on electrical discharge grinding technics and tool's life of polycrystalline cubic boron nitride cutting tool. Procedia CIRP 68:637-642

113. Rahim MZ, Ding S, Mo J (2016) Electrical discharge grinding of polycrystalline diamond - Effect of wheel rotation. Mach Sci Technol 20:62-78. https://doi.org/10.1080/10910344.2015.1085315

114. Zindani D, Kumar K (2020) A brief review on cryogenics in machining process. SN Appl Sci. https://doi.org/10.1007/ s42452-020-2899-5

115. Zhao W, Gong L, Ren F et al (2018) Experimental study on chip deformation of Ti-6Al-4V titanium alloy in cryogenic cutting. Int J Adv Manuf Technol 96:4021-4027. https://doi.org/10.1007/ s00170-018-1890-4

116. Woodcraft AL (2007) An introduction to cryogenics. European Organization for Nuclear Research Cern/At

117. Dreitser GA (2003) Modern problems of cryogenic heat transfer and its enhancement (generalization of experimental results, practical recommendations and different applications). In: Kakaç S, Smirnov HF, Avelino MR (eds) Low temperature and cryogenic refrigeration. Springer, Netherlands, Dordrecht, pp 201-220

118. Lu T (2014) A metrics-based sustainability assessment of cryogenic machining using modeling and optimization of process performance. University of Kentucky

119. Courbon C, Pusavec F, Dumont F et al (2013) Tribological behaviour of Ti6Al4V and Inconel718 under dry and cryogenic conditions - application to the context of machining with carbide tools. Tribol Int 66:72-82. https://doi.org/10.1016/j.triboint.2013.04.010

120. Pusavec F, Courbon C, Rech J et al (2014) An investigation of the effect of nitrogen phase on cryogenic machining performance and a case study on machining of Inconel 718 alloy. ASME 2014 International Manufacturing Science and Engineering Conference, MSEC 2014 Collocated with the JSME 2014 International Conference on Materials and Processing and the 42nd North American Manufacturing Research Conference 2. https://doi.org/10.1115/MSEC2014-3992

121. Lu T, Kudaravalli R, Georgiou G (2018) Cryogenic machining through the spindle and tool for improved machining process performance and sustainability: pt. II, sustainability performance study. Procedia Manuf 21:273-280. https://doi.org/10. 1016/j.promfg.2018.02.121
122. Pimenov DYu, Mia M, Gupta MK et al (2021) Improvement of machinability of $\mathrm{Ti}$ and its alloys using cooling-lubrication techniques: a review and future prospect. J Market Res 11:719753. https://doi.org/10.1016/j.jmrt.2021.01.031

123. Raza SW, Pervaiz S, Deiab I (2014) Tool wear patterns when turning of titanium alloy using sustainable lubrication strategies. Int J Precis Eng Manuf 15:1979-1985. https://doi.org/10. 1007/s12541-014-0554-Z

124. Liu Z, An Q, Xu J et al (2013) Wear performance of (ncAlTiN)/(a-Si3N4) coating and (nc-AlCrN)/(a-Si3N4) coating in high-speed machining of titanium alloys under dry and minimum quantity lubrication (MQL) conditions. Wear 305:249259. https://doi.org/10.1016/j.wear.2013.02.001

125. Gupta MK, Sood PK, Sharma VS (2016) Optimization of machining parameters and cutting fluids during nano-fluid based minimum quantity lubrication turning of titanium alloy by using evolutionary techniques. J Clean Prod 135:12761288. https://doi.org/10.1016/j.jclepro.2016.06.184

126. Jamil M, Khan AM, Hegab H et al (2019) Effects of hybrid A12O3-CNT nanofluids and cryogenic cooling on machining of Ti-6Al-4V. Int J Adv Manuf Technol 102:3895-3909. https:// doi.org/10.1007/s00170-019-03485-9

127. Sun Y, Huang B, Puleo DA, Jawahir IS (2015) Enhanced machinability of Ti-5553 alloy from cryogenic machining: comparison with MQL and flood-cooled machining and modeling. Procedia CIRP 31:477-482. https://doi.org/10.1016/j. procir.2015.03.099

128. Kaynak Y, Kitay O (2018) Porosity, surface quality, microhardness and microstructure of selective laser melted 3161 stainless steel resulting from finish machining. J Manuf Mater Process. https://doi.org/10.3390/jmmp2020036

129. Nur R, Noordin MY, Izman S, Kurniawan D (2017) Machining parameters effect in dry turning of AISI 316L stainless steel using coated carbide tools. Proc Inst Mech Eng E: J Process Mech Eng 231:676-683. https://doi.org/10.1177/0954408915624861

130. Alexeev VP, Balyakin AV, Khaimovich AI (2017) Influence of the direction of selective laser sintering on machinability of parts from 316L steel. IOP Conf Ser Mater Scie Eng. https:// doi.org/10.1088/1757-899X/177/1/012120

131. de Assis CLF, Mecelis GR, Coelho RT (2020) An investigation of stainless steel 316L parts produced by powder bed fusion submitted to micro-endmilling operations. Int J Adv Manuf Technol 109:1867-1880. https://doi.org/10.1007/s00170-020-05710-2

132. Dhananchezian M, Kumar MP, Sornakumar T (2011) Cryogenic turning of AISI 304 stainless steel with modified tungsten carbide tool inserts. Mater Manuf Processes 26:781-785. https:// doi.org/10.1080/10426911003720821

133. Hong SY, Ding Y (2001) Cooling approaches and cutting temperatures in cryogenic machining of Ti-6Al-4V. Int J Mach Tools Manuf 41:1417-1437. https://doi.org/10.1016/S0890-6955(01)00026-8

134. Sun S, Brandt M, Palanisamy S, Dargusch MS (2015) Effect of cryogenic compressed air on the evolution of cutting force and tool wear during machining of Ti-6Al-4V alloy. J Mater Process Technol 221:243-254. https://doi.org/10.1016/j.jmatprotec.2015.02.017

135. Pradhan S, Singh S, Prakash C et al (2019) Investigation of machining characteristics of hard-to-machine Ti-6Al-4V-ELI alloy for biomedical applications. J Mater Res Technol 8:48494862. https://doi.org/10.1016/j.jmrt.2019.08.033

136. Pujana J, Rivero A, Celaya A, López de Lacalle LN (2009) Analysis of ultrasonic-assisted drilling of Ti6Al4V. Int J Mach Tools Manuf 49:500-508. https://doi.org/10.1016/j.ijmachtools.2008.12.014

137. Ferreira P, Simões F, Relvas C (2014) Experimental analysis of milling operations in Ti-6Al-4V and Co-28Cr-6Mo alloys for medical devices. Key Eng Mater 611-612:1282-1293. https:// doi.org/10.4028/www.scientific.net/KEM.611-612.1282 
138. Kaynak Y, Lu T, Jawahir IS (2014) Cryogenic machining-induced surface integrity: a review and comparison with dry, MQL, and flood-cooled machining. Mach Sci Technol 18:149-198. https:// doi.org/10.1080/10910344.2014.897836

139. Kaynak Y, Karaca HE, Jawahir IS (2014) Surface integrity characteristics of NiTi shape memory alloys resulting from dry and cryogenic machining. Procedia CIRP 13:393-398. https://doi. org/10.1016/j.procir.2014.04.067

140. Kaynak Y, Huang B, Karaca HE, Jawahir IS (2017) Surface characteristics of machined NiTi shape memory alloy: the effects of cryogenic cooling and preheating conditions. J Mater Eng Perform 26:3597-3606. https://doi.org/10.1007/s11665-017-2791-7

141. Carou D, Rubio EM, Davim JP (2015) Analysis of ignition risk in intermittent turning of UNS M11917 magnesium alloy at low cutting speeds based on the chip morphology. Proc Inst Mech Eng B J Eng Manuf 229:365-371. https://doi.org/10.1177/0954405414527961

142. Shokrani A, Dhokia V, Newman ST (2012) Environmentally conscious machining of difficult-to-machine materials with regard to cutting fluids. Int J Mach Tools Manuf 57:83-101. https://doi. org/10.1016/j.ijmachtools.2012.02.002

143. Pu Z, Dillon OW, Jawahir IS, Puleo DA (2010) Microstructural changes of AZ31 magnesium alloys induced by cryogenic machining and its influence on corrosion resistance in simulated body fluid for biomedical applications. ASME 2010 Int Manuf Scie Eng Conf, MSEC 1:271-277. https://doi.org/10.1115/ MSEC2010-34234

144. Pu Z, Puleo DA, Dillon OW, Jawahir IS (2011) Controlling the biodegradation rate of magnesium-based implants through surface nanocrystallization induced by cryogenic machining

145. Pu Z, Outeiro JC, Batista AC et al (2012) Enhanced surface integrity of AZ31B Mg alloy by cryogenic machining towards improved functional performance of machined components. Int J Mach Tools Manuf 56:17-27. https://doi.org/10.1016/j.ijmachtools.2011.12.006

146. Danish M, Ginta TL, Habib K et al (2017) Thermal analysis during turning of AZ31 magnesium alloy under dry and cryogenic conditions. Int J Adv Manuf Technol 91:2855-2868. https://doi.org/10.1007/s00170-016-9893-5

147. Bertolini R, Bruschi S, Ghiotti A et al (2017) The effect of cooling strategies and machining feed rate on the corrosion behavior and wettability of AZ31 alloy for biomedical applications. Procedia CIRP 65:7-12. https://doi.org/10.1016/j.procir.2017.03.168

148. Davis R, Singh A (2021) Performance study of cryo-treated end mill via wet, cryogenic, and hybrid lubri-coolant-milling induced surface integrity of biocompatible Mg alloy AZ91D. Proc Inst Mech Eng C J Mech Eng Sci. https://doi.org/10.1177/09544062211017160

149. Davis R, Singh A (2020) Tailoring surface integrity of biomedical Mg alloy AZ31B using distinct end mill treatment conditions and machining environments. J Mater Eng Perform 29:76177635. https://doi.org/10.1007/s11665-020-05203-z

150. Davis R, Singh A, Sabino RM et al (2021) Performance investigation of cryo-treated end Mill on the mechanical and in vitro behavior of hybrid-lubri-coolant-milled Ti-6Al-4V alloy. J Manuf Process 71:472-488. https://doi.org/10.1016/j.jmapro. 2021.09.052

151. Hong SY, Markus I, Jeong WC (2001) New cooling approach and tool life improvement in cryogenic machining of titanium alloy Ti-6Al-4V. Int J Mach Tools Manuf 41:2245-2260. https://doi. org/10.1016/S0890-6955(01)00041-4

152. Hong SY, Ding Y, Jeong J (2002) Experimental evaluation of friction coefficient and liquid nitrogen lubrication effect in cryogenic machining. Mach Sci Technol 6:235-250. https://doi.org/ 10.1081/MST-120005958

153. Su Y, He N, Li L, Li XL (2006) An experimental investigation of effects of cooling/lubrication conditions on tool wear in highspeed end milling of Ti-6Al-4V. Wear 261:760-766. https://doi. org/10.1016/j.wear.2006.01.013
154. Sharif S, Rahim EA (2007) Performance of coated- and uncoated-carbide tools when drilling titanium alloy-Ti-6Al4V. J Mater Process Technol 185:72-76. https://doi.org/10.1016/j. jmatprotec.2006.03.142

155. Khan AA, Ahmed MI (2008) Improving tool life using cryogenic cooling. J Mater Process Technol 196:149-154. https://doi.org/ 10.1016/j.jmatprotec.2007.05.030

156. Kaynak Y, Karaca HE, Noebe RD, Jawahir IS (2013) Tool-wear analysis in cryogenic machining of NiTi shape memory alloys: a comparison of tool-wear performance with dry and MQL machining. Wear 306:51-63. https://doi.org/10.1016/j.wear.2013.05.011

157. Kaynak Y (2014) Machining and phase transformation response of room-temperature austenitic NiTi shape memory alloy. J Mater Eng Perform 23:3354-3360. https://doi.org/10.1007/ s11665-014-1058-9

158. Safari H, Sharif S, Izman S et al (2014) Cutting force and surface roughness characterization in cryogenic high-speed end milling of Ti-6Al-4V ELI. Mater Manuf Processes 29:350-356. https:// doi.org/10.1080/10426914.2013.872257

159. Kaynak Y, Tobe H, Noebe RD et al (2014) The effects of machining on the microstructure and transformation behavior of NiTi Alloy. Scripta Mater 74:60-63. https://doi.org/10.1016/j.scriptamat.2013. 10.023

160. Kaynak Y, Karaca HE, Jawahir IS (2015) Cutting speed dependent microstructure and transformation behavior of NiTi alloy in dry and cryogenic machining. J Mater Eng Perform 24:452-460. https://doi.org/10.1007/s11665-014-1247-6

161. Al-Ghamdi KA, Iqbal A, Hussain G (2015) Machinability comparison of AISI 4340 and Ti-6Al-4V under cryogenic and hybrid cooling environments: a knowledge engineering approach. Proc Inst Mech Eng B J Eng Manuf 229:2144-2164. https://doi.org/ $10.1177 / 0954405414548496$

162. Kaynak Y, Robertson SW, Karaca HE, Jawahir IS (2015) Progressive tool-wear in machining of room-temperature austenitic NiTi alloys: The influence of cooling/lubricating, melting, and heat treatment conditions. J Mater Process Technol 215:95-104. https://doi.org/10.1016/j.jmatprotec.2014.07.015

163. Shokrani A, Dhokia V, Newman ST (2016) Comparative investigation on using cryogenic machining in CNC milling of Ti-6Al4V titanium alloy. Mach Sci Technol 20:475-494. https://doi.org/ 10.1080/10910344.2016.1191953

164. Shokrani A, Dhokia V, Newman ST (2016) Investigation of the effects of cryogenic machining on surface integrity in CNC end milling of Ti-6Al-4V titanium alloy. J Manuf Process 21:172179. https://doi.org/10.1016/j.jmapro.2015.12.002

165. Schoop J, Sales WF, Jawahir IS (2017) High speed cryogenic finish machining of Ti-6Al4V with polycrystalline diamond tools. J Mater Process Technol 250:1-8. https://doi.org/10.1016/j.jmatp rotec.2017.07.002

166. Sivaiah P, Chakradhar D (2018) Effect of cryogenic coolant on turning performance characteristics during machining of 17-4 PH stainless steel: a comparison with MQL, wet, dry machining. CIRP J Manuf Sci Technol 21:86-96. https://doi.org/10.1016/j. cirpj.2018.02.004

167. Shokrani A, Dhokia V, Newman ST (2018) Energy conscious cryogenic machining of Ti-6Al-4V titanium alloy. Proc Inst Mech Eng B J Eng Manuf 232:1690-1706. https://doi.org/10. $1177 / 0954405416668923$

168. Bruschi S, Bertolini R, Ghiotti A et al (2018) Machining-induced surface transformations of magnesium alloys to enhance corrosion resistance in human-like environment. CIRP Ann 67:579582. https://doi.org/10.1016/j.cirp.2018.04.040

169. Bertolini R, Lizzul L, Pezzato L et al (2019) Improving surface integrity and corrosion resistance of additive manufactured Ti6Al4V alloy by cryogenic machining. Int J Adv Manuf Technol 104:2839-2850. https://doi.org/10.1007/s00170-019-04180-5 
170. Shokrani A, Al-Samarrai I, Newman ST (2019) Hybrid cryogenic MQL for improving tool life in machining of Ti-6Al-4V titanium alloy. J Manuf Process 43:229-243. https://doi.org/10. 1016/j.jmapro.2019.05.006

171. Gajrani KK (2020) Assessment of cryo-MQL environment for machining of Ti-6Al-4V. J Manuf Process 60:494-502. https:// doi.org/10.1016/j.jmapro.2020.10.038

172. Khalil ANM, Azmi AI, Murad MN, Ali MAM (2021) Influence of hybrid cooling-lubricating strategy in the turning of ASTM F2063 austenitic nickel-titanium alloy. Tribol Ind 43:83-95. https://doi.org/10.24874/ti.1005.11.20.02

173. Kuczmaszewski J, Zagórski I, Zgórniak P (2016) Thermographic study of chip temperature in high-speed dry milling magnesium alloys. Manag Prod Eng Rev 7:86-92. https://doi.org/10.1515/ mper-2016-0020

174. Krishnamurthy G, Bhowmick S, Altenhof W, Alpas AT (2017) Increasing efficiency of Ti-alloy machining by cryogenic cooling and using ethanol in MRF. CIRP J Manuf Sci Technol 18:159172. https://doi.org/10.1016/j.cirpj.2017.01.001

175. Wang F, Zhao J, Li A, Zhao J (2014) Experimental study on cutting forces and surface integrity in high-speed side milling of Ti-6Al-4V titanium alloy. Mach Sci Technol 18:448-463. https:// doi.org/10.1080/10910344.2014.926690

176. Velmurugan C, Senthilkumar V, Dinesh S, Arulkirubakaran D (2018) Machining of NiTi-shape memory alloys-a review. Mach Sci Technol 22:355-401. https://doi.org/10.1080/10910344. 2017.1365894

177. Zainal Abidin Z, Tarisai Mativenga P, Harrison G (2020) Chilled air system and size effect in micro-milling of nickel-titanium shape memory alloys. International Journal of Precision Engineering and Manufacturing - Green Technology 7:283-297. https://doi.org/10.1007/s40684-019-00040-5

178. Singh R, Singh RP, Trehan R (2021) State of the art in processing of shape memory alloys with electrical discharge machining: A review. Proc Inst Mech Eng B J Eng Manuf 235:333-366. https:// doi.org/10.1177/0954405420958771

179. Azhari A, Schindler C, Kerscher E, Grad P (2012) Improving surface hardness of austenitic stainless steel using waterjet peening process. Int J Adv Manuf Technol 63:1035-1046. https://doi. org/10.1007/s00170-012-3962-1

180. Saptaji K, Gebremariam MA, Azhari MABM (2018) Machining of biocompatible materials: a review. Int J Adv Manuf Technol 97:2255-2292. https://doi.org/10.1007/s00170-018-1973-2

181. Yuvaraj N, Pavithra E, Shamli CS (2020) Investigation of surface morphology and topography features on abrasive water jet milled surface pattern of SS 304. J Test Eval. https://doi.org/10.1520/ JTE20180856

182. Zagórski I, Klonica M, Kulisz M, Loza K (2018) Effect of the AWJM method on the machined surface layer of AZ91D magnesium alloy and simulation of roughness parameters using neural networks. Materials. https://doi.org/10.3390/ma11112111

183. Liu HT (2010) Waterjet technology for machining fine features pertaining to micromachining. J Manuf Process 12:8-18. https:// doi.org/10.1016/j.jmapro.2010.01.002

184. Melentiev R, Fang F (2020) Fabrication of micro-channels on Co$\mathrm{Cr}-\mathrm{Mo}$ joints by micro-abrasive jet direct writing. J Manuf Process 56:667-677. https://doi.org/10.1016/j.jmapro.2020.05.022

185. Putz M, Dix M, Morczinek F, Dittrich M (2018) Suspension technology for abrasive waterjet (AWJ) cutting of ceramics. Procedia CIRP 77:367-370. https://doi.org/10.1016/j.procir.2018.09.037

186. Kong MC, Axinte D, Voice W (2011) Challenges in using waterjet machining of NiTi shape memory alloys: an analysis of controlled-depth milling. J Mater Process Technol 211:959-971. https://doi.org/10.1016/j.jmatprotec.2010.12.015

187. Jarosz K, Löschner P, Niesłony P (2016) Effect of cutting speed on surface quality and heat-affected zone in laser cutting of $316 \mathrm{~L}$ stainless steel. Procedia Eng 149:155-162. https://doi.org/10. 1016/j.proeng.2016.06.650

188. Pramanik D, Goswami S, Kuar AS et al (2019) A parametric study of kerf deviation in fiber laser micro cutting on Ti6Al4V Superalloy. Mater Today Proc 18:3348-3356. https://doi.org/10. 1016/j.matpr.2019.07.257

189. Pramanik D, Kuar AS, Sarkar S, Mitra S (2021) Optimisation of edge quality on stainless steel $316 \mathrm{~L}$ using low power fibre laser beam machining. Adv Mater Process Technol 7:42-53. https:// doi.org/10.1080/2374068X.2020.1745734

190. Ahmed N, Ishfaq K, Moiduddin K et al (2019) Machinability of titanium alloy through electric discharge machining. Mater Manuf Processes 34:93-102. https://doi.org/10.1080/10426914.2018.1532092

191. Wuttisarn T, Tangwarodomnukun V, Dumkum C (2020) Laser micromachining of titanium alloy in water and ice at different temperatures. Opt Laser Technol. https://doi.org/10.1016/j.optlastec. 2019.106024

192. Neurohr AJ, Dunand DC (2011) Shape-memory NiTi with twodimensional networks of micro-channels. Acta Biomater 7:18621872. https://doi.org/10.1016/j.actbio.2010.11.038

193. Sharma N, Kumar K, Kumar V (2018) Post-processing of NiTi alloys: Issues and challenges. Powder Metall Met Ceram 56:599609. https://doi.org/10.1007/s11106-018-9933-9

194. Li C, Nikumb S, Wong F (2006) An optimal process of femtosecond laser cutting of NiTi shape memory alloy for fabrication of miniature devices. Opt Lasers Eng 44:1078-1087. https://doi. org/10.1016/j.optlaseng.2005.08.003

195. Pfeifer R, Herzog D, Hustedt M, Barcikowski S (2010) Pulsed $\mathrm{Nd}$ :YAG laser cutting of NiTi shape memory alloys-influence of process parameters. J Mater Process Technol 210:1918-1925. https://doi.org/10.1016/j.jmatprotec.2010.07.004

196. Mohammed MK, Al-Ahmari A (2020) Laser-machining of microchannels in NiTi-based shape-memory alloys: Experimental analysis and process optimization. Materials. https://doi.org/ 10.3390/ma13132945

197. Singh R, Khamba JS (2006) Ultrasonic machining of titanium and its alloys: A review. J Mater Process Technol 173:125-135. https://doi.org/10.1016/j.jmatprotec.2005.10.027

198. Zou X, Cong W, Wu N et al (2013) Cutting temperature in rotary ultrasonic machining of titanium: Experimental study using novel Fabry-Perot fibre optic sensors. Int J Manuf Res 8:250261. https://doi.org/10.1504/IJMR.2013.055242

199. Churi NJ, Pei ZJ, Treadwell C (2006) Rotary ultrasonic machining of titanium alloy: Effects of machining variables. Mach Sci Technol 10:301-321. https://doi.org/10.1080/10910340600902124

200. Dvivedi A, Kumar P (2007) Surface quality evaluation in ultrasonic drilling through the Taguchi technique. Int J Adv Manuf Technol 34:131-140. https://doi.org/10.1007/s00170-006-0586-3

201. Strasky J, Janecek M, Harcuba P (2011) Electric discharge machining of Ti-6Al-4V alloy for biomedical use. WDS'11 Proceedings of Contributed Papers, Part III 127-131

202. Mwangi JW, Weisheit L, Bui VD et al (2018) Influence of microEDM on the phase transformation behaviour of medical-grade nitinol. Shape Mem Superelasticity 4:450-461. https://doi.org/ 10.1007/s40830-018-00195-1

203. Ho KH, Newman ST (2003) State of the art electrical discharge machining (EDM). Int J Mach Tools Manuf 43:1287-1300. https://doi.org/10.1016/S0890-6955(03)00162-7

204. Jahan MP, Wong YS, Rahman M (2009) A study on the quality micro-hole machining of tungsten carbide by micro-EDM process using transistor and RC-type pulse generator. J Mater Process Technol 209:1706-1716. https://doi.org/10.1016/j.jmatprotec.2008.04.029

205. Mahbub R, Jahan MP, Kirwin R, Alavi F (2018) Micro-EDM induced surface modification of titanium alloy for biocompatibility. Int J Mach Mach Mater 20:274. https://doi.org/10.1504/ijmmm. 2018.10014654 
206. Ntasi A, Mueller WD, Eliades G, Zinelis S (2010) The effect of electro discharge machining (EDM) on the corrosion resistance of dental alloys. Dent Mater 26:e237-e245. https://doi.org/10. 1016/j.dental.2010.08.001

207. Chen SL, Lin MH, Chen CC, Ou KL (2008) Effect of electrodischarging on formation of biocompatible layer on implant surface. J Alloy Compd 456:413-418. https://doi.org/10.1016/j. jallcom.2007.02.055

208. Otsuka F, Kataoka Y, Miyazaki T (2012) Enhanced osteoblast response to electrical discharge machining surface. Dent Mater J 31:309-315. https://doi.org/10.4012/dmj.2011-039

209. Klocke F, Schwade M, Klink A, Kopp A (2011) EDM machining capabilities of magnesium $(\mathrm{Mg})$ alloy WE43 for medical applications. Procedia Eng 19:190-195. https://doi.org/10.1016/j. proeng.2011.11.100

210. Ndaliman MB, Khan AA, Ali MY (2013) Influence of dielectric fluids on surface properties of electrical discharge machined titanium alloy. Proc Inst Mech Eng B J Eng Manuf 227:1310-1316. https://doi.org/10.1177/0954405413488592

211. Klocke F, Schwade M, Klink A et al (2013) Influence of electro discharge machining of biodegradable magnesium on the biocompatibility. Procedia CIRP 5:88-93. https://doi.org/10.1016/j. procir.2013.01.018

212. Aliyu AA, Abdul-Rani AM, Ginta TL et al (2017) A review of additive mixed-electric discharge machining: current status and future perspectives for surface modification of biomedical implants. Adv Mater Sci Eng. https://doi.org/10.1155/2017/ 8723239

213. Talla G, Gangopadhayay S, Biswas CK (2017) State of the art in powder-mixed electric discharge machining: a review. Proc Inst Mech Eng B J Eng Manuf 231:2511-2526. https://doi.org/10. $1177 / 0954405416634265$

214. Joshi AY, Joshi AY (2019) A systematic review on powder mixed electrical discharge machining. Heliyon. https://doi.org/ 10.1016/j.heliyon.2019.e02963

215. Bui VD, Mwangi JW, Schubert A (2019) Powder mixed electrical discharge machining for antibacterial coating on titanium implant surfaces. J Manuf Process 44:261-270. https://doi.org/10.1016/j. jmapro.2019.05.032

216. Kolli M, Kumar A (2014) Effect of boron carbide powder mixed into dielectric fluid on electrical discharge machining of titanium alloy. Procedia Mater Sci 5:1957-1965. https://doi.org/10.1016/j. mspro.2014.07.528

217. Kolli M, Kumar A (2017) Surfactant and graphite powderassisted electrical discharge machining of titanium alloy. Proc Inst Mech Eng B J Eng Manuf 231:641-657. https://doi.org/10. 1177/0954405415579019

218. Alam ST, Amin AN, Hossain MdI et al (2021) Performance evaluation of graphite and titanium oxide powder mixed dielectric for electric discharge machining of Ti-6Al-4V. SN Appl Sci. https:// doi.org/10.1007/s42452-021-04450-6

219. Yaşar H, Ekmekci B (2014) Ti-6Al-4V surfaces in SiC powder mixed electrical discharge machining. Adv Mater Res 856:226230. https://doi.org/10.4028/www.scientific.net/AMR.856.226

220. Li L, Zhao L, Li ZY et al (2017) Surface characteristics of Ti-6Al$4 \mathrm{~V}$ by $\mathrm{SiC}$ abrasive-mixed EDM with magnetic stirring. Mater Manuf Processes 32:83-86. https://doi.org/10.1080/10426914. 2016.1151043

221. Öpöz TT, Yaşar H, Ekmekci N, Ekmekci B (2018) Particle migration and surface modification on Ti6Al4V in $\mathrm{SiC}$ powder mixed electrical discharge machining. J Manuf Process 31:744758. https://doi.org/10.1016/j.jmapro.2018.01.002

222. Joshi AY, Joshi AY (2021) Feasibility analysis of powdermixed deionized water as dielectric for machining Ti6Al4V. J Inst Eng (India): C 102:337-347. https://doi.org/10.1007/ s40032-020-00639-7
223. Gosai ND, Joshi AY (2016) Experimental investigation and optimization of process parameters used in the silicon powder mixed electro discharge machining of Ti-6Al-4V alloy using response surface methodology. J Manuf Sci Prod 16:21-32. https://doi. org/10.1515/jmsp-2015-0013

224. Shabgard M, Khosrozadeh B (2017) Investigation of carbon nanotube added dielectric on the surface characteristics and machining performance of Ti-6 Al-4V alloy in EDM process. J Manuf Process 25:212-219. https://doi.org/10.1016/j.jmapro. 2016.11.016

225. Kumar SS, Varol T, Canakci A et al (2021) A review on the performance of the materials by surface modification through EDM. Int J Lightweight Mater Manuf 4:127-144. https://doi. org/10.1016/j.ijlmm.2020.08.002

226. Patel S, Thesiya D, Rajurkar A (2018) Aluminium powder mixed rotary electric discharge machining (PMEDM) on Inconel 718. Aust J Mech Eng 16:21-30. https://doi.org/10.1080/14484846. 2017.1294230

227. Kumar A, Mandal A, Dixit AR, Das AK (2018) Performance evaluation of Al2O3 nano powder mixed dielectric for electric discharge machining of Inconel 825. Mater Manuf Processes 33:986-995. https://doi.org/10.1080/10426914.2017.1376081

228. Ekmekci N, Ekmekci B (2016) Electrical discharge machining of Ti6Al4V in hydroxyapatite powder mixed dielectric liquid. Mater Manuf Processes 31:1663-1670. https://doi.org/10.1080/ 10426914.2015.1090591

229. Ekmekci N, Ekmekci B (2014) Hydroxyapatite deposition onto Ti-6Al-4V surface in powder mixed electrical discharge machining. Adv Mater Res 856:205-209. https://doi.org/10. 4028/www.scientific.net/AMR.856.205

230. Opoz T, Yasar H, Murphy M et al (2019) Ti6Al4V surface modification by hydroxyapatite powder mixed electrical discharge machining for medical application. Int J Adv Eng P Sci. https://doi.org/10.7240/jeps.450383

231. Bui VD, Mwangi JW, Meinshausen AK et al (2020) Antibacterial coating of Ti-6Al-4V surfaces using silver nano-powder mixed electrical discharge machining. Surf Coat Technol. https://doi.org/10.1016/j.surfcoat.2019.125254

232. Daneshmand S, Monfared V, Lotfi Neyestanak AA (2017) Effect of tool rotational and $\mathrm{Al} 2 \mathrm{O} 3$ powder in electro discharge machining characteristics of NiTi-60 shape memory alloy. SILICON 9:273-283. https://doi.org/10.1007/s12633-016-9412-1

233. Camara C, Peris-Lopez P, Tapiador JE (2015) Security and privacy issues in implantable medical devices: a comprehensive survey. J Biomed Inform 55:272-289. https://doi.org/10. 1016/j.jbi.2015.04.007

234. Packianather MS, Le CH, Pham DT, Le HQ (2018) Advanced micro and nano manufacturing technologies used in medical domain. IFMBE Proc 63:637-642. https://doi.org/10.1007/ 978-981-10-4361-1_109

235. Ekmekci B, Yaşar H, Ekmekci N (2016) A discharge separation model for powder mixed electrical discharge machining. J Manuf Sci Eng Trans ASME. https://doi.org/10.1115/1.4033042

236. Zhu Z, Guo D, Xu J et al (2020) Processing characteristics of micro electrical discharge machining for surface modification of TiNi shape memory alloys using a TiC powder dielectric. Micromachines 11:1-15. https://doi.org/10.3390/mi11111018

237. Davis R, Singh A, Debnath K et al (2021) Surface modification of medical-grade Ni55.6Ti44.4 alloy via enhanced machining characteristics of $\mathrm{Zn}$ powder mixed- $\mu$-EDM. Surf Coat Technol. https://doi.org/10.1016/j.surfcoat.2021.127725

238. Davis R, Singh A, Debnath K et al (2021) Effect of powder particle concentration and tool electrode material amid zinc powdermixed $\mu \mathrm{EDM}$ of biocompatible $\mathrm{Mg}$ alloy AZ91D. J Mater Eng Perform. https://doi.org/10.1007/s11665-021-05788-z 
239. Mahajan A, Sidhu SS (2018) Surface modification of metallic biomaterials for enhanced functionality: a review. Mater Technol 33:93-105. https://doi.org/10.1080/10667857.2017.1377971

240. Chillman A, Ramulu M, Hashish M (2007) Waterjet peening and surface preparation at $600 \mathrm{MPa}$ : a preliminary experimental study. J Fluids Eng Trans ASME 129:485-490. https://doi.org/ $10.1115 / 1.2436580$

241. Lieblich M, Barriuso S, Ibáñez J et al (2016) On the fatigue behavior of medical Ti6Al4V roughened by grit blasting and abrasiveless waterjet peening. J Mech Behav Biomed Mater 63:390-398. https://doi.org/10.1016/j.jmbbm.2016.07.011

242. Arola DD, McCain ML (2000) Abrasive waterjet peening: a new method of surface preparation for metal orthopedic implants. J Biomed Mater Res 53:536-546. https://doi.org/10.1002/10974636(200009)53:5\%3c536::aid-jbm13\%3e3.3.co;2-m

243. Barriuso S, Lieblich M, Multigner M et al (2011) Roughening of metallic biomaterials by abrasiveless waterjet peening: Characterization and viability. Wear 270:634-639. https://doi.org/10. 1016/j.wear.2011.01.024

244. Kong MC, Srinivasu D, Axinte D et al (2013) On geometrical accuracy and integrity of surfaces in multi-mode abrasive waterjet machining of NiTi shape memory alloys. CIRP Ann Manuf Technol 62:555-558. https://doi.org/10.1016/j.cirp.2013.03.021

245. Frotscher M, Kahleyss F, Simon T et al (2011) Achieving small structures in thin NiTi sheets for medical applications with water jet and micro machining: a comparison. J Mater Eng Perform 20:776-782. https://doi.org/10.1007/s11665-010-9789-8

246. Xiao X, Zheng K, Liao W (2014) Theoretical model for cutting force in rotary ultrasonic milling of dental zirconia ceramics. Int J Adv Manuf Technol 75:1263-1277. https://doi.org/10.1007/ s00170-014-6216-6

247. Theisen W, Schuermann A (2004) Electro discharge machining of nickel-titanium shape memory alloys. Mater Sci Eng A 378:200-204. https://doi.org/10.1016/j.msea.2003.09.115

248. Ntasi A, Mueller WD, Eliades G, Zinelis S (2010) The effect of electro discharge machining $(\mathrm{EDM})$ on the corrosion resistance of dental alloys. Dent Mater. https://doi.org/10.1016/j.dental.2010.08.001

249. Dubey AK, Yadava V (2008) Laser beam machining-a review. Int J Mach Tools Manuf 48:609-628. https://doi.org/10.1016/j. ijmachtools.2007.10.017

250. Meijer J (2004) Laser beam machining (LBM), state of the art and new opportunities. J Mater Process Technol 149:2-17

251. Sealy MP, Guo YB, Liu JF, Li C (2016) Pulsed laser cutting of magnesium-calcium for biodegradable stents. Procedia CIRP 42:67-72. https://doi.org/10.1016/j.procir.2016.02.190

252. Almeida IA, de Rossi W, Lima MSF et al (2006) Optimization of titanium cutting by factorial analysis of the pulsed Nd:YAG laser parameters. J Mater Process Technol 179:105-110. https:// doi.org/10.1016/j.jmatprotec.2006.03.107

253. Hung CH, Chang FY (2017) Curve micromachining on the edges of nitinol biliary stent by ultrashort pulses laser. Opt Laser Technol 90:1-6. https://doi.org/10.1016/j.optlastec.2016.10.018

254. Zinelis S (2007) Surface and elemental alterations of dental alloys induced by electro discharge machining (EDM). Dent Mater 23:601-607. https://doi.org/10.1016/j.dental.2006.03.021

255. Yeo SH, Tan PC, Kurnia W (2007) Effects of powder additives suspended in dielectric on crater characteristics for micro electrical discharge machining. J Micromech Microeng. https://doi.org/ 10.1088/0960-1317/17/11/N01

256. Chen YF, Lin YC (2009) Surface modifications of Al-Zn-Mg alloy using combined EDM with ultrasonic machining and addition of TiC particles into the dielectric. J Mater Process Technol 209:4343-4350. https://doi.org/10.1016/j.jmatprotec.2008.11.013

257. Peng PW, Ou KL, Lin HC et al (2010) Effect of electrical-discharging on formation of nanoporous biocompatible layer on titanium. J Alloy Compd 492:625-630. https://doi.org/10.1016/j.jallcom.2009.11.197
258. Kibria G, Bhattacharyya B (2011) Investigation into micro-hole geometrical accuracy during micro-EDM of Ti-6Al-4V employing different dielectrics. Int J Mach Mach Mater 10:310-325. https://doi.org/10.1504/IJMMM.2011.043090

259. Harcuba P, Bačáková L, Stráský J et al (2012) Surface treatment by electric discharge machining of Ti-6Al-4V alloy for potential application in orthopaedics. J Mech Behav Biomed Mater 7:96-105. https://doi.org/10.1016/j.jmbbm.2011.07.001

260. Zain ZM, Ndaliman MB, Khan AA, Ali MY (2012) Electrodischarge machining of SUS 304 stainless steel with TaC powder-mixed dielectric. Adv Mater Res 576:72-75. https:// doi.org/10.4028/www.scientific.net/AMR.576.72

261. Lee WF, Sen YT, Wu YC, Peng PW (2013) Nanoporous biocompatible layer on Ti-6Al-4V alloys enhanced osteoblast-like cell response. J Exp Clin Med 5:92-96. https://doi.org/10.1016/j. jecm.2013.04.002

262. Prihandana GS, Mahardika M, Hamdi M et al (2013) Study of workpiece vibration in powder-suspended dielectric fluid in micro-EDM processes. Int J Precis Eng Manuf 14:1817-1822. https://doi.org/10.1007/s12541-013-0243-3

263. Yang TS, Huang MS, Wang MS et al (2013) Effect of electrical discharging on formation of nanoporous biocompatible layer on Ti-6Al-4V alloys. Implant Dent 22:374-379. https://doi. org/10.1097/ID.0b013e31829a170a

264. Kibria G, Shivakoti I, Bhattacharyya B (2014) Experimentation and analysis into micro-hole machining of Ti-6Al-4V by micro-EDM using boron carbide powder mixed de-ionized water. Int J Manuf Mater Mech Eng 4:22-41. https://doi.org/ 10.4018/ijmmme.2014010102

265. Huang TS, Hsieh SF, Chen SL et al (2015) Surface modification of TiNi-based shape memory alloys by dry electrical discharge machining. J Mater Process Technol 221:279-284. https://doi.org/10.1016/j.jmatprotec.2015.02.025

266. Prakash C, Kansal HK, Pabla BS, Puri S (2015) Processing and characterization of novel biomimetic nanoporous bioceramic surface on $\beta$-Ti implant by powder mixed electric discharge machining. J Mater Eng Perform 24:3622-3633. https://doi. org/10.1007/s11665-015-1619-6

267. Kuriachen B, Mathew J (2016) Effect of powder mixed dielectric on material removal and surface modification in microelectric discharge machining of Ti-6Al-4V. Mater Manuf Processes 31:439-446. https://doi.org/10.1080/10426914.2015.1004705

268. Lee BEJ, Ho S, Mestres G et al (2016) Dual-topography electrical discharge machining of titanium to improve biocompatibility. Surf Coat Technol 296:149-156. https://doi.org/10. 1016/j.surfcoat.2016.04.024

269. Sales WF, Oliveira ARF, Raslan AA (2016) Titanium perovskite (CaTiO3) formation in Ti6Al4V alloy using the electrical discharge machining process for biomedical applications. Surf Coat Technol 307:1011-1015. https://doi.org/10.1016/j.surfcoat. 2016.10.028

270. Cyril J, Paravasu A, Jerald J et al (2017) Experimental investigation on performance of additive mixed dielectric during micro-electric discharge drilling on 316L stainless steel. Mater Manuf Processes 32:638-644. https://doi.org/10.1080/10426 914.2016.1221107

271. Abdul-Rani AM, Razak MA, Littlefair G et al (2017) Improving EDM process on AZ31 magnesium alloy towards sustainable biodegradable implant manufacturing. Procedia Manuf 7:504-509. https://doi.org/10.1016/j.promfg.2016.12.057

272. Prakash C, Kansal HK, Pabla BS, Puri S (2017) On the influence of nanoporous layer fabricated by PMEDM on $\beta$-Ti implant: biological and computational evaluation of boneimplant interface. Mater Today Proc 4:2298-2307. https://doi. org/10.1016/j.matpr.2017.02.078 
273. Jahan MP, Kakavand P, Alavi F (2017) A comparative study on micro-electro-discharge-machined surface characteristics of Ni-Ti and Ti-6Al-4V with respect to biocompatibility. Procedia Manuf 10:232-242. https://doi.org/10.1016/j.promfg.2017.07.051

274. Mahajan A, Sidhu SS (2018) Enhancing biocompatibility of Co-Cr alloy implants via electrical discharge process. Mater Technol 33:524-531. https://doi.org/10.1080/10667857.2018. 1475144

275. Razak MA, Rani AMA, Saad NM et al (2018) Controlling corrosion rate of magnesium alloy using powder mixed electrical discharge machining. IOP Conf Ser Mater Sci Eng. https://doi. org/10.1088/1757-899X/344/1/012010

276. Mahajan A, Sidhu SS (2019) In vitro corrosion and hemocompatibility evaluation of electrical discharge treated cobaltchromium implant. J Mater Res 34:1363-1370. https://doi.org/ 10.1557/jmr.2019.73

277. Tiwary AP, Pradhan BB, Bhattacharyya B (2019) Influence of various metal powder mixed dielectric on micro-EDM characteristics of Ti-6Al-4V. Mater Manuf Processes 34:1103-1119. https://doi.org/10.1080/10426914.2019.1628265

278. Mahajan A, Sidhu SS (2019) Potential of electrical discharge treatment to enhance the in vitro cytocompatibility and tribological performance of Co-Cr implant. J Mater Res 34:2837-2847. https://doi.org/10.1557/jmr.2019.240

279. Mohanty S, Kumar V, Kumar Das A, Dixit AR (2019) Surface modification of Ti-alloy by micro-electrical discharge process using tungsten disulphide powder suspension. J Manuf Process 37:28-41. https://doi.org/10.1016/j.jmapro.2018.11.007

280. Bains PS, Bahraminasab M, Sidhu SS, Singh G (2020) On the machinability and properties of Ti-6Al-4V biomaterial with n-HAp powder-mixed ED machining. Proc Inst Mech Eng [H] 234:232-242. https://doi.org/10.1177/0954411919891887

281. Arun Pillai KV, Hariharan P, Krishna Murthy R (2020) Micro ED milling of Ti-6Al-4V with $\mathrm{SiC}$ nano powder mixed dielectrics at different ranges of discharge energy. SILICON. https://doi.org/ 10.1007/s12633-020-00578-z

282. Yaşar H, Ekmekci B (2021) The effect of micro and nano hydroxyapatite powder on biocompatibility and surface integrity of Ti6Al4V (ELI) in powder mixed electrical discharge machining. Surf Topogr Metrol Prop. https://doi.org/10.1088/ 2051-672X/abdda2

283. Nagase T, Iijima Y, Matsugaki A et al (2020) Design and fabrication of Ti-Zr-Hf-Cr-Mo and Ti-Zr-Hf-Co-Cr-Mo high-entropy alloys as metallic biomaterials. Mater Sci Eng, C. https://doi.org/ 10.1016/j.msec.2019.110322

284. Kargozar S, Ramakrishna S, Mozafari M (2019) Chemistry of biomaterials: future prospects. Curr Opin Biomed Eng 10:181190. https://doi.org/10.1016/j.cobme.2019.07.003

285. Romero-Resendiz L, Gómez-Sáez P, Vicente-Escuder A, AmigóBorrás V (2021) Development of Ti-In alloys by powder metallurgy for application as dental biomaterial. J Market Res 11:1719-1729. https://doi.org/10.1016/j.jmrt.2021.02.014

286. da Silva LRR, Sales WF, Campos FDAR et al (2021) A comprehensive review on additive manufacturing of medical devices. Prog Addit Manuf 6:517-553. https://doi.org/10.1007/ s40964-021-00188-0
287. Esteban-Tejeda L, Smirnov A, Prado C et al (2016) Multifunctional ceramic-metal biocomposites with Zinc containing antimicrobial glass coatings. Ceram Int 42:7023-7029. https://doi. org/10.1016/j.ceramint.2016.01.090

288. He Y, Zhang Y, Jiang Y et al (2018) Microstructure evolution, electrochemical properties and in-vitro properties of $\mathrm{Ti}-\mathrm{Nb}-\mathrm{Zr}$ based biocomposite by hydroxyapatite bioceramic. J Alloy Compd 764:987-1002. https://doi.org/10.1016/j.jallcom.2018.06.132

289. Yang K, Zhou C, Fan H et al (2018) Bio-functional design, application and trends in metallic biomaterials. Int J Mol Sci. https:// doi.org/10.3390/ijms 19010024

290. Shang W, Ye M, Cai T et al (2018) Tuning of the hydrophilicity and hydrophobicity of nitrogen doped carbon dots: A facile approach towards high efficient lubricant nanoadditives. J Mol Liq 266:65-74. https://doi.org/10.1016/j.molliq.2018.06.042

291. Amiril SAS, Rahim EA, Syahrullail S (2017) A review on ionic liquids as sustainable lubricants in manufacturing and engineering: Recent research, performance, and applications. J Clean Prod 168:1571-1589. https://doi.org/10.1016/j.jclepro.2017.03.197

292. Khemchandani B, Somers A, Howlett P et al (2014) A biocompatible ionic liquid as an antiwear additive for biodegradable lubricants. Tribol Int 77:171-177. https://doi.org/10.1016/j.triboint. 2014.04.016

293. She Z, Nie Y, Zhong H et al (2021) Effect of surface deformation on biocompatibility of biomedical alloys. Mater Sci Eng, C. https://doi.org/10.1016/j.msec.2020.111636

294. Yang Z, Zhu L, Zhang G et al (2020) Review of ultrasonic vibrationassisted machining in advanced materials. Int J Mach Tools Manuf. https://doi.org/10.1016/j.ijmachtools.2020.103594

295. Duraccio D, Mussano F, Faga MG (2015) Biomaterials for dental implants: current and future trends. J Mater Sci 50:4779-4812. https://doi.org/10.1007/s10853-015-9056-3

296. Al-Amin M, Abdul-Rani AM, Danish M et al (2021) Investigation of coatings, corrosion and wear characteristics of machined biomaterials through hydroxyapatite mixed-EDM process: a review. Materials 14:3597

297. Al-Amin M, Abdul Rani AM, Abdu Aliyu AA et al (2020) Powder mixed-EDM for potential biomedical applications: a critical review. Mater Manuf Processes. https://doi.org/10.1080/10426914.2020. 1779939

298. Wang F, Liu Y, Zhang Y et al (2014) Compound machining of titanium alloy by super high speed EDM milling and arc machining. J Mater Process Technol 214:531-538. https://doi.org/10. 1016/j.jmatprotec.2013.10.015

299. Rahim MZ, Ding S, Mo J (2016) Electrical discharge grinding of polycrystalline diamond-Effect of wheel rotation. Mach Sci Technol 20:62-78

300. Bouet G, Cabanettes F, Bidron G et al (2019) Laser-Based Hybrid Manufacturing of Endosseous Implants: Optimized Titanium Surfaces for Enhancing Osteogenic Differentiation of Human Mesenchymal Stem Cells. ACS Biomater Sci Eng 5:4376-4385. https://doi.org/10.1021/acsbiomaterials.9b00769

Publisher's Note Springer Nature remains neutral with regard to jurisdictional claims in published maps and institutional affiliations. 